\title{
OPTIMAL CONTROL OF NON-ISOTHERMAL, BATCH POLYMERIZATION OF METHACRYLATES WITH SPECIFIED TIME, MONOMER CONVERSION, AND AVERAGE MOLECULAR WEIGHTS
}

by

\section{BARANITHARAN SANMUGA SUNDARAM}

B.Tech., Coimbatore Institute of Technology, India, 2000

\author{
A thesis \\ presented to Ryerson University \\ in partial fulfillment of the \\ requirement for the degree of \\ Master of Applied Science \\ in the Program of \\ Chemical Engineering.
}

Toronto, Ontario, Canada, 2004

Baranitharan S. Sundaram, 2004 
UMI Number: EC53420

\section{INFORMATION TO USERS}

The quality of this reproduction is dependent upon the quality of the copy submitted. Broken or indistinct print, colored or poor quality illustrations and photographs, print bleed-through, substandard margins, and improper alignment can adversely affect reproduction.

In the unlikely event that the author did not send a complete manuscript and there are missing pages, these will be noted. Also, if unauthorized copyright material had to be removed, a note will indicate the deletion.

\section{UMI}

UMI Microform EC53420

Copyright 2009 by ProQuest LLC

All rights reserved. This microform edition is protected against unauthorized copying under Title 17, United States Code.

ProQuest LLC

789 East Eisenhower Parkway

P.O. Box 1346

Ann Arbor, MI 48106-1346 


\section{Author's Declaration}

I hereby declare that I am the sole author of this thesis.

I authorize Ryerson University to lend this thesis to other institutions or individuals for the purpose of scholarly research.

I further authorize Ryerson University to reproduce this thesis by photocopying or by other means, in total or in part, at the request of other institutions or individuals for the purpose of scholarly research. 


\section{Borrower's Page}

Ryerson University requires the signatures of all persons using or photocopying this thesis. Please sign below, and give address and date.

\begin{tabular}{|c|c|c|c|}
\hline Name & Signature & Address & Date \\
\hline & & & \\
\hline & & & \\
\hline & & & \\
\hline & & & \\
\hline & & & \\
\hline & & & \\
\hline & & & \\
\hline & & & \\
\hline & & & \\
\hline & & & \\
\hline & & & \\
\hline & & & \\
\hline & & & \\
\hline & & & \\
\hline & & & - \\
\hline & & & \\
\hline & & & \\
\hline
\end{tabular}




\title{
Optimal Control of Non-Isothermal, Batch Polymerization of Methacrylates with Specified Time, Monomer Conversion, and Average Molecular Weights
}

\author{
Baranitharan Sanmuga Sundaram \\ Master of Applied Science, 2004 \\ Department of Chemical Engineering, \\ Ryerson University
}

\section{Abstract}

Optimal control policies are determined for the free radical polymerization of three different, polymerization processes, in a non-isothermal batch reactor as follows:

1. Bulk polymerization of $n$-butyl methacrylate

2. Solution polymerization of methyl methacrylate with monofunctional initiatior

3. Solution polymerization of methyl methacrylate with bifunctional initiator

Four different optimal control objectives are realized for the above threc processes. The objectives are: (i) maximization of monomer conversion in a specified operation lime, (ii) minimization of operation time for a specified, final monomer conversion, (jii) maximization of monomer conversion for a specified, final number average polymer molecular weight, and (iv) maximization of monomer conversion for a specified, final weight average polymer molecular weight.

The realization of these objectives is expected to be very useful for the batch production of polymers. To realize the above four different optimal control objecilives, a genetje aigorithmsbased optimal control method is applied, and the temperature of heat-exchange flud inside reactor jacket is used as a control function. Necessary equations arc jrovided in the above three processes to suitably transform the process model in the range of a specified variable other than time, and to evaluate the elements of jacobian to help in the accurate solution of the process model. The results of this optimal control application reveal considerable improvements in the performance of the batch polymerization processes. 


\section{Acknowledgments}

First of all I wish to place on record my deep sense of gratitude to Dr. Simant R. Upreti. He not only motivated me to work hard, but also motivated me to learn many new types of software. Also, he helped me in verifying all the model equations that are presented in this thesis, and spent his valuable time in developing jacobian for the complex models. Whenever I faced problem on my computer programming or in the IATEX document writing, he sat with me and cleared all my queries, which I have never seen anywhere. Under his excellent guidance, helpful feedback, and continuous support throughout my research, this work was successfully completed.

I also would like to thank the Department of Chemical Engineering and the School of Graduate Studies of Ryerson University for their support in terms of department facilities, research stipend, and scholarship.

Also, I would like to thank our technologist Mr. Tondar Tajrobehkar for his timely help in. allowing using many computers in our lab to run my optimal control program. Finally I would like to thank my friends, roommates and my family members for their great moral support and their timely help.

I would like to acknowledge my supervisor's funding resources Natural Science and Engineering Research Council of Canada (NSERC) for providing me financial support for my research work. 


\section{Dedication}

I am dedicating this thesis to three people.

First.....my guardian angel, who brought me into this world, taught me good culture, gave me good education i.e. my mother S. Sivakami

Second.....he is not in this world to see my every success, but he lives in my memory. I believe his soul is watching my every movement, and he is with me on my every successes i. e. my father V. Sanmuga Sundaram (Late May,09,2003)

Third.....my mentor, well-wisher, care taker, who motivated me to work hard. without his excellent support, I should not be able to submit many papers i.e. my supervisor Dr. Simant R. Upreti. 


\section{Contents}

1 Introduction 3

1.1 Optimal Control $\ldots \ldots \ldots \ldots \ldots \ldots$

1.2 Genetic Algorithm based Optimal Control Technique . . . . . . . . . 5

1.2 .1 Algorithm ..................... 7

1.3 Optimal Control of Batch Polymerization in a Non-isothermal Batch Reactor 9

1.4 Optimal Control Objectives $\ldots \ldots \ldots \ldots \ldots$

1.5 Butyl Methacrylate Polymerization . . . . . . . . . . . . . . 11

1.6 Methyl Methacrylate Polymerization with Monofunctional Initiator . . . . . 12

1.7 Methyl Methacrylate Polymerization with Bifunctional Initiator . . . . . . 14

2 Mathematical Modeling for Bulk, Batch BMA Polymerization 15

2.1 Free Radical Polymerization Mechanism . . . . . . . . . . . . . . 15

2.2 Mathematical Model . . . . . . . . . . . . . . . . . . 16

2.3 Optimal Control Objectives $\ldots \ldots \ldots \ldots \ldots \ldots \ldots$

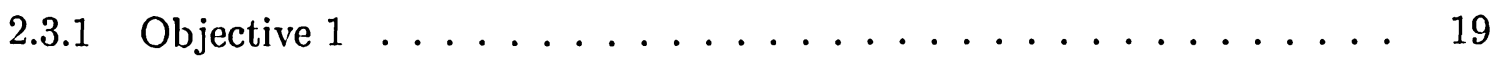

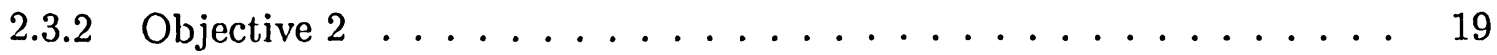

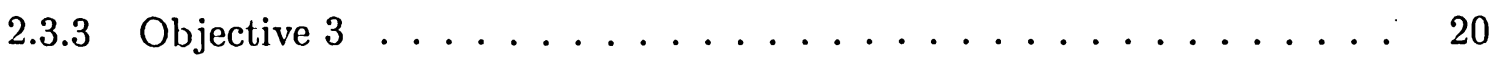

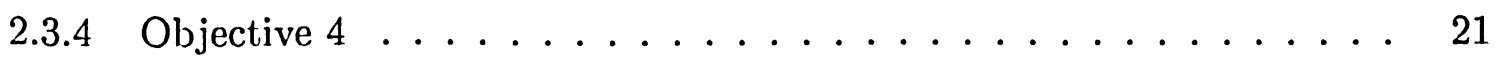

2.4 Integration of Equations of Change $\ldots \ldots \ldots \ldots \ldots \ldots$

2.4 .1 Equations to Evaluate Jacobians . . . . . . . . . . . . 22 


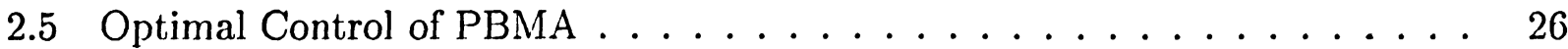

3 Results for Bulk, Batch BMA Polymerization 30

3.1 Results - Optimal control of PBMA . . . . . . . . . . . . . . 30

3.1.1 Results For Objective $1 \ldots \ldots \ldots$. . . . . . . . . . . 30

3.1 .2 Results For Objective $2 \ldots \ldots \ldots$. . . . . . . . . . . 32

3.1.3 Results For Objective $3 \ldots \ldots \ldots$. . . . . . . . . . . 33

3.1.4 Results For Objective $4 \ldots \ldots \ldots \ldots$. . . . . . . . . 35

3.2 Computational Time $\ldots \ldots \ldots \ldots \ldots \ldots \ldots \ldots$

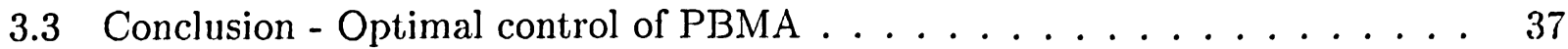

4 Mathematical Modeling for Solution, Batch MMA Polymerization With Monofunctional Initiator

4.1 Free Radical Polymerization Mechanism . . . . . . . . . . . . . . . . 40

4.2 Mathematical Model . . . . . . . . . . . . . . . . . . . . 41

4.3 Rate Coefficient for Propagation . . . . . . . . . . . . . . . . . . 44

4.4 Rate Coefficient for Termination . . . . . . . . . . . . . . . . 45

4.5 Optimal Control Objectives $\ldots \ldots \ldots \ldots \ldots \ldots$

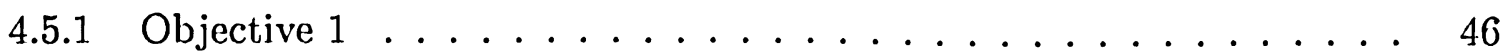

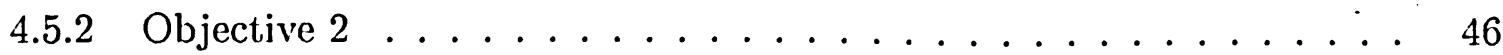

4.5 .3 Objective $3 \ldots \ldots \ldots \ldots \ldots \ldots \ldots \ldots \ldots \ldots$

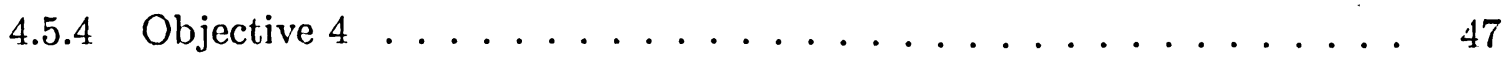


4.6 Integration of Batch Process Model . . . . . . . . . . . . 48

4.6.1 Equations to Evaluate Jacobians . . . . . . . . . . . . . 49

4.7 Optimal Control of PMMA with Monofunctional Initiator . . . . . . . . 54

5 Results for Solution, Batch MMA Polymerization with Monofunctional Initiator

5.1 Results - Optimal control of PMMA with monofunctional initiator . . . . . . 57

5.1 .1 Results For Objective $1 \ldots \ldots \ldots \ldots \ldots$

5.1 .2 Results For Objective $2 \ldots \ldots \ldots \ldots$. . . . . . 58

5.1 .3 Results For Objective $3 \ldots \ldots \ldots 60 \ldots$

5.1 .4 Results For Objective $4 \ldots \ldots \ldots \ldots 2$

5.2 Computational Time . . . . . . . . . . . . . . . . . 64

5.3 Conclusion - Optimal control of PMMA with monofunctional initiator . . . . 64

6 Mathematical Modeling for Solution, Batch MMA Polymerization with Bifunctional Initiator

6.1 Free Radical Polymerization Mechanism . . . . . . . . . . . . . . 67

6.2 Mathematical Model . . . . . . . . . . . . . . . . . 69

6.3 Rate Coefficient for Propagation . . . . . . . . . . . . . . . 72

6.4 Rate Coefficient for Termination . . . . . . . . . . . . . . 73

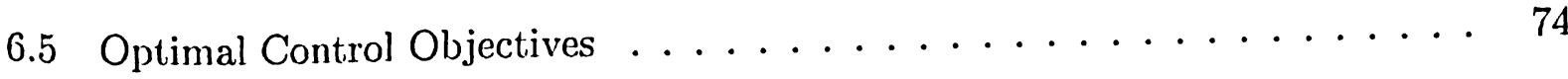

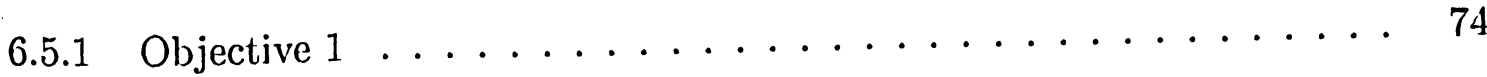

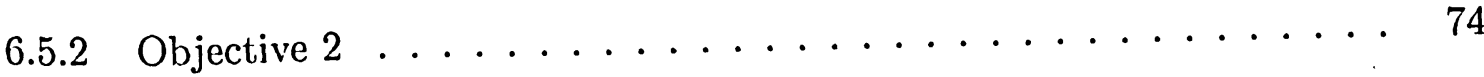




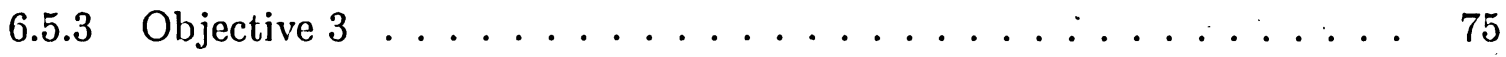

6.5 .4 Objective $4 \ldots \ldots \ldots \ldots \ldots \ldots \ldots$

6.6 Integration of Batch Process Model $\ldots \ldots \ldots \ldots 77$

6.6.1 Equations to Evaluate Jacobians _. . . . . . . . . . . 77

6.7 Optimal Control of PMMA with Bifunctional Initiator $\ldots \ldots \ldots \ldots$

7 Results for Solution, Batch MMA Polymerization with Bifunctional Ini$\begin{array}{ll}\text { tiator } & 88\end{array}$

7.1 Results - Optimal control of PMMA with bifunctional initiator . . . . . . 88

7.1.1 Results For Objective 1................. 88

7.1 .2 Results For Objective $2 \ldots \ldots \ldots$. . . . . . . . . . . 90

7.1.3 Results For Objective $3 \ldots \ldots$. . . . . . . . . . . . 91

7.1 .4 Results For Objective $4 \ldots \ldots \ldots 3$

7.2 Computational Time . . . . . . . . . . . . . . . . 95

7.3 Conclusion - Optimal control of PMMA with bifunctional initiator . . . . . . 95

$\begin{array}{lll}8 & \text { Final Conclusion and Future Work } & 98\end{array}$

8.1 Future Work . . . . . . . . . . . . . . . . . . . . . . 99 


\section{List of Tables}

2.1 Model parameters used in calculations $\ldots \ldots \ldots \ldots \ldots$

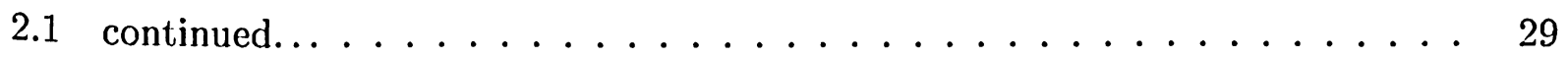

3.1 Summary of optimal control results $\ldots \ldots \ldots \ldots$

4.1 Model parameters used in calculations $\ldots \ldots \ldots \ldots \ldots 5$

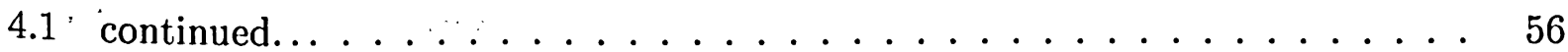

5.1 Summary of optimal control results $\ldots \ldots \ldots \ldots 6$

6.1 Model parameters used in calculations $\ldots \ldots \ldots \ldots 6$

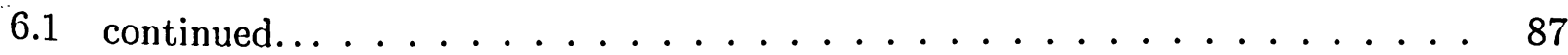

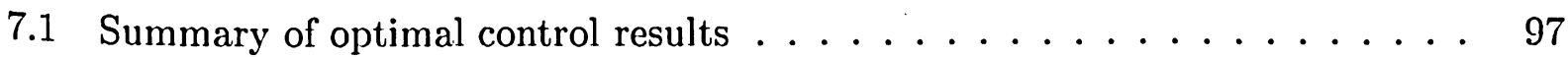




\section{List of Figures}

3.1 Optimal reactor jacket temperature versus time for Objective $1 \ldots \ldots$. . . 31

3.2 Reactor temperature and monomer conversion versus time for Objective $1 \quad$. $\quad 32$

3.3 Optimal number average molecular weight versus time for Objectives 1-4 . 33

3.4 Optimal weight average molecular weight versus time for Objectives 1-4 . . 34

3.5 Optimal jacket temperature versus time for Objectives $2-4 \ldots \ldots$. . . . 35

3.6 Optimal reactor temperature versus time for Objectives $2-4 \ldots \ldots \ldots$

5.1 Optimal reactor jacket temperature versus time for Objective $1 \ldots \ldots$

5.2 Reactor temperature and monomer conversion versus time for Objective 1 - 59

5.3 Optimal number average molecular weight versus time for Objectives 1-4 . . 60

5.4 Optimal weight average molecular weight versus time for Objectives 1-4 . . 61

5.5 Optimal jacket temperature versus time for Objectives $2-4 \ldots \ldots \ldots 2$

5.6 Optimal monomer conversion versus time for Objectives $2-4 \ldots \ldots 63$

5.7 Optimal reactor temperature versus time for Objectives $2-4 \ldots \ldots \ldots 4$

7.1 Optimal reactor jacket temperature versus time for Objective $1 \ldots \ldots$. . . $\quad 89$

7.2 Reactor temperature and monomer conversion versus time for Objective 1 . $\quad 90$

7.3 Optimal number average molecular weight versus time for Objectives 1-4 . . 91

7.4 Optimal weight average molecular weight versus time for Objectives 1--4 . . 92

7.5 Optimal jacket temperature versus time for Objectives $2-4 \ldots \ldots$. . . . 93

7.6 Optimal monomer conversion versus time for Objectives $2-4 \ldots \ldots$. . . . 94 
7.7 Optimal reactor temperature versus time for Objectives $2-4 \ldots \ldots \ldots$ 


\section{Notation}

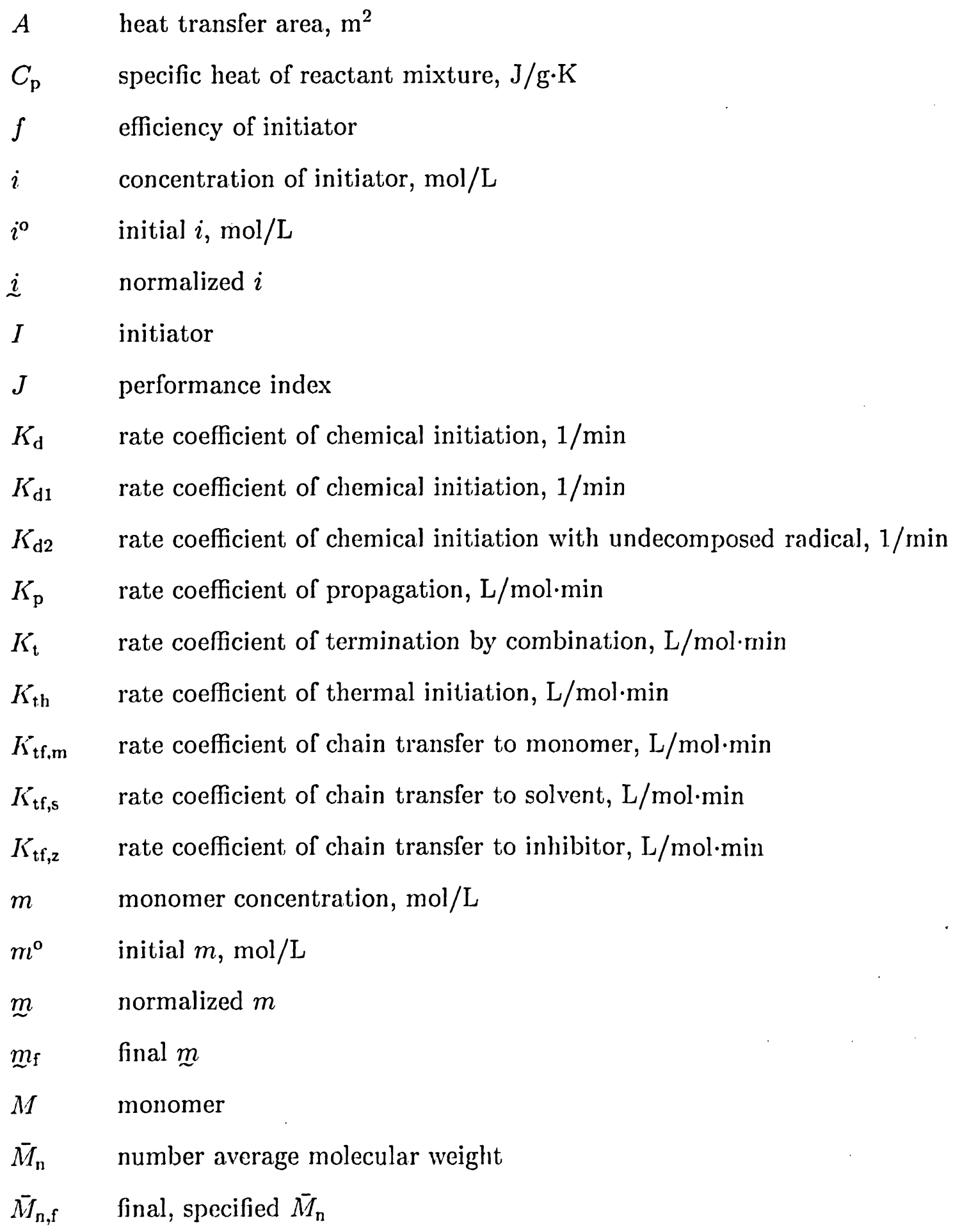


$\bar{M}_{\mathrm{w}} \quad$ weight average molecular weight

$\bar{M}_{\text {w,f }} \quad$ final, specified $\bar{M}_{\mathrm{w}}$

$M_{\mathrm{m}} \quad$ monomer molecular weight, $\mathrm{g} / \mathrm{mol}$

$P_{l} \quad$ dead polymer of chain length $l$

$\tilde{P}_{l} \quad$ dead polymer of chain length $l$, with one undecomposed peroxide

$\tilde{\tilde{P}}_{l} \quad$ dead polymer of chain length $l$, with two undecomposed peroxide

$R_{\text {in }} \quad$ initiator radical

$\tilde{R}_{\text {in }} \quad$ initiator radical with one undecomposed peroxide

$R_{i} \quad$ radical of chain length $l$

$\tilde{R}_{i} \quad$ radical of chain length $l$, with one undecomposed peroxide

$R_{k} \quad$ radical of chain length $k$

$\tilde{R}_{k} \quad$ radical of chain length $k$, with one undecomposed peroxide

$s \quad$ solvent concentration, $\mathrm{mol} / \mathrm{L}$

$s^{0} \quad$ initial $s, \mathrm{~mol} / \mathrm{L}$

$s \quad$ normalized $s$

$S$ solvent

$t \quad$ time, $\min$

$t_{\mathrm{f}} \quad$ final, specified operation time, $\min$

$T \quad$ temperature of reactants (or reactor), ${ }^{\circ} \mathrm{C}$

$T^{\circ} \quad$ initial $T,{ }^{\circ} \mathrm{C}$

$T_{\max } \quad$ upper limit to $T,{ }^{\circ} \mathrm{C}$

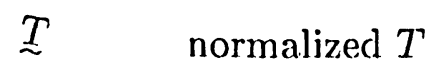

$T_{\mathrm{j}}$ temperature of heat exchange fluid in reactor jacket, ${ }^{\circ} \mathrm{C}$

$T_{\mathrm{j}, \text { max }} \quad$ upper limit to $T_{\mathrm{j}},{ }^{\circ} \mathrm{C}$

$T_{\mathrm{j}, \min } \quad$ lower limit to $T_{\mathrm{j}},{ }^{\circ} \mathrm{C}$ 
$U$ heat transfer coefficient for reactor wall and jacket, $\mathrm{J} / \mathrm{m}^{2} \cdot \min \cdot \mathrm{K}$

$V \quad$ volume of reactants inside reactor, $\mathrm{L}$

$V^{\circ} \quad$ initial $V, \mathrm{~L}$

V normalized $V$

$X \quad$ monomer conversion, $\%$

$X_{\mathrm{f}} \quad$ specified, final $X$

$y_{k} \quad k$ th state variable

$y_{i} \quad i$ th state variable

$z \quad$ concentration of inhibitor, $\mathrm{mol} / \mathrm{L}$

$z^{\mathrm{o}} \quad$ initial $z, \mathrm{~mol} / \mathrm{L}$

$z \quad$ normalized $z$

$Z \quad$ inhibitor

$Z \cdot \quad$ inactive inhibitor radical

\section{Greek Symbols}

$-\Delta H \quad$ heat of polymerization, $\mathrm{J} / \mathrm{mol}$

$\lambda_{i} \quad i$-th moment of live polymer radical

$\lambda_{i} \quad$ normalized $\lambda_{i}$

$\tilde{\lambda}_{i} \quad i$-th moment of live polymer radical with one undecomposed peroxide

$\tilde{\lambda}_{i} \quad$ normalized $\tilde{\lambda}_{i}$

$\mu_{i} \quad i$-th moment of dead polymer

$\mu_{i} \quad$ normalized $\mu_{i}$

$\tilde{\mu}_{i} \quad i$-th moment of dead polymer with one undecomposed peroxide

$\tilde{\mu}_{i} \quad$ normalized $\tilde{\mu}_{i}$

$\tilde{\tilde{\mu}}_{i} \quad i$-th moment of dead polymer with two undecomposed peroxide

$\tilde{\tilde{\mu}}_{i} \quad$ normalized $\tilde{\tilde{\mu}}_{i}$ 
$\mu^{\circ} \quad$ parameter used to normalize radical and polymer moments

$\rho_{\mathrm{m}} \quad$ monomer density, $\mathrm{g} / \mathrm{L}$

$\rho_{\mathrm{p}} \quad$ polymer density, $\mathrm{g} / \mathrm{L}$

$\rho_{\mathrm{s}} \quad$ solvent density, $\mathrm{g} / \mathrm{L}$

\section{Abbreviations}

BMA n-Butyl Methacrylate

PBMA Poly(n-Butyl Methacrylate)

AIBN 2,2'-Azobisisobutyronitrile

MMA Methyl Methacrylate

PMMA Poly Methyl Methacrylate

FRP Free Radical Polymerization

BPO Benzoyl Peroxide 


\section{Thesis Organization}

This thesis is organized in the following manor:

Chapter 1 of this thesis begins with the brief introduction of the optimal control technique, and the genetic algorithm-based optimal control technique. Followed by discussion of genetic. algorithm-based optimal control technique in a non-isotherma! batch reactor (Section 1.2), this chapter explains the importance of batch reactor in the polyner industry, and the previous optimal control studies on a batch reactor (Section 1.3). Further, the same chapter explains the formulation of four different optimal control objectives, and the application of this technique in bulk, batch n-butyl methacrylate (BMA) polymerization, solution batch methyl methacrylate (MMA) with monofunctional initiator, and solution batch MMA with bifunctional initiator.

Chapter 2 explains the reaction mechanism for the free radicai polymerization of n-butyl methacrylate and the development of mathematical model for bulk, butyl methacrylate polymerization in a non-isothermal batch polymerization reactor. Also, it explains the changes in the differential equation by applying normalized state variables. Further; the same chapter explains the formulation of four different optimal control objectives, and the development of analytical jacobian to integrate the developed model.

Chapter 3 discusses the optimal control results that obtained for the four different optimal control objectives, which are formulated for the bulk, batch polymerization of n-buty] methacrylate in a non-isothermal batch reactor. Further, the same chapter explains the conclusion, and the future work that can be done in the optimal control of butyl methacrylate polymerization.

Chapter 4 explains the development of mathematical model on the basis of free rudical polymerization mechanism for the solution polymerization of methyl methacrylate with monofunctional initiator in a non-isothermal batch polymerization reactor, and the changes 
in the differential equation by applying normalized state variables, also the incorporation gel and glass effect model. Further, the same chapter explains the formulation of four different optimal control objectives, and the development of analytical jacobian to integrate the developed model.

Chapter 5 discusses the optimal control results that obtained for the four different optimal control objectives, which are formulated for the batch polymerization of methyl methacrylate with monofunctional initiator in a non-isothermal batch reactor. Further, the same chapter explains the conclusion, and the future work that can be done in the optimal control of methyl methacrylate polymerization with monofunctional initiator.

Chapter 6 explains the development of mathematical model on the basis of free radical polymerization mechanism for the solution polymerization of methyl methacrylate with bifunctional initiator in a non-isothermal batch polymerization reactor, and the changes in the differential equation by applying normalized state variables, also the incorporation gel and glass effect model. Further, the same chapter explains the formulation of four different optimal control objectives, and the development of analytical jacobian to integrate the developed model.

Chapter 7 discusses the optimal control results that obtained for the four different optimal control objectives, which are formulated for the batch polymerization of methyl methacrylate with bifunctional initiator in a non-isothermal batch reactor.

Chapter 8 summarizes the optimal control work that is presented for the batch methacrylates polymerization with specified time, monomer conversion, and average molecular weights. Also, it recommends the future work that one can perform from this optimal control studies. 


\section{Introduction}

Optimal control is an optimization of function(s) not variables. In general, the optimal control of process denotes off-line determination of optimization function(s), the online application of which would achieve a desired objective. The application of oj,timization function(s) in optimal control provides extreme flexibility and enhanced capabilities io realize process objectives with greater performance. Together with the increase in computing pover, and the development of more efficient optimal control techniques, research in the optimal control of industrial processes has begun to gain prominence.

Conventionally to find the optimal policies for a process, technicgues based on the caiculus of variation, dynamic programming, and nonlinear programming are avaisonje. Deternining optimal control with nonlinear programming becomes very difficult, when the system becomes very complex to solve. In dynanic programming, the dimensionality beconcs prohibitively large even with modestly sized problem. Techniques based on Variational calcuius are prone to be erroneous while solving the derivatives.

In this work, a new robust genetic algorithm based optimal control technique, developed by Upreti [2004], is used to determine four different optimal control onjectives to obtain minimization of operation time and maximization of monomer conversion in a non-isothermal batch reactor, under different specifications. These objectives have been developed and realized for the following three different polymerization processes:

1. Bulk polymerization of n-butyl methacrylate (BMA) in a non-isothermal batch reactor [Upreti and Sundaram, 2004b]

2. Solution polymerization of methyl methacrylate (MMA) with monofunctiona! initiator in a non-isothermal batch reactor [Sundaram and Upreti, 2004]

3. Solution polymerization of MMA with bifunctional initiator in a non-isothermal batch reactor [Upreti and Sundaram, 2004a] 


\subsection{Optimal Control}

The objective of optimal control is to determine the optimal control policy that will cause a process to satisfy the physical constraints and at the same time minimize (or maximize) some performance criterion [Kirk, 1970].

Optimal control is applicable in many areas. In industrial practice, determining optimal control policies are usually performed by trial and error experience. There has been significant research in the last decade to develop efficient optimal control techniques that would ensure high standards of product quality and operational safety with the minimal production costs [Upreti, 2004].

In the optimal control of a process, an optimization parameter is a function of an independent variable. Optimal control implies off-line determination of optimization function(s), the online application of which would achieve a desired objective. It is the application of optimization function(s), as opposed to optimization variable(s), which offers extreme flexibility and enhanced capabilities to realize process objectives with superior performance.

Optimal control techniques are based on variational calculus using Pontryagin's maximum and minimum principle [Pontryagin et al., 1962], dynamic programming [Luus, 1990], nonlinear programming [Biegler et al., 2002], and search methods [Luus and Hennessy, 1999, Gupta, 1995, Lee et al., 1997, 1999, Wang and Chiou, 1997].

Recently, Upreti [2004j developed a new robust genetic algorithm based optimal control technique. This optimal control method iteratively uses the three genetic operations of selection, crossover and inutation in the size-varying domain of control function with logarithmic and linear mappings. The method does not require any input of feasible control solution, or any auxiliary condition. Selection stochastically picks control functions from their population on the basis of performance index or "fitness". A control function with better fitness has a greater probability to populate a new set of control functions. Crossover works on the new set 


\subsection{Genetic Algorithm based Optimal Control Technique}

or population, which has a greater representation of control functions with better fitnesses. Crossover recombines the building blocks of these control functions, which are represented through binary digits, or bits. This operation results in a newer population of "children", some of which are likely to be better than their "parents". Finally, mutation changes the bits of children with a very low probability, and is equivalent to a local search for the control functions of even better fitnesses. This method has been successfuliy applied earlier for the optimal control of ethylene polymerization in an industrial tubular reactor [Yao et al., 2004].

\subsection{Genetic Algorithm based Optimal Control Tech.- nique}

Upreti [2004] explained this technique in detail for a general process rnodel, which has been explained here for a non-isothermal batch polymer reactor model.

To define optimal control, let us consider a batch polymer reacior with a simple process model equation,

$$
\frac{\mathrm{d} x}{\mathrm{~d} t}=f(x(t), u(t)), \quad 0 \leq t \leq t_{f}
$$

in Equation (1.1), $x(t)$ is a state vector $[n \times 1]$ and $u(t)$ is a control vector [ $m \times 1$, and both are functions of time, $t$, over a given process operation time $t_{f}$. In a non-isothermal batein polymer reactor, $x(t)$ is a vector of state variables, which are voinme and temperature of reactants, the concentrations of monomer, initiator, solvent, inlibitor, and of the moments of radicals, dead polymer molecules. $u(t)$ is a control function within soms: specifjed bounds. Here, we consider jacket temperature $\left(T_{j}\right)$ as a control function.

Let us impose two inequality constraints $[g(x(t), u(t))]$ on the reactor and the jacket temperatures of the above batch process model. Inequality constraint on the jacket temperature $\left(T_{j}\right)$ is as follows

$$
T_{\mathrm{j}, \min }(t) \leq T_{\mathrm{j}}(t) \leq T_{\mathrm{j}, \max }(t)
$$


Constraint on one of the state variable such as reactor temperature is given by

$$
T(t) \leq T_{\max }(t)
$$

State vector $T(t)$ is known at $t=0$. Equation (1.1) is subject to the satisfaction of $g\left[T(t), T_{\mathrm{j}}(t)\right]$, a vector of constraints on $T(t)$ and $T_{\mathrm{j}}(t)$. The objective is to obtain the optimal control function, which would optimize a given performance index $\mathbf{J}$.

Here, we consider optimal performance index $\hat{\mathbf{J}}$ is either maximization of monomer conversion or minimization of batch operation time. Rector temperature places a vital role to get this optimum result, and is a key parameter to control monomer conversion and the batch operation time. In the heat transfer (non-isothermal) model, monomer conversion and the batch operation time are concerned to jacket temperature.

Moreover, monomer conversion and the batch operation time are the sign to estimate process efficiency for an assigned product. The discrete step values of $T_{\mathrm{j}}(t)$, equispaced over process operation time, are considered as optimization variables. These step values form a control vector $T_{j}(t)$.

$N_{u}$ is the number of control stages of step values for control function $T_{\mathrm{j}}(t)$. This new robust technique [Upreti, 2004] is applied on a problem by randomly initializing a mean control value $\bar{T}_{j_{\mathrm{i}}}$ for a given number of control stages, $i=0,1, \ldots . N_{u}-1$

At any $i$ th stage, the step value of control, $T_{j_{\mathrm{i}}}$, is calculable from mean control value $\bar{T}_{j_{\mathrm{i}}}$, and a binary-coded deviation $\Delta T_{j_{\mathrm{i}, 2}}$ by means of some mapping. $T_{j_{\mathrm{j}}}, \bar{T}_{\mathrm{j}_{\mathrm{i}}}, \Delta T_{j_{\mathrm{i}, 2}}$ can be written in the vector form as $\mathbf{T}_{\mathrm{j}}, \overline{\mathrm{T}}_{\mathrm{j}}, \Delta \mathrm{T}_{j_{2}}$ respectively for the $N_{u}$ stages. In addition to mean control value $\bar{T}_{j}$, a population of $\Delta \mathbf{T}_{j_{2}}$ is also randomly generated.

The presented technique uses the mapping to relate a binary-coded deviation value $\left(\triangle T_{\mathrm{j}_{\mathrm{i}, 2}}\right)$ and mean value $\left(\bar{T}_{j_{\mathrm{i}}}\right)$ to a control value $\left(T_{j_{\mathrm{i}}}\right)$ by providing an optimal control vector $\hat{\mathrm{T}}_{\mathbf{j}}(\mathrm{t})$ corresponding to each binary coded deviation vector $\Delta \mathbf{T}_{j_{2}}$ in its population. To generate optimal 
control vector $\hat{\mathbf{T}}_{\mathrm{j}}(\mathrm{t})$, the genetic operation of selection, cross-over, and mutation are successively applied to the population of binary-coded deviation vector $\Delta \mathrm{T}_{j_{2}}$. There are two different mappings employed in this study:

Logarithmic mapping emphasizes the relative order of magnitudes of control values at different stages during the initial iterations. It provides the step value, $T_{j_{\mathrm{i}}}=b^{y_{i}}$.

where, $b$ is the logarithmic base, which can be expressed as

$$
b=T_{\mathrm{j}, \max }-T_{\mathrm{j}, \min }
$$

In Equation (1.4), $b$ is the logarithmic base, and $T_{\mathrm{j}, \max }$ and $T_{\mathrm{j}, \min }$ are the maximum and minimum values of control function $T_{\mathbf{j}}(t)$.

and $y_{i}$ is from

$$
y_{i}=\log _{\mathrm{b}} \bar{T}_{j_{\mathrm{i}}}+\frac{\log _{\mathrm{b}} D}{2^{N_{\mathrm{bit}}}-1} \Delta T_{j_{\mathrm{i}, 2}}
$$

$\mathrm{D}$ is the variable of control domain between the limits of $D_{\min }>0$ and $b$, and $N_{\text {bit }}$ is the number of bits specified to represent any $i$ th element of $\Delta \mathrm{T}_{j_{2}}$ i. e. $\Delta T_{j_{\mathrm{i}, 2}}$.

Linear mapping used to refine an optimal control solution straightforward after the initial iteration. This mapping is generally given by

$$
T_{j_{\mathrm{i}}}=\bar{T}_{j_{\mathrm{i}}}+\frac{D}{2^{N_{\mathrm{bit}}}-1} \Delta T_{j_{\mathrm{i}, 2}}
$$

The property combined logarithmic and linear mapping leads to an efficient search of robust, control solutions in a large control domain with a very low value of $N_{\text {bit }}$.

\subsubsection{Algorithm}

The algorithm summarizes the presented genetic algorithm based optimal controi techuique [Upreti, 2004] for a non-isothermal batch reactor as following: 
-1.-Initialize,

(i) $\overline{\mathrm{T}}_{\mathrm{j}}$, the vector of mean values of control function for all $N_{u}$ stages using,

$$
\bar{T}_{j_{\mathrm{i}}}=T_{\mathrm{j}, \text { min }}+R_{\mathrm{i}}\left(T_{\mathrm{j}, \max }-T_{\mathrm{j}, \text { min }}\right), \quad 0 \leq R_{i} \leq 1, \quad i=0,1, \ldots, N_{u}-1
$$

where $R_{i}$ is the $i$ th pseudo-random number obtained from a pseudo-random number generator.

(ii) A population of $N_{\text {pop }}$ binary-coded deviation vectors $\Delta \mathbf{T}_{j_{2}}$ using the pseudo-random number generator, where $N_{\text {pop }}=N_{u} N_{\text {bit }}$.

(iii) The variable control domain, $D=\left(T_{\mathrm{j}, \max }-T_{\mathrm{j}, \min }\right) / 2$.

(iv) A boolean variable (needed to enable the alternation of logarithmic mapping with linear mapping), ALTERNATE $=$ FALSE.

2. Set logarithmic mapping for the genetic operations of selection, crossover, and mutation.

3. Carry out the following operations on the population of $\Delta \mathbf{T}_{j_{2}}$ for $N_{\text {gen }}$ generations:

(i) Performance index evaluation for each $\Delta \mathbf{T}_{j_{2}}$.

(ii) Selection based on scaled performance index.

(iii). Crossover with probability $p_{c}$.

(iv) Mutation with probability $p_{m}$.

4. Store the resulting optimal value of performance index $(\hat{\mathbf{J}})$, and corresponding optimal control vector $\left(\hat{\mathbf{T}}_{\mathbf{j}}(\mathbf{t})\right)$.

5. Replace $\overline{\mathbf{T}}_{\mathrm{j}}$ by $\hat{\mathrm{T}}_{\mathrm{j}}(\mathrm{t})$

6. If ALTERNATE is TRUE, repeat Steps 3-5 once with linear mapping.

7. If ALTERNATE is FAISSE, then if for $N_{o}$ (number of "inactive" iterations) consecutive iterations, the fractional change in optimal value of performance index $(\hat{\mathrm{J}})$ is less than $1 \%$, set ALTERNATE = TRUE. (This step executes only once.) 
8. If $D$ is equal to either $D_{\min }$ or $D_{\max }$, set the size-variation factor for control domain, $C=C^{-1}$. (This step allows the alternation of the successive contraction of $D$ with its successive expansion.)

9. Set $D=C D$. If $D<D_{\min }$, set $D=D_{\min }$. If $D>D_{\max }$, set $D=D_{\max }$. (This step allows the variation of $D$ within its limits.)

10. Go to Step 2 until the specified number of iterations, $N_{\mathrm{itr}}$ (number of iterations), are done.

\subsection{Optimal Control of Batch Polymerization in a Non- isothermal Batch Reactor}

Polymerization in batch reactors is carried out extensively in polymer industry because of its operational simplicity, and production adaptability. During batch polymerization, process variables undergo significant changes with time. The optimal performance of this process is determinable by optimizing an objective function subject to process and safety constraints under time-varying conditions. The determination of optimization parameters requires the satisfaction of a differential-algebraic process model.

Because the efficiency of batch reactors, and their product properties are strong functions of reaction temperature, its optimal determination has received a lot of atitention since the early works of Denbigh [1958], and Aris [1960]. Such a determination guides as to how a control function should change with time in order to achieve a ciesired objective. Moreover, this determination provides valuable information on the design of reactor, and the upper limits to its expected performance. This advantage has been the major source of notivation for many optimal control studies on batch reactors [Luus and Okongwu, 1999, Joggsdon and Biegler, 1993, Luus, 1994, Bojkov and Luus, 1996, Hicks et al., 1969, Chen and Huang, 1931, Thomas and Kiparissides, 1984, Louie et al., 1985, Ponnuswamy et, al., 1987, Hsil and Chen, 1988, O'Driscoll et al., 1989, O'Driscoll and Ponnuswany, 1990. Chang and Laj, 1992]. For 


\subsection{Optimal Control Objectives}

batch polymerization, many researchers [Hicks et al., 1969, Chang and Lai, 1992, Thomas and Kiparissides, 1984, O'Driscoll and Ponnuswamy, 1990] have applied optimal control for the minimization of operation time, and the production of polymer with desired number and weight average molecular weights.

In case of batch reactors, an optimization function typically varies with the independent variable, time. However, in general, an independent variable could be any function of process variables. In recent years, there has been a growing interest in the optimal control of batch reactors [Luus and Okongwu, 1999], which have provided very interesting and challenging problems of academic as well as industrial interest.

In this work, the mathematical model developed for the three polymerization processes such as bulk, batch BMA polymerization and solution, batch MMA polymerization by using mono and bifunctional initiators are highly non-linear. Furthermore, due to the incorporation of inequality constraints, the relation between the performance index and jacket temperature of our four objectives to be defined later would not necessarily be unimodal and continuous for the four optimal control objectives. To realize our four optimal control objectives for these highly nonlinear and complex polymerization models, one needs a very robust optimal control control technique. In this work, the newly developed robust optimal control technique [Upreti, 2004] is used to realize our four optimal control objectives.

\subsection{Optimal Control Objectives}

Four different optimal control objectives are formulated to enhance the performance of the batch polymerization process in a non-isothermal batch reactor. Each objective combines the optimization of a variable with the specification or satisfaction of another. The objectives are:

1. maximization of monomer conversion in a specified operation time, 
2. minimization of operation time for a specified, final monomer conversion;

3. maximization of monomer conversion for a specified, final number average polymer molecular weight, and

4. maximization of monomer conversion for a specified, final weight average polymer molecular weight.

The temperature of heat-exchange fluid inside reactor jacket is used as a control function, which influences the temperature of reaction mixture.

\subsection{Optimal Control of BMA Polymerization in a Non- isothermal Batch Reactor}

Poly (n-Butyl Methacrylate) or PBMA, is an important polymer used in paint industry as a resin in coating, has the property of strikingly good resistance to weathering and gloss retention. After an extensive literature survey on the free radical polymerization (FRP) of methacrylates, we found that no work has been done on the optimal control of n-Butyl Methacrylate (BMA) polymerization.

In this work, the optimal control of free radical, bulk polymerization of n-Butyl Methacrylate is implemented in a non-isothermal batch reactor using monofunctional 2,2'-azobisisobutyronitrile (AIBN) as an initiator. Four optimal control objectives (Section 1.4) are formulated based on the detailed process model (Refer Chapter 2). A robust optimal control method based on genetic algorithms [Upreti, 2004] is used to determine optimal control policies. 


\subsection{Optimal Control of MMA Polymerization in Non- isothermal Batch Reactor with Monofunctional Ini- tiator}

Poly(methyl methacrylate) or PMMA is a valuable polymer, which is extensively used to manufacture cast and extruded sheets, granules for automotive sector, goods for construction and household applications, electrical and audio-video systems, and medical equipment. A transparent thermoplastic, PMMA is highly resistant to ultraviolet degradation, and corrosive weather conditions. As such, PMMA is of immense commercial interest, especially to automotive and aerospace industry. PMMA is mainly produced by the free radical polymerization of methyl methacrylate using typical peroxide or azo initiators in non-isothermal, batch reactors.

The optimal control for the batch polymerization of methyl methacrylate (MMA) was first investigated by King and Skaates [1969]. They used trial and error simulations based on steady-state hypothesis for radical concentration, and an empirical gel effect model for bulk polymerization. They considered the temperature of heat-exchange fluid as a two-step control function of time, and determined optimal step-switching times under the constraints of 10\% MMA conversion, and a specified maximum reactor temperature. Since then, several studies have been undertaken on the optimal control problem for MMA [Louie et al., 1985]. In general, these studies apply variational calculus on simplified and workable polymerization models to determine optimal control policies (i.e. functions of time) such as temperature, initiator and monomer concentrations. These policies optimize different variables, e.g. operation time, final monomer conversion, polymer molecular weight and polydispersity, subject to various constraints on process and polymer property.

A notable study is by Ponnuswamy et al. [1987], who not only determined the optimal control policies for semi-batch MMA polymerization but also tested them experimentally. Using the framework of variational calculus based on a simplified model of polymerization, they deter- 
mined (i) optimal initiator concentration policy to minimize operation time, and.(ii) optimal reaction temperature policies to minimize polydispersity. Both of these objectives were constrained by specified, final monomer concentration and number average polymer molecular weight. Although experimental results generally agreed with optimal control predictions, discrepancies in number average polymer molecular weights were observed, which indicate the limitations of the polymerization model used to simplify the mathematical framework required for optimal control.

There have been a couple of optimal control studies on batch MMA polymerization using innovative approaches. Chang and Lai [1992] proposed a two-step method for optimal control, which first calculates instantaneous values of number average degree of polymerization based on a final specification, and then uses them in a steady state model to compute control function values with nonlinear programming. They applied this method for the optimal control of MMA polymerization in a batch reactor for specified final monomer conversion, number average degree of polymerization, and polydispersity. Tian et; al. [2001] used netiral networks to generate optimal temperature policy for specified number average molecular. weight, monomer conversion, and polydispersity for a batch MMA polymerization reactor.

In this work, the optimal control of free radical MMA polymerization is implemented in a nonisothermal batch reactor using a rigorous unsteady state model. A robust optimal control method based on genetic algorithms [Upreti, 2004] is used to determine optimal control policies. Benzene is used as a solvent, and benzoyl peroxide is used as a monofunctional initiator. Four optimal control objectives (Section 1.4) are formulated based on the detailed process model (Refer Chapter 4). 


\subsection{Optimal Control of MMA Polymerization in Non- isothermal Batch Reactor with Bifunctional Initia- tor}

Bifunctional initiator is very useful in obtaining high initiation rates, and high polymer molecular weights. [Simionescu et al., 1990].

After an extensive literature survey on the optimal control studies of methyl methacrylate polymerization in a batch reactor, we found that no work has been done on the optimal control of MMA polymerization with bifunctional initiator. Whereas, we found very few publication on the free radical polymerization of MMA with bifunctional initiator [Simionescu et al., 1990; 1988, Subramanian and Kapur, 1958], which convey the kinetic study of MMA polymerization with bifunctional initiator.

In this work, we initially consider free radical polymerization of methyl methacrylate with benzene solvent is carried out in a batch reactor by using bifunctional initiator. Four optimal control objectives (Section 1.4) are formulated based on the detailed process model (Refer Chapter 6)

We determine the optimal control of free radical, solution polymerization of MMA with a bifunctional initiator using a detailed unsteady state process model. A robust optimal control method based on genetic algorithms [Upreti, 2004] is used to determine optimal control policies. Benzene is used as a solvent, and N,N'-bis[(4-t-butylazo-4-cyanovaleryl)oxyethyl]azo-bis-formamide is used as a bifunctional initiator. We consider this bifunctional initiator is chemically and thermally symmetrical and hence, both peroxide groups decompose at the same rate. Thermal symmetry literally means that both peroxide groups decompose at the same rate whether the peroxide groups are alike or not [Dhib et al., 2000]. 


\section{Mathematical Modeling for Bulk, Batch BMA Polymerization}

In this chapter, we discuss the development of mathematical model on the basis of free radical polymerization mechanism for the bulk polymerization of n-butyl methacrylate in a non-isothermal batch polymerization reactor, and the changes in the differential equation by applying normalized state variables. Further, we discuss the formulation of four different optimal control objectives, and the development of analytical jacobian to integrate the developed model.

\subsection{Free Radical Polymerization Mechanism}

Based on the approach of Villalobos et al. [1993], and Dhib et al. [2000], the following free radical polymerization mechanism is used in this study:

Thermal Initiation:

$$
3 M \stackrel{K_{\mathrm{th}}}{\longrightarrow} 2 R_{1}
$$

Chemical Initiation:

$$
I \stackrel{K_{\mathrm{d}}}{\longrightarrow} 2 R_{\mathrm{in}}
$$

Propagation:

$$
R_{l}+M \stackrel{K_{\mathrm{p}}}{\longrightarrow} R_{l+1}, \quad l \geq 1
$$


Termination:

$$
R_{l}+R_{k} \stackrel{K_{\mathrm{t}}}{\longrightarrow} P_{l+k}, \quad l, k \geq 1
$$

Transfer to Monomer:

$$
R_{i}+M \stackrel{K_{\mathrm{tf}, \mathrm{m}}}{\longrightarrow} P_{l}+R_{1}, \quad l \geq 1
$$

Transfer to Inhibitor (or Impurity):

$$
R_{l}+Z \stackrel{K_{\mathrm{tf}, \mathrm{z}}}{\longrightarrow} P_{l}+Z, \quad l \geq 1
$$

\subsection{Mathematical Model}

A mathematical model, following the approach of Villalobos et al. [1993], and Dhib et al. [2000], is provided below for a non-isothermal, bulk, batch polymerization reactor. The model comprises the equations of change of volume $(V)$ and temperature $(T)$ of reactants, and the concentrations of monomer $(m)$, initiator $(i)$, inhibitor $(z)$, and of the first three moments of radicals and dead polymer molecules. The symbols in following expressions are defined in Notation.

$$
\begin{aligned}
\frac{\mathrm{d} V}{\mathrm{~d} t} & =-K_{\mathrm{p}} m \lambda_{0} V M_{\mathrm{m}}\left[\frac{1}{\rho_{\mathrm{p}}}-\frac{1}{\rho_{\mathrm{m}}}\right] \\
\frac{\mathrm{d} T}{\mathrm{~d} t} & =\frac{-\Delta H K_{\mathrm{p}} m \lambda_{0}}{\rho_{\mathrm{m}} C_{\mathrm{p}}}-\frac{U A\left(T-T_{\mathrm{j}}\right)}{V \rho_{\mathrm{m}} C_{\mathrm{p}}} \\
\frac{\mathrm{d} m}{\mathrm{~d} t} & =-K_{\mathrm{p}} m \lambda_{0}-\frac{m}{V} \frac{\mathrm{d} V}{\mathrm{~d} t} \\
\frac{\mathrm{d} i}{\mathrm{~d} t} & =K_{\mathrm{d}} i-\frac{i}{V} \frac{\mathrm{d} V}{\mathrm{~d} t} \\
\frac{\mathrm{d} z}{\mathrm{~d} t} & =-K_{\mathrm{t} f, \mathrm{z}} z \lambda_{0}-\frac{z}{V} \frac{\mathrm{d} V}{\mathrm{~d} t}
\end{aligned}
$$


For moments of radicals:

$$
\begin{aligned}
\frac{\mathrm{d} \lambda_{0}}{\mathrm{~d} t}= & 2 K_{\mathrm{th}} m^{3}+2 f K_{\mathrm{d}} i-K_{\mathrm{t}} \lambda_{0}^{2}-K_{\mathrm{tf}, \mathrm{z}} z \lambda_{0}-\frac{\lambda_{0}}{V} \frac{\mathrm{d} V}{\mathrm{~d} t} \\
\frac{\mathrm{d} \lambda_{1}}{\mathrm{~d} t}= & 2 K_{\mathrm{th}} m^{3}+2 f K_{\mathrm{d}} i+K_{\mathrm{p}} m \lambda_{0}-K_{\mathrm{t}} \lambda_{0} \lambda_{1}+K_{\mathrm{tf}, \mathrm{m}} m\left(\lambda_{0}-\lambda_{1}\right) \\
& -K_{\mathrm{tf}, \mathrm{z}} z \lambda_{1}-\frac{\lambda_{1}}{V} \frac{\mathrm{d} V}{\mathrm{~d} t} \\
\frac{\mathrm{d} \lambda_{2}}{\mathrm{~d} t}= & 2 K_{\mathrm{th}} m^{3}+2 f K_{\mathrm{d}} i+K_{\mathrm{p}} m\left(\lambda_{0}+2 \lambda_{1}\right)-K_{\mathrm{t}} \lambda_{0} \lambda_{2}+K_{\mathrm{tf}, \mathrm{m}} m\left(\lambda_{0}-\lambda_{2}\right) \\
& -K_{\mathrm{tf}, \mathrm{z}} z \lambda_{2}-\frac{\lambda_{2}}{V} \frac{\mathrm{d} V}{\mathrm{~d} t}
\end{aligned}
$$

For moments of dead polymer molecules:

$$
\begin{aligned}
& \frac{\mathrm{d} \mu_{0}}{\mathrm{~d} t}=\frac{K_{\mathrm{t}} \lambda_{0}^{2}}{2}+\left(K_{\mathrm{tf}, \mathrm{m}} m+K_{\mathrm{tf}, \mathrm{z}} z\right) \lambda_{0}-\frac{\mu_{0}}{V} \frac{\mathrm{d} V}{\mathrm{~d} t} \\
& \frac{\mathrm{d} \mu_{1}}{\mathrm{~d} t}=K_{\mathrm{t}} \lambda_{0} \lambda_{1}+\left(K_{\mathrm{tf}, \mathrm{m}} m+K_{\mathrm{tf}, \mathrm{z}} z\right) \lambda_{1}-\frac{\mu_{1}}{V} \frac{\mathrm{d} V}{\mathrm{~d} t} \\
& \frac{\mathrm{d} \mu_{2}}{\mathrm{~d} t}=K_{\mathrm{t}}\left(\lambda_{0} \lambda_{2}+\lambda_{1}^{2}\right)+\left(K_{\mathrm{tf}, \mathrm{m}} m+K_{\mathrm{tf}, \mathrm{z}} z\right) \lambda_{2}-\frac{\mu_{2}}{V} \frac{\mathrm{d} V}{\mathrm{~d} t}
\end{aligned}
$$

The equations of change for radicals and polymer are necessary to realize the optimal control objectives (Objectives 2-4 ahead), which specify parameters other than time as independent variables.

Let us define normalized state variables as

$$
\begin{aligned}
& \underset{\sim}{V}=1-\frac{V}{V^{0}}, \quad \underset{\sim}{T}=1-\frac{T}{T^{0}}, \quad \underset{\sim}{m}=1-\frac{m}{m^{0}}, \quad \stackrel{i}{\sim}=1-\frac{i}{i^{0}} \\
& z=1-\frac{z}{z^{0}}, \quad \lambda_{j}=1-\frac{\lambda_{j}}{\mu^{0}}, \quad{\underset{\sim}{\mu}}_{j}=1-\frac{\mu_{j}}{\mu^{0}} ; \quad j=0,1,2
\end{aligned}
$$


where $V^{\mathrm{o}}, T^{\circ}, m^{\mathrm{o}}, i^{\mathrm{o}}$ and $z^{\mathrm{o}}$ are the initial values of $V, T, m, i$ and $z$, respectively, and $\mu^{\circ}$ is a parameter used to normalize radical and polymer moments. Then the equations of change for the normalized state variables are given by

$$
\frac{\mathrm{d} y_{k}}{\mathrm{~d} t}=\left\{\begin{array}{l}
-\frac{1}{y_{k}^{\circ}} \frac{\mathrm{d} y_{k}}{\mathrm{~d} t}, \text { if } \cdot y_{k}^{\circ} \neq 0 \\
0, \text { if } y_{k}^{\circ}=0
\end{array}\right\} ; k=0,1,2, \ldots, 10
$$

where $y_{k}$ is the normalized form of a state variable, $y_{k}$, with the normalization factor, $y_{k}^{\circ}$.

\subsection{Optimal Control Objectives}

Based on the above unsteady state model, four optimal control objectives for a batch polymerization reactor are formulated as follows:

Objective 1 Maximization of monomer conversion for a specified operation time Objective 2 Minimization of batch processing time for a specified monomer conversion

Objective 3 Maximization of monomer conversion for a specified number average polymer molecular weight

Objective 4 Maximization of monomer conversion for a specified weight average polymer molecular weight

For the above objectives, the temperature of heat-exchange fluid in reactor jacket (or "jacket temperature") is considered as a control function of a specified parameter. An inequality constraint in the form of an upper limit to the temperature of reactants is imposed as

$$
T \leq T_{\max }
$$


There are two additional inequality constraints in the form of lower and upper limits to jacket temperature, i.e.,

$$
T_{\mathrm{j}, \min } \leq T_{\mathrm{j}} \leq T_{\mathrm{j}, \max }
$$

\subsubsection{Objective 1}

The optimal control objective is to determine the control policy for jacket temperature that would maximize monomer conversion in a specified batch operation time $\left(t_{f}\right)$, i. e., the performance index,

$$
\underset{\max }{J}=X\left(t_{\mathrm{f}}\right)=X_{\mathrm{f}}
$$

In Equation (2.16), $X$ is monomer conversion given by

$$
X=1-\frac{m V}{m^{\circ} V^{0}}=1-(1-\underset{\sim}{m})(1-V)
$$

This objective requires the satisfaction of Equations (2.1)-(2.6), or their normalized counterparts.

\subsubsection{Objective 2}

The optimal control objective is to determine the control policy for jacket temperature that would minimize operation time for a specified, final monomer conversion expressed in terms of fractional reduction in monomer concentration $\left(m_{\mathrm{f}}\right)$, i. e., the performance index,

$$
\underset{\min }{J}=t\left(m_{\mathrm{f}}\right)=t_{\mathrm{f}}
$$

This objective requires the transformation of Equations (2.1)-(2.11) so that the independent variable is fractional reduction in monomer concentration $(m)$. The transformed equations 


\subsection{Optimal Control Objectives}

are given by

$$
\begin{aligned}
& \frac{\mathrm{d} t}{\mathrm{~d} m}=\left[\frac{\mathrm{d} m}{\mathrm{~d} t}\right]^{-1} \\
& \frac{\mathrm{d} y_{i}}{\mathrm{~d} m}=\left[\frac{\mathrm{d} m}{\mathrm{~d} t}\right]^{-1} \frac{\mathrm{d} y_{i}}{\mathrm{~d} t} ; \quad i=0,1,3,4, \ldots, 10
\end{aligned}
$$

with time as a new state variable.

\section{3:3 Objective 3}

The optimal control objective is to determine the control policy for jacket temperature that would maximize monomer conversion for a specified, final weight average polymer molecular weight $\left(\bar{M}_{\mathrm{n}, \mathrm{f}}\right)$, i.e., the performance index,

$$
\underset{\max }{J}=X\left(\bar{M}_{\mathrm{n}, \mathrm{f}}\right)=X_{\mathrm{f}}
$$

This objective requires the satisfaction of Equations (2.1)-(2.11) after their transformation so that the independent variable is number average polymer molecular weight $\left(\bar{M}_{n}\right)$. The transformed equations are given by

$$
\frac{\mathrm{d} y_{i}}{\mathrm{~d} \bar{M}_{\mathrm{n}}}=\left[\frac{\mathrm{d} \bar{M}_{\mathrm{n}}}{\mathrm{d} t}\right]^{-1} \frac{\mathrm{d} y_{k}}{\mathrm{~d} t} ; \quad k=0,1,2, \ldots, 10
$$

where

$$
\begin{aligned}
& \bar{M}_{\mathrm{n}}=M_{\mathrm{m}}\left(\frac{\mu_{1}+\lambda_{1}}{\mu_{0}+\lambda_{0}}\right) \\
& \frac{\mathrm{d} \bar{M}_{\mathrm{n}}}{\mathrm{d} t}=\frac{M_{\mathrm{m}} \mu^{\mathrm{o}}}{\mu_{0}+\lambda_{0}}\left[\bar{M}_{\mathrm{n}}\left(\frac{\mathrm{d} \mu_{0}}{\mathrm{~d} t}+\frac{\mathrm{d} \lambda_{0}}{\mathrm{~d} t}\right)-\left(\frac{\mathrm{d} \mu_{1}}{\mathrm{~d} t}+\frac{\mathrm{d} \lambda_{1}}{\mathrm{~d} t}\right)\right]
\end{aligned}
$$

The additional equation of change for time as a state variable is given by

$$
\frac{\mathrm{d} t}{\mathrm{~d} \bar{M}_{\mathrm{n}}}=\left[\frac{\mathrm{d} \bar{M}_{\mathrm{n}}}{\mathrm{d} t}\right]^{-1}
$$




\subsubsection{Objective 4}

The optimal control objective is to determine the control policy for jacket temperature that would maximize monomer conversion for a specified, final weight average polymer molecular weight $\left(\bar{M}_{\mathrm{w}, \mathrm{f}}\right)$, i.e., the performance index,

$$
\underset{\max }{J}=X\left(\bar{M}_{\mathrm{w}, \mathrm{f}}\right)=X_{\mathrm{f}}
$$

This objective requires the satisfaction of Equations (2.1)-(2.11) after their transformation so that the independent variable is weight average polymer molecular weight $\left(\bar{M}_{\mathrm{w}}\right)$. The transformed equations are given by

$$
\frac{\mathrm{d} y_{i}}{\mathrm{~d} \bar{M}_{\mathrm{w}}}=\left[\frac{\mathrm{d} \bar{M}_{\mathrm{w}}}{\mathrm{d} t}\right]^{-1} \frac{\mathrm{d} y_{i}}{\mathrm{~d} t} ; \quad i=0,1,2, \ldots, 10
$$

where

$$
\begin{aligned}
\bar{M}_{\mathrm{w}} & =M_{\mathrm{m}}\left(\frac{\mu_{2}+\lambda_{2}}{\mu_{1}+\lambda_{1}}\right) \\
\frac{\mathrm{d} \bar{M}_{\mathrm{w}}}{\mathrm{d} t} & =\frac{M_{\mathrm{m}} \mu^{\mathrm{o}}}{\mu_{1}+\lambda_{1}}\left[\bar{M}_{\mathrm{w}}\left(\frac{\mathrm{d} \mu_{1}}{\mathrm{~d} t}+\frac{\mathrm{d} \lambda_{1}}{\mathrm{~d} t}\right)-\left(\frac{\mathrm{d} \tilde{\mu}_{2}}{\mathrm{~d} t}+\frac{\mathrm{d} \lambda_{2}}{\mathrm{~d} t}\right)\right]
\end{aligned}
$$

The additional equation of change for time as a state variable is given by

$$
\frac{\mathrm{d} t}{\mathrm{~d} \bar{M}_{\mathrm{w}}}=\left[\frac{\mathrm{d} \bar{M}_{\mathrm{w}}}{\mathrm{d} t}\right]^{-1}
$$

For Objectives 2-4, the above transformations of the process model, Equations (2.1)-(2.11), enable its integration in the range of a specified independent variable (other than time) up to its specified, final value.

\subsection{Integration of Equations of Change}

The four optimal control objectives described above require the integration of corresponding equations of change with different inclependent variables $\left(t, \underset{\sim}{m}, \bar{M}_{\mathrm{n}}\right.$ and $\left.\bar{M}_{\mathrm{w}}\right)$ for performance 
index evaluations. These equations are very stiff and non-linear. In this work, they were numerically integrated using semi-implicit Bader-Deufhard algorithm, and adaptive step-size control [Press et al., 2002]. Analytical jacobians were employed for integration. The equations to evaluate the elements of jacobian corresponding to each optimal control objective are provided in the next section.

\subsubsection{Equations to Evaluate Jacobians}

Equations for the analytical evaluation of jacobian are for normalized state variables, and time (for Objectives 2-4) with respect to the independent variable depending on an optimal control objective. Using the start-up values, $y_{i}^{\circ}$, and the basic jacobian elements, $\frac{\mathrm{d}}{\mathrm{d} y_{j}}\left(\frac{\mathrm{d} y_{i}}{\mathrm{~d} t}\right)$, $i, j=0,1,2, \ldots, 10$, the jacobian elements are sequentially calculable as described below.

\section{Jacobian for Objective 1}

For all state variables, the elements of the jacobian are given by

$$
\frac{\mathrm{d}}{\mathrm{d} y_{j}}\left(\frac{\mathrm{d} y_{i}}{\mathrm{~d} t}\right)=\left\{\begin{array}{l}
\frac{y_{j}^{\mathrm{o}}}{y_{i}^{\mathrm{o}}} \frac{\mathrm{d}}{\mathrm{d} y_{j}}\left(\frac{\mathrm{d} y_{i}}{\mathrm{~d} t}\right), \text { if } y_{i}^{\mathrm{o}}>0 \\
0, \text { if } y_{i}^{\mathrm{o}}=0
\end{array}\right\} ; \quad i, j=0,1,2, \ldots, 10
$$

This jacobian is same for other optimal control objectives until the independent variable of Equations (2.1)-(2.11), which initially is time, is changed to $\underset{\sim}{m}, \bar{M}_{\mathrm{n}}$ and $\bar{M}_{\mathrm{w}}$ for Objectives 2 , 3 and 4 , respectively. Time then becomes a new state variable. For this transformation, the new independent variable must be non-zero. The jacobians for Objectives 2-4 are then sequentially calculable as follows: 


\section{Jacobian for Objective 2 After Transformation}

The jacobian elements for time, corresponding to $i=0$, are given by

$$
\frac{\mathrm{d}}{\mathrm{d} y_{j}}\left(\frac{\mathrm{d} t}{\mathrm{~d} m}\right)=-m^{\mathrm{o}} y_{j}^{\mathrm{o}}\left[\frac{\mathrm{d} m}{\mathrm{~d} t}\right]^{-2} \frac{\mathrm{d}}{\mathrm{d} y_{j}}\left(\frac{\mathrm{d} m}{\mathrm{~d} t}\right) ; \quad j=0,1,2, \ldots, 10
$$

The jacobian elements for remaining state variables, corresponding to $i=1,2, \ldots, 10$, are given by

$$
\frac{\mathrm{d}}{\mathrm{d} \underline{y}_{j}}\left(\frac{\mathrm{d} \underline{y}_{i}}{\mathrm{~d} \sim_{\sim}}\right)=-\frac{1}{y_{i}^{0}} \frac{\mathrm{d} y_{i}}{\mathrm{~d} t} \frac{\mathrm{d}}{\mathrm{d} \underline{y}_{j}}\left(\frac{\mathrm{d} t}{\mathrm{~d} m}\right)+\alpha ; \quad j=0,1,2, \ldots,(n-1)
$$

In Equation (2.33),

$$
\alpha=\left\{\begin{array}{l}
-m^{\circ}\left[\frac{\mathrm{d} m}{\mathrm{~d} t}\right]^{-1} \frac{y_{j}^{\mathrm{o}}}{y_{i}^{\mathrm{o}}} \frac{\mathrm{d}}{\mathrm{d} y_{j}}\left(\frac{\mathrm{d} y_{i}}{\mathrm{~d} t}\right), \text { if } y_{i}^{\circ}>0 \\
0, \text { if } y_{i}^{\mathrm{o}}=0
\end{array}\right.
$$

Jacobian for Objective 3 After Transformation

The basic jacobian elements for $\bar{M}_{\mathrm{n}}$ are given by

$$
\begin{aligned}
\frac{\mathrm{d}}{\mathrm{d} y_{j}}\left(\frac{\mathrm{d} \bar{M}_{\mathrm{n}}}{\mathrm{d} t}\right)= & \frac{M_{\mathrm{m}}}{\mu_{0}+\lambda_{0}}\left[\frac{\mathrm{d}}{\mathrm{d} y_{j}}\left(\frac{\mathrm{d} \mu_{1}}{\mathrm{~d} t}\right)+\frac{\mathrm{d}}{\mathrm{d} y_{j}}\left(\frac{\mathrm{d} \lambda_{1}}{\mathrm{~d} t}\right)\right]-\frac{M_{\mathrm{m}}}{\mu_{1}+\lambda_{1}}\left[\frac{\mathrm{d}}{\mathrm{d} y_{j}}\left(\frac{\mathrm{d} \mu_{0}}{\mathrm{~d} t}\right)+\right. \\
& \left.\frac{\mathrm{d}}{\mathrm{d} y_{j}}\left(\frac{\mathrm{d} \lambda_{0}}{\mathrm{~d} t}\right)\right]+\beta_{0} ; \quad j=0,1,2, \ldots, 10
\end{aligned}
$$


In Equation (2.35),

$$
\beta_{0}=\left\{\begin{array}{l}
\frac{-M_{\mathrm{m}}}{\left(\mu_{0}+\lambda_{0}\right)^{2}}\left[\left(\frac{\mathrm{d} \mu_{1}}{\mathrm{~d} t}+\frac{\mathrm{d} \lambda_{1}}{\mathrm{~d} t}\right)-2 \bar{M}_{\mathrm{n}}\left(\frac{\mathrm{d} \mu_{0}}{\mathrm{~d} t}+\frac{\mathrm{d} \lambda_{0}}{\mathrm{~d} t}\right)\right], \text { for } y_{j}=\mu_{0}, \lambda_{0} \\
\frac{-M_{\mathrm{m}}}{\left(\mu_{0}+\lambda_{0}\right)^{2}}\left(\frac{\mathrm{d} \mu_{0}}{\mathrm{~d} t}+\frac{\mathrm{d} \lambda_{0}}{\mathrm{~d} t}\right), \text { for } y_{j}=\mu_{1}, \lambda_{1} \\
0, \text { for remaining } y_{j} \mathrm{~s}
\end{array}\right.
$$

The jacobian elements for time as the state variable, corresponding to $i=11$, are given by

$$
\begin{aligned}
& \frac{\mathrm{d}}{\mathrm{d} y_{j}}\left(\frac{\mathrm{d} t}{\mathrm{~d} \bar{M}_{\mathrm{n}}}\right)=y_{j}^{\circ}\left[\frac{\mathrm{d} \bar{M}_{\mathrm{n}}}{\mathrm{d} t}\right]^{-2} \frac{\mathrm{d}}{\mathrm{d} y_{j}}\left(\frac{\mathrm{d} \bar{M}_{\mathrm{n}}}{\mathrm{d} t}\right) ; j=0,1,2, \ldots, 10 \\
& \frac{\mathrm{d}}{\mathrm{d} t}\left(\frac{\mathrm{d} t}{\mathrm{~d} \bar{M}_{\mathrm{n}}}\right)=0
\end{aligned}
$$

The jacobian elements for remaining state variables, corresponding to $i=0,1,2, \ldots, 10$, are given by

$$
\begin{aligned}
& \frac{\mathrm{d}}{\mathrm{d} y_{j}}\left(\frac{\mathrm{d} y_{i}}{\mathrm{~d} \bar{M}_{\mathrm{n}}}\right)=-\frac{1}{y_{i}^{0}} \frac{\mathrm{d} y_{i}}{\mathrm{~d} t} \frac{\mathrm{d}}{\mathrm{d} y_{j}}\left(\frac{\mathrm{d} t}{\mathrm{~d} \bar{M}_{\mathrm{n}}}\right)+\gamma_{0} ; j=0,1,2, \ldots, 10 \\
& \frac{\mathrm{d}}{\mathrm{d} t}\left(\frac{\mathrm{d} y_{i}}{\mathrm{~d} \bar{M}_{\mathrm{n}}}\right)=0
\end{aligned}
$$

In Equation (2.39),

$$
\gamma_{0}=\left\{\begin{array}{l}
{\left[\frac{\mathrm{d} \bar{M}_{\mathrm{n}}}{\mathrm{d} t}\right]^{-1} \frac{y_{j}^{\mathrm{o}}}{y_{i}^{\mathrm{o}}} \frac{\mathrm{d}}{\mathrm{d} y_{j}}\left(\frac{\mathrm{d} y_{i}}{\mathrm{~d} t}\right), \text { if } y_{i}^{\mathrm{o}}>0} \\
0, \text { if } y_{i}^{\mathrm{o}}=0
\end{array}\right.
$$


Jacobian for Objective 4 After Transformation

The basic jacobian elements for $\bar{M}_{\mathrm{w}}$ given by

$$
\begin{aligned}
\frac{\mathrm{d}}{\mathrm{d} y_{j}}\left(\frac{\mathrm{d} \bar{M}_{\mathrm{w}}}{\mathrm{d} t}\right)= & \frac{M_{\mathrm{m}}}{\mu_{1}+\lambda_{1}}\left[\frac{\mathrm{d}}{\mathrm{d} y_{j}}\left(\frac{\mathrm{d} \mu_{2}}{\mathrm{~d} t}\right)+\frac{\mathrm{d}}{\mathrm{d} y_{j}}\left(\frac{\mathrm{d} \lambda_{2}}{\mathrm{~d} t}\right)\right]-M_{\mathrm{m}} \frac{\mu_{2}+\lambda_{2}}{\left(\mu_{1}+\lambda_{1}\right)^{2}}\left[\frac{\mathrm{d}}{\mathrm{d} y_{j}}\left(\frac{\mathrm{d} \mu_{1}}{\mathrm{~d} t}\right)\right. \\
& \left.+\frac{\mathrm{d}}{\mathrm{d} y_{j}}\left(\frac{\mathrm{d} \lambda_{1}}{\mathrm{~d} t}\right)\right]+\beta_{1} ; \quad j=0,1,2, \ldots, 10
\end{aligned}
$$

In Equation (2.42),

$$
\beta_{1}=\left\{\begin{array}{l}
\frac{-M_{\mathrm{m}}}{\left(\mu_{1}+\lambda_{1}\right)^{2}}\left[\left(\frac{\mathrm{d} \mu_{2}}{\mathrm{~d} t}+\frac{\mathrm{d} \lambda_{2}}{\mathrm{~d} t}\right)-2 \bar{M}_{\mathrm{w}}\left(\frac{\mathrm{d} \mu_{1}}{\mathrm{~d} t}+\frac{\mathrm{d} \lambda_{1}}{\mathrm{~d} t}\right)\right], \text { for } y_{j}=\mu_{1}, \lambda_{1} \\
\frac{-M_{\mathrm{m}}}{\left(\mu_{1}+\lambda_{1}\right)^{2}}\left(\frac{\mathrm{d} \mu_{1}}{\mathrm{~d} t}+\frac{\mathrm{d} \lambda_{1}}{\mathrm{~d} t}\right), \text { for } y_{j}=\mu_{2}, \lambda_{2} \\
0, \text { for remaining } y_{j} \mathrm{~s}
\end{array}\right.
$$

The jacobian elements for $t$ as the state variable, corresponding to $i=11$, are given by

$$
\begin{aligned}
& \frac{\mathrm{d}}{\mathrm{d} y_{j}}\left(\frac{\mathrm{d} t}{\mathrm{~d} \bar{M}_{\mathrm{w}}}\right)=y_{j}^{\mathrm{o}}\left[\frac{\mathrm{d} \bar{M}_{\mathrm{w}}}{\mathrm{d} t}\right]^{-2} \frac{\mathrm{d}}{\mathrm{d} y_{j}}\left(\frac{\mathrm{d} \bar{M}_{\mathrm{w}}}{\mathrm{d} t}\right) ; j=0,1,2, \ldots, 10 \\
& \frac{\mathrm{d}}{\mathrm{d} t}\left(\frac{\mathrm{d} t}{\mathrm{~d} \bar{M}_{\mathrm{w}}}\right)=0
\end{aligned}
$$

The jacobian elements for remaining state variables, corresponding to $i=0,1,2, \ldots, 10$, are given by

$$
\begin{aligned}
& \frac{\mathrm{d}}{\mathrm{d} y_{j}}\left(\frac{\mathrm{d} y_{i}}{\mathrm{~d} \bar{M}_{\mathrm{w}}}\right)=-\frac{1}{y_{i}^{0}} \frac{\mathrm{d} y_{i}}{\mathrm{~d} t} \frac{\mathrm{d}}{\mathrm{d} y_{j}}\left(\frac{\mathrm{d} t}{\mathrm{~d} \bar{M}_{\mathrm{w}}}\right)+\gamma_{1} ; j=0,1,2, \ldots, 10 \\
& \frac{\mathrm{d}}{\mathrm{d} t}\left(\frac{\mathrm{d} y_{i}}{\mathrm{~d} \bar{M}_{\mathrm{w}}}\right)=0
\end{aligned}
$$


In Equation (2.46),

$$
\gamma_{1}=\left\{\begin{array}{l}
{\left[\frac{\mathrm{d} \bar{M}_{\mathrm{w}}}{\mathrm{d} t}\right]^{-1} \frac{y_{j}^{\mathrm{o}}}{y_{i}^{\mathrm{o}}} \frac{\mathrm{d}}{\mathrm{d} y_{j}}\left(\frac{\mathrm{d} y_{i}}{\mathrm{~d} t}\right), \text { if } y_{i}^{\mathrm{o}}>0} \\
\cdots \\
0, \text { if } y_{i}^{\circ}=0
\end{array}\right.
$$

For the integration of equations of change for Objectives 3 and $4, \mu^{\circ}$ was adjusted so that the difference between value of independent variable (e.g. $\bar{M}_{n}$ ), and that calculated using other state variables (e.g. from Equation (2.23)) is negligible. For Objectives 2-4, the transformation of process model was done as soon as the new independent variable achieved a finite value lying within the first stage of optimal control.

Various parameters used in calculations are provided in Table 2.1. The reactants for polymerization are monomer, n-Butyl Methacrylate or BMA, monofunctional initiator, 2,2'Azobisisobutyronitrile or AIBN, and some impurity as an inhibitor. The product is the polymer, poly(BMA). The reference for the comparison of optimal control results is the "bàse case" of isothermal, BMA polymerization with AIBN initiator at $60^{\circ} \mathrm{C}$, which was verified from the experimental data published by Nair and Muthana [1961].

\subsection{Optimal Control of PBMA}

The mathematical model of bulk, batch polymerization reactor is highly non-linear. Furthermore; due to the inequality constraints of Equation (2.14) and (2.15), the relation between the performance index and jacket temperature for Objectives 1-4 would not necessarily be unimodal and continuous for the four optimal control objectives. To realize these difficult objectives, a robust optimal control method based on genetic algorithms [Upreti, 2004] was applied.

In this work, the temperature of heat-exchange fluid inside reactor jacket (or jacket temperature) was employed as a control function of specified independent variable. Jacket 
temperature was considered to be a series of five discrete step values equispaced in the range of independent variable. The number of step values (or control stages), the mathematical model of bulk, batch polymerization reactor with its parameters, and the process constraints of Equations (2.14) and (2.15) were input to the optimal control method. These inputs are needed to evaluate the performance index (fitness) for a given control function. The application of the method yielded the optimal control function by stochastically applying genetic operations on a randomly generated set (population) of control functions constrained by Equation (2.15). Since the method generates optimal control functions within the control domain, the constraints of Equation (2.15) are satisfied automatically. The method eliminates any control function for which any other process constraint (Equation (2.14) in this application) is violated during the evaluation of corresponding performance index. 
Table 2.1: Model parameters used in calculations

\begin{tabular}{|c|c|c|}
\hline Parameter & Value or Expression & Source \\
\hline$\therefore$ & 0.6 & \multirow{12}{*}{ This study } \\
\hline$i^{\circ}, \mathrm{mol} / \mathrm{L}$ & $1.829 \times 10^{-2}$ & \\
\hline$m^{\circ}, \mathrm{mol} / \mathrm{L}$ & 6.035 & \\
\hline$T^{\circ},{ }^{\circ} \mathrm{C}$ & 60 (Objectives $1 \&$ 2), 0 (Objectives $3 \&$ 4) & \\
\hline$T_{\max },{ }^{\circ} \mathrm{C}$ & 90 & \\
\hline$T_{\mathrm{j}, \max },{ }^{\circ} \mathrm{C}$ & 120 & \\
\hline$T_{\mathrm{j}, \min },{ }^{\circ} \mathrm{C}$ & 4 (Objectives $1 \& 2$ ), -20 (Objectives $3 \& 4$ ) & \\
\hline$z^{\circ}, \mathrm{mol} / \mathrm{L}$ & $4.5 \times 10^{-5}$ & \\
\hline$v^{\circ}, \mathrm{L}$ & 1 & \\
\hline$K_{\mathrm{th}}, \mathrm{L} / \mathrm{mol} \cdot \min$ & 0 & \\
\hline$K_{\mathrm{tf}, \mathrm{z}}, \mathrm{L} / \mathrm{mol} \cdot \mathrm{min}$ & $1.4 \times 10^{3} K_{\mathrm{p}}$ & \\
\hline$M_{\mathrm{m}}, \mathrm{g} / \mathrm{mol}$ & 142.2 (for BMA) & \\
\hline$K_{\mathrm{d}}, \mathrm{L} / \min$ & $4.26 \times 10^{-4}$ & $\begin{array}{l}\text { Nair and } \\
\text { Muthana } \\
{[1961]}\end{array}$ \\
\hline$K_{\mathrm{p}}, \mathrm{L} / \mathrm{mol} \cdot \min$ & $2 \times 10^{8} \exp \left[-2.8057 \times 10^{3} /(T+273.15)\right]$ & $\begin{array}{l}\text { Davis and } \\
\text { O'Driscoll } \\
{[1990]}\end{array}$ \\
\hline$U A, \mathrm{~J} / \mathrm{min} \cdot \mathrm{K}$ & $6.5475 \times 10^{2}$ & $\begin{array}{l}\text { Villalobos } \\
\text { et al. [1993] }\end{array}$ \\
\hline
\end{tabular}


Table 2.1: continued...

\begin{tabular}{|l|l|l|}
\hline Parameter & Value or Expression & Source \\
\hline \hline$-\Delta H, \mathrm{~J} / \mathrm{mol}$ & $5.7541 \times 10^{4}$ & $\begin{array}{l}\text { Brandrup } \\
\text { et al. [1999] }\end{array}$ \\
\hline$K_{\mathrm{tf}, \mathrm{m}, \mathrm{L} / \mathrm{mol} \cdot \mathrm{min}}$ & $1.4 \times 10^{-5} K_{\mathrm{p}}$ & Yaws \\
\hline$\rho_{\mathrm{m}}, \mathrm{g} / \mathrm{L}$ & $286.91 \times 0.2545^{-[1-(T+273.15) / 616]^{0.2857}}$ & {$[1999]$} \\
\hline$C_{\mathrm{p}}, \mathrm{J} / \mathrm{g} \cdot \mathrm{K}$ & $\begin{array}{l}1.8966 \times 10^{4}+1.5380 \times 10^{2}(T+273.15) \\
4.2659 \times 10^{-1}(T+273.15)^{2}+5.2022 \times 10^{-4}(T+\end{array}$ & \\
\hline$K_{\mathrm{t}}, \mathrm{L} / \mathrm{mol} \cdot \mathrm{min}$ & $2 \times 10^{31} \exp [-1,803.8 /(T+273.15)]$ & $\begin{array}{l}\text { Burnett } \\
\text { et al. [1953] }\end{array}$ \\
\hline & $2 \times 15)^{3}$ & $\begin{array}{l}\text { Buback } \\
\text { et al. [1997] }\end{array}$ \\
\hline
\end{tabular}




\section{Results for Bulk, Batch BMA Polymerization}

\section{$3.1 \quad$ Results}

The optimal control results for the four objectives are summarized and compared with the base case in Table 3.1. The results show significant performance improvements by $34-395 \%$ in the performance of bulk, batch polymerization of BMA.

\subsubsection{Results For Objective 1}

To realize this objective, monomer conversion in batch polymerization was maximized in the specified processing time of $70 \mathrm{~min}$. The optimal control policy for jacket temperature (i. e. optimal jacket temperature versus time) is presented in Figure 3.1. It is observed that optimal jacket temperature is close to its upper reactor temperature limit of $90^{\circ} \mathrm{C}$. The figure shows the evolution of jacket temperature from a random series of step values of jacket temperature to its optimal level as the iterations of the optimal control method continue. Final monomer conversion progressively increases, and corresponding to optimal jacket temperature, the optimal value of the conversion is $36.5 \%$, which is an improvement of $43 \%$ over that in base case.

Figure 3.2 shows the change in optimal reactor temperature and monomer conversion with time, which correspond to the application of optimal jacket temperature shown in Figure 3.1. Corresponding variables for base case are also shown in Figure 3.2. It is observed that optimal reactor temperature after the first control stage is in phase with optimal jacket temperature, which indicates its strong influence on reaction temperature. At all times, optimal reactor temperature is well within the upper limit of $90^{\circ} \mathrm{C}$ specified through Equation (2.14). For time greater than zero, the optimal value of reactor temperature is found to exceed that for base case. It is this higher value corresponding to optimal jacket temperature which is primarily responsible for increased reaction rates, and subsequently, higher monomer con- 


\subsection{Results - Optimal control of PBMA}

Figure 3.1: Optimal reactor jacket temperature versus time for Objective 1

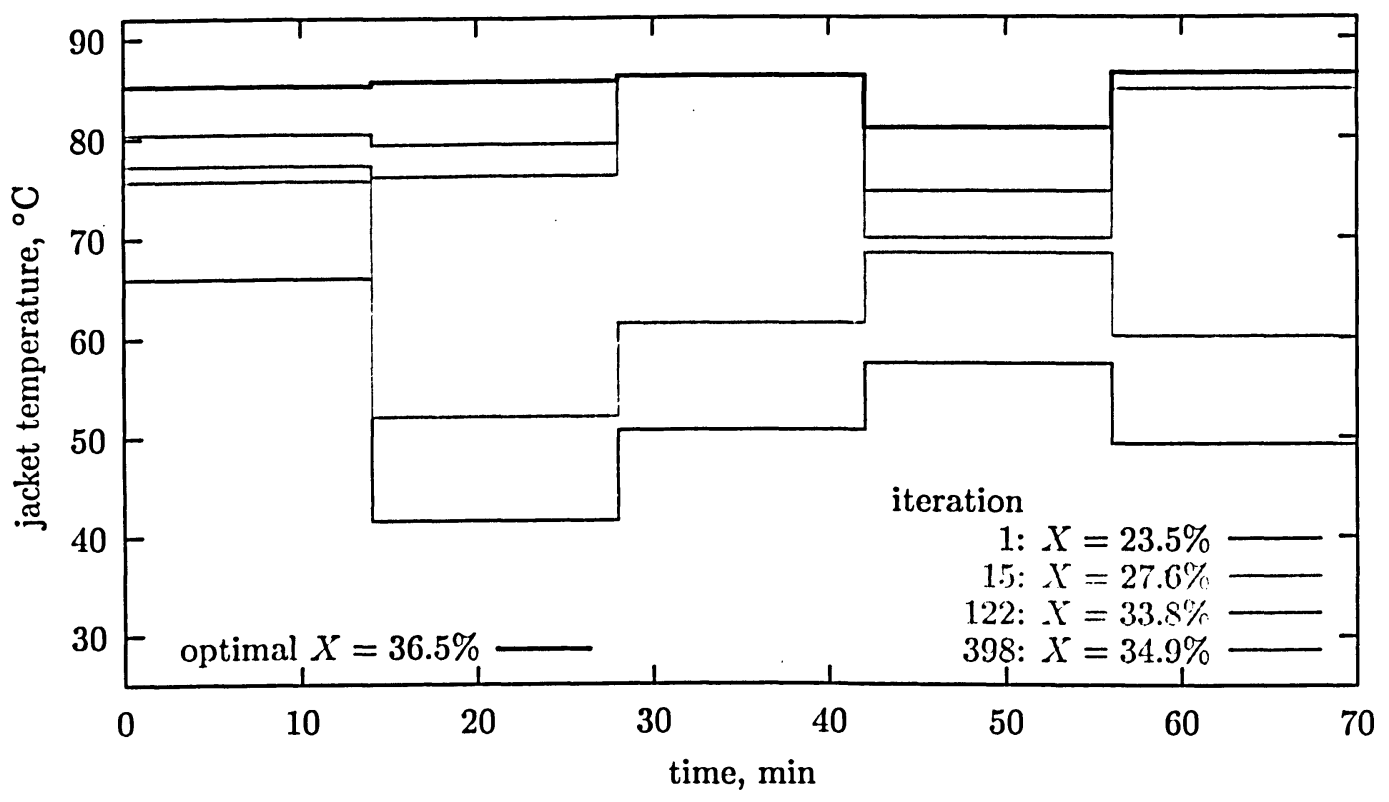

version. In fact, as seen in Figure 3.2, optimal monomer conversion, for time greater than zero, is always higher than the monomer conversion for base case.

The optimal values of number and weight average polymer molecular weights $\left(\bar{M}_{\mathrm{n}}\right.$ and $\left.\bar{M}_{\mathrm{w}}\right)$ are respectively shown in Figure 3.3 and 3.4 along with those for base case. It is observed that the initial rate of increase of optimal $\bar{M}_{\mathrm{n}}$ as well as $\bar{M}_{\mathrm{w}}$ with time is significantly higher and more prolonged than that in base case. In comparison to base case, the final values of optimal $\bar{M}_{\mathrm{n}}$ and $\bar{M}_{\mathrm{w}}$ are higher by about $40 \%$ and $43 \%$, respectively. This increase suggests that high optimal reactor temperature under the present unsteady state conditions favors the generation of polymer molecules with longer chain lengths. In fact, this departure in the values of average polymer molecular weights from base case motivated the formulation of Objectives 3 and 4, which target the maximization of monomer conversion with specified, final $\bar{M}_{\mathrm{n}}$ and $\bar{M}_{\mathrm{w}}$, respectively. 
Figure 3.2: Reactor temperature and monomer conversion versus time for Objective 1

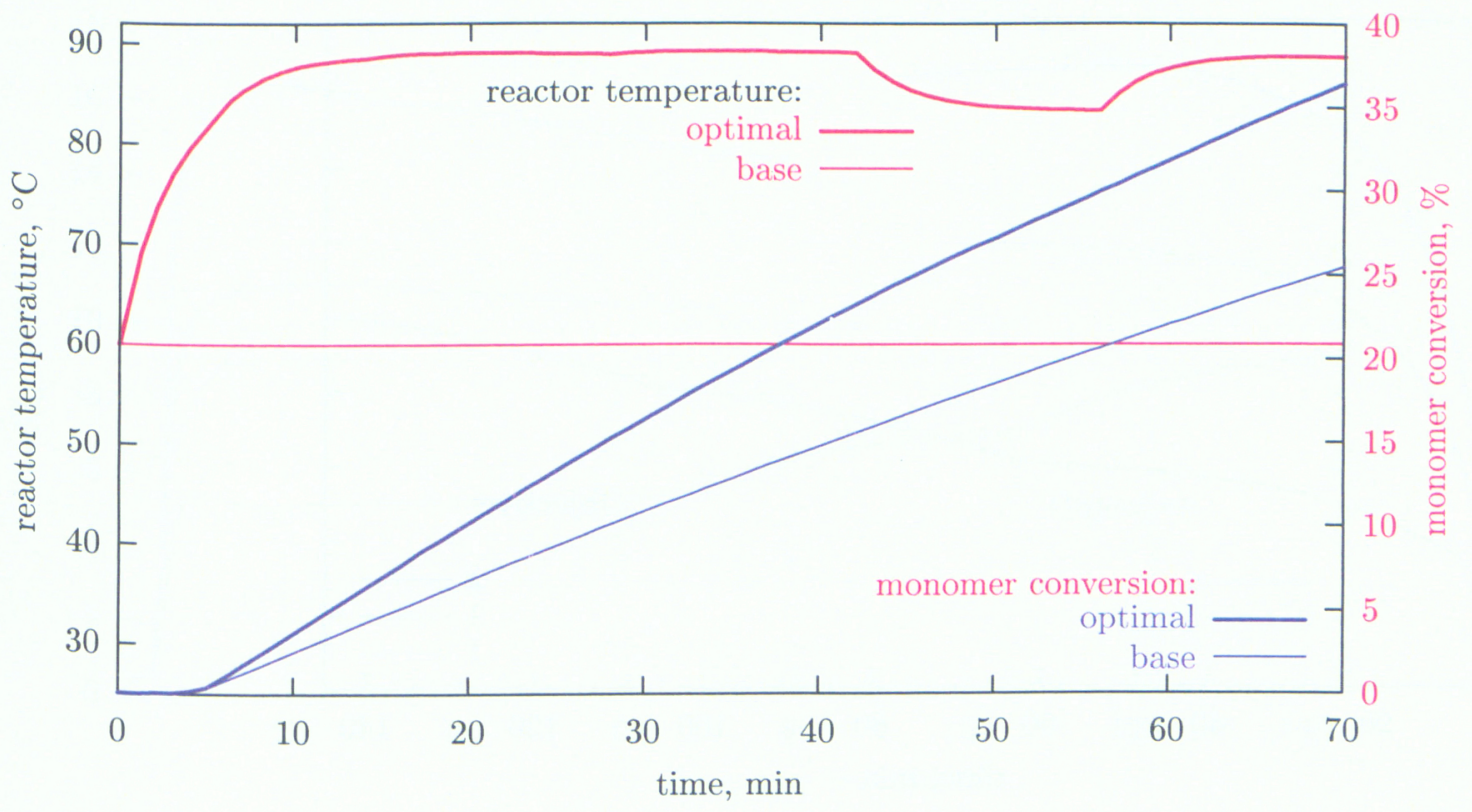

\subsubsection{Results For Objective 2}

To realize this objective, the operation time of batch polymerization was minimized for the specified, final monomer conversion of $40 \%$. The optimal control policy for jacket temperature is presented in Figure 3.5. Optimal jacket temperature is close to its upper reactor temperature limit of $90^{\circ} \mathrm{C}$, similar to what was observed for Objective 1. Moreover, the time-averaged value of optimal jacket temperature is approximately same as that in case of Objective 1. This similarity of optimal jacket temperature is reasonable because the attainment of each of Objectives 1 and 2 demands that the overall rate of monomer conversion be maximized through jacket temperature.

Optimal reactor temperature, shown in Figure 3.6, closely follows optimal jacket temperature second control stage onward. This behavior was observed earlier in case of Objective 1. Corresponding to optimal jacket temperature, the optimal value of the operation time is 79.1 min, which is a reduction by $34 \%$ relative to that of base case. 
Figure 3.3: Optimal number average molecular weight versus time for Objectives 1-4

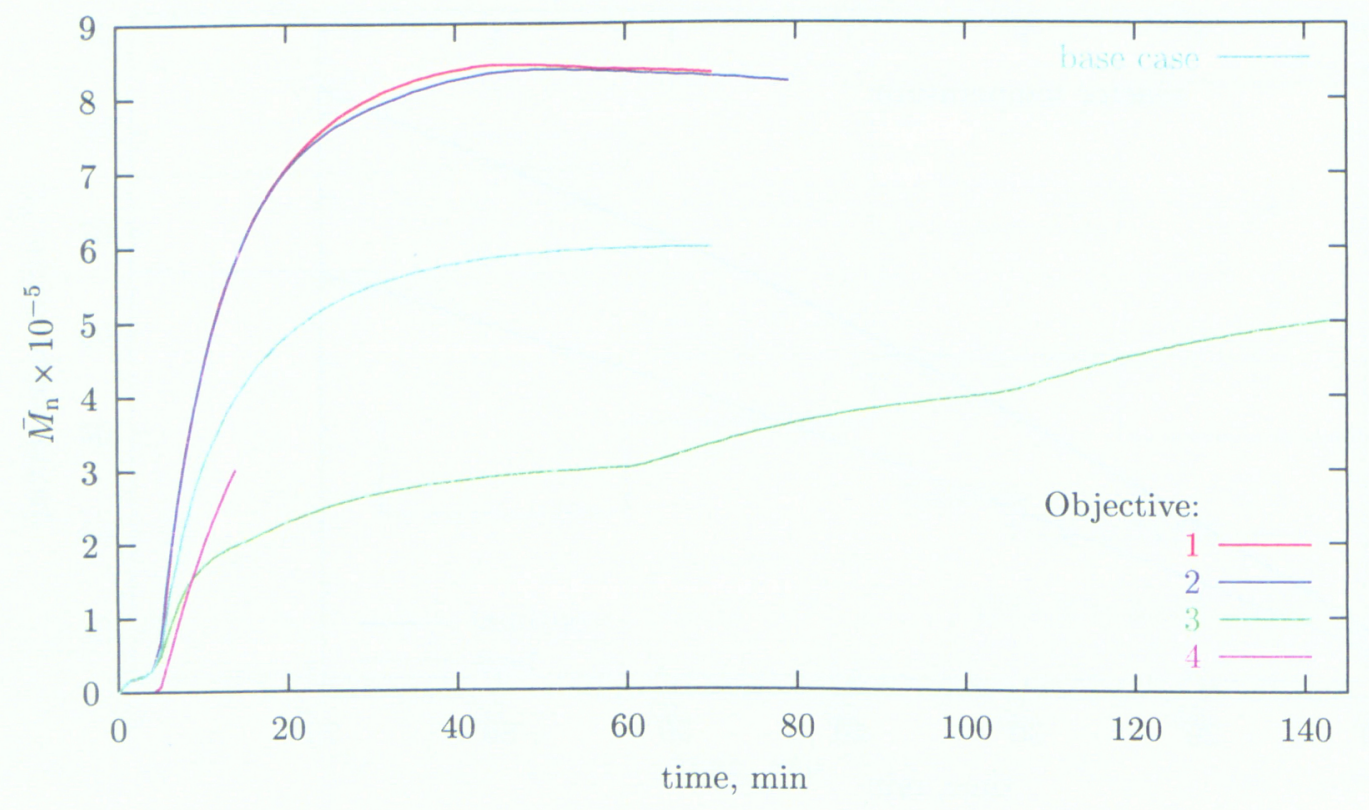

The optimal number and weight average polymer molecular weights $\left(\bar{M}_{\mathrm{n}}\right.$ and $\left.\bar{M}_{\mathrm{w}}\right)$ are respectively shown in Figure 3.3 and 3.4. The change in the average molecular weights with time almost coincides with that in case of Objective 1. The reason is that corresponding optimal reactor and jacket temperatures for Objective 1 and 2 are not much different, and are close to their upper limit.

\subsubsection{Results For Objective 3}

To realize this objective, monomer conversion in the bulk, batch polymerization of BMA was maximized for the specified, final number average molecular weight, $\bar{M}_{\mathrm{n}, \mathrm{f}}=5 \times 10^{5}$. For base case with the constant reactor temperature of $60^{\circ} \mathrm{C}$, the time needed to achieve this value of $\bar{M}_{\mathrm{n}, \mathrm{f}}$ is about 22 min with $7.8 \%$ monomer conversion as seen in Figures 3.3 and 3.2, respectively. Generally, the time needed for a given $\bar{M}_{\mathrm{n}, \mathrm{f}}$ increases with a decrease in reaction temperature. To enable extended operation time for optimal control through 
Figure 3.4: Optimal weight average molecular weight versus time for Objectives 1-4

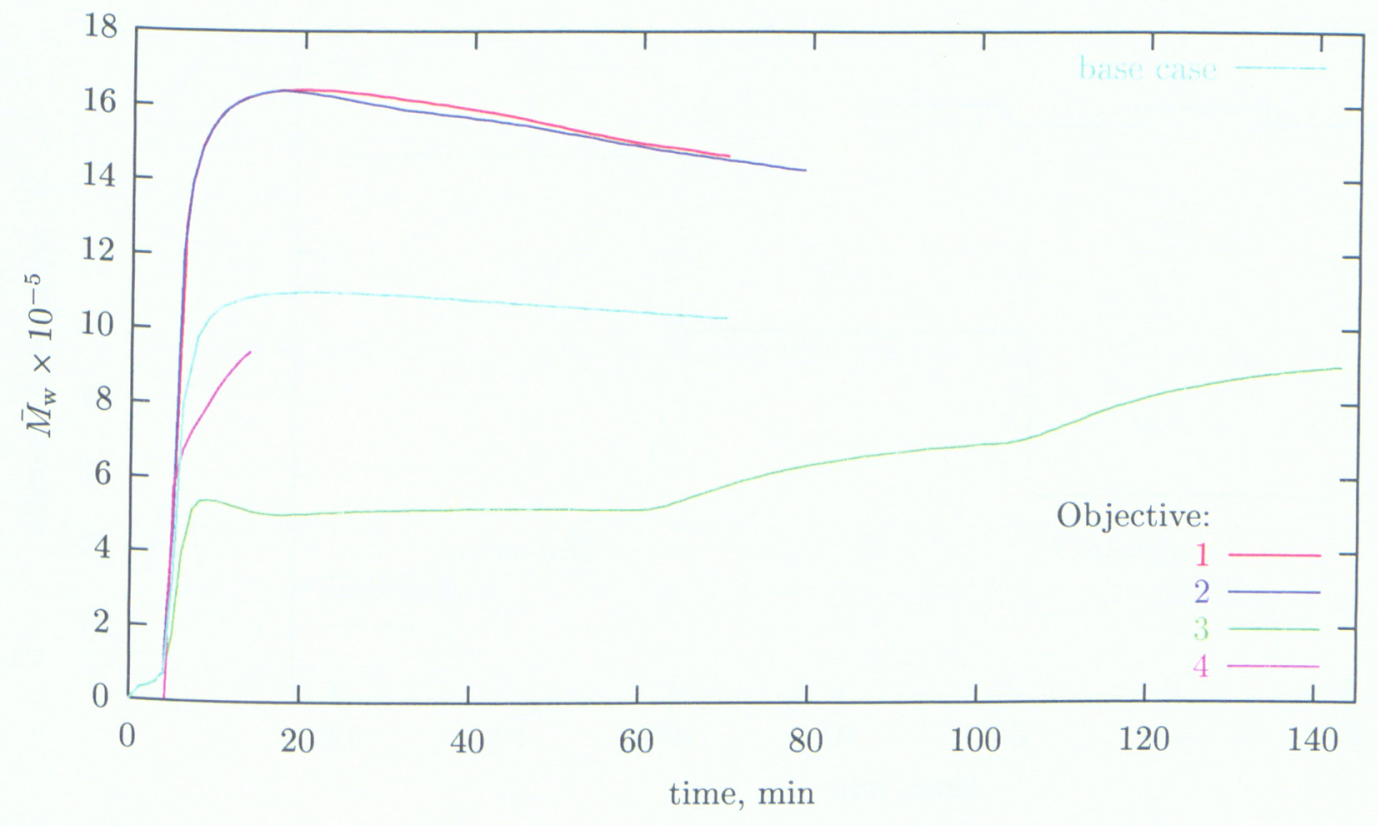

jacket temperature, and to facilitate higher monomer conversion (during longer operation time), the initial temperature of reactor was set at a low value of $0^{\circ} \mathrm{C}$. Furthermore, lower temperature range was made available to jacket temperature by reducing its lower limit to $-20^{\circ} \mathrm{C}$.

Figure 3.5 shows the resulting optimal control policy for jacket temperature, which spans $142.9 \mathrm{~min}$ of operation time, and yields the final monomer conversion of $38.6 \%$. This conversion is a substantial improvement by approximately four folds over that in base case. Although the lower limit for jacket temperature is $-20^{\circ} \mathrm{C}$, its lowest optimal value is above $0^{\circ} \mathrm{C}$. Optimal jacket temperature climbs up with time after its initial decline, and is closely followed by corresponding optimal reactor temperature as seen in Figure 3.6. While lower, initial reactor temperature obviates the early attainment of $\bar{M}_{\mathrm{n}, \mathrm{f}}$ with low monomer conversion, higher reactor temperature later on boosts the final monomer conversion. The optimal rates of change of $\bar{M}_{\mathrm{n}}$ (Figure 3.3 ) and $\bar{M}_{\mathrm{w}}$ (Figure 3.4 ) are initially smaller relative to re- 
Figure 3.5: Optimal jacket temperature versus time for Objectives 2-4

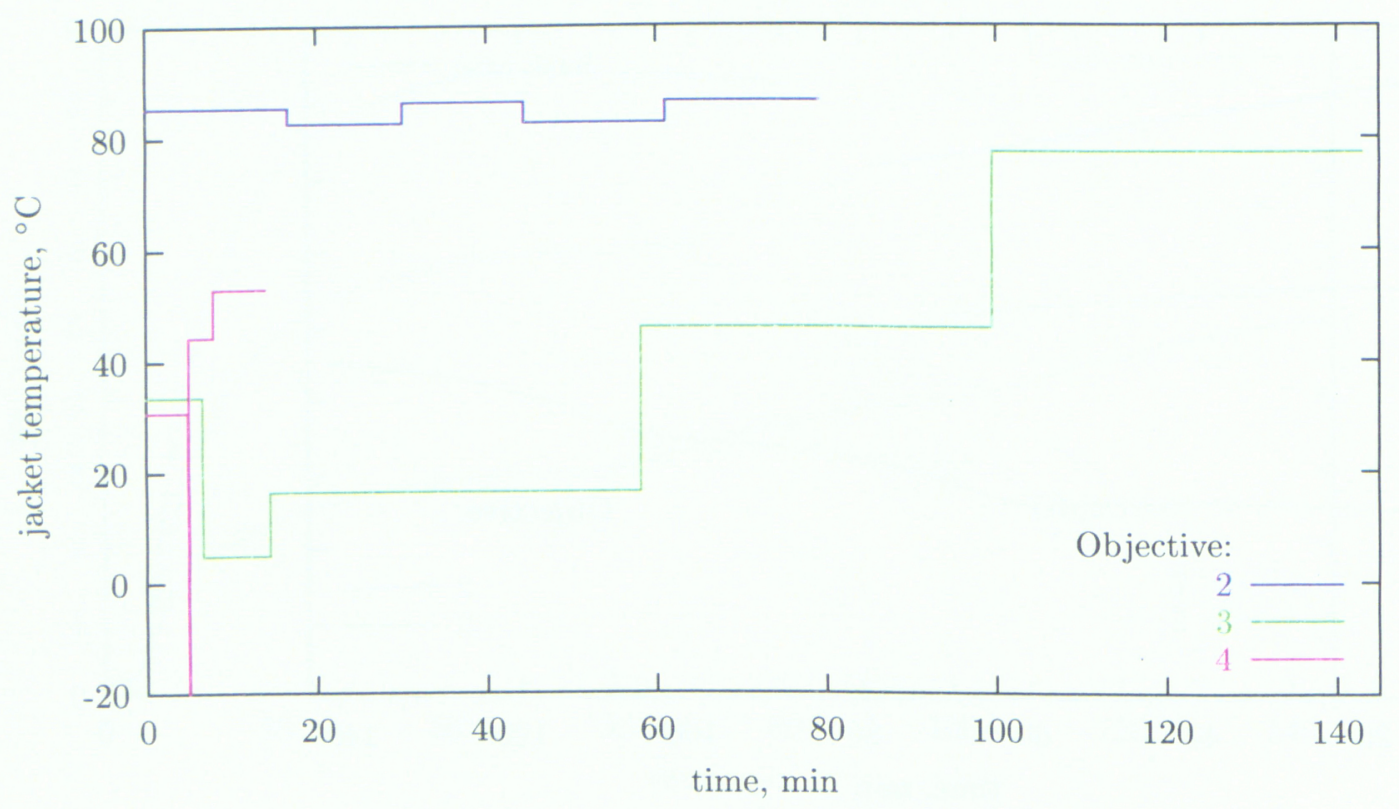

spectively those in base case. These optimal rates of change with time become more gradual later on.

\subsubsection{Results For Objective 4}

To realize this objective, monomer conversion in batch polymerization was maximized for the specified, final weight average molecular weight, $\bar{M}_{\mathrm{w}, \mathrm{f}}=9.4 \times 10^{5}$. For base case with the constant reactor temperature of $60^{\circ} \mathrm{C}$, the time needed to achieve this value of $\bar{M}_{\mathrm{w}, \mathrm{f}}$ is about 7 min with $1.5 \%$ monomer conversion as seen in Figures 3.4 and 3.2, respectively. During that short time, the rate of change of $\bar{M}_{\mathrm{w}}$ with time is about an order of magnitude higher than that for $\bar{M}_{\mathrm{n}}$. As a result, the realization of the present optimal control objective with high monomer conversions is expected to be very challenging. Optimal control results for this objective were obtained for the same initial reactor temperature, and the lower limit of jacket temperature that were used for Objective 3 . 
Figure 3.6: Optimal reactor temperature versus time for Objectives 2-4

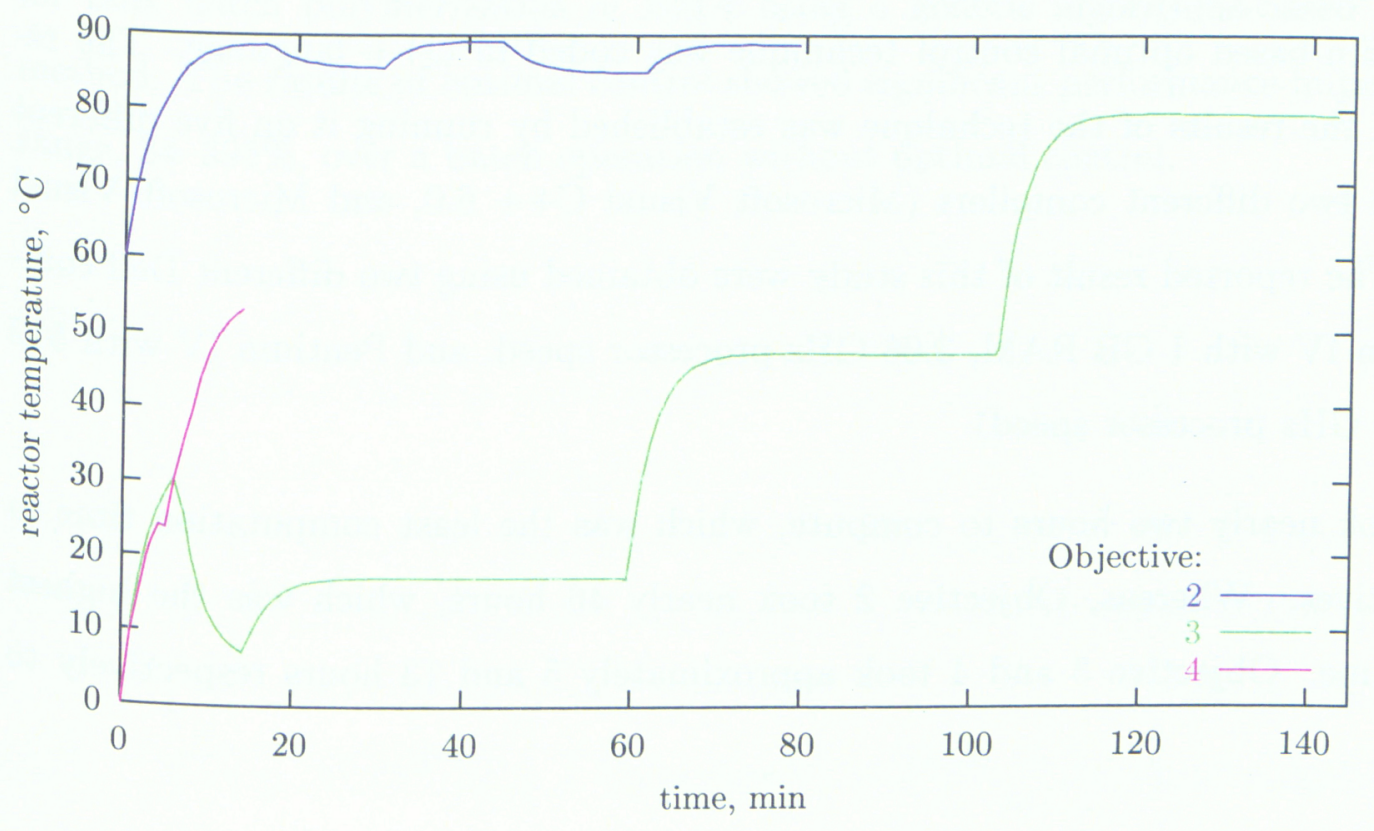

Figure 3.5 shows the resulting optimal jacket temperature versus time which spans only 13.9 min of operation time, and yields a final monomer conversion, which although is an improvement by $100 \%$ over base case, is still a low value of $3 \%$. It is observed that the second and third control stages of jacket temperature are of small durations (less than a minute each) with values 4.6 and $-20^{\circ} \mathrm{C}$ respectively. The reason is that jacket temperature is equispaced over the range of $\bar{M}_{\mathrm{w}}$, which has a very high initial rate of change with time, especially during the second and third control stages. The variation in optimal jacket temperature with time is however analogous to that in case of Objective 3. After an initial decline, optimal jacket temperature climbs up with time, and is closely followed by corresponding optimal reactor temperature as seen in Figure 3.6. The rates of change of optimal $\bar{M}_{\mathrm{n}}$ (Figure 3.3) and optimal $\bar{M}_{\mathrm{w}}$ (Figure 3.4 ) are initially not much different than those in base case, indicating the severe limitation of short time available for optimal control. 


\subsection{Computational Time}

Genetic algorithm-based optimal control technique was coded in $\mathrm{C}++$ language. The reproducibility of the results of the technique was established by running it on five different computers, and two different compilers (Microsoft Visual $\mathrm{C}++6.0$, and Microsoft Visual Studio. Net). The reported result of this study were obtained using two different Dell computers (Pentium IV with 1 GB RAM, 3.06 GHz processor speed, and Pentium IV with 512 GB RAM, $2.80 \mathrm{GHz}$ processor speed)

Objective 1 took nearly two hours to compute, which was the least computation time in the four objectives. Whereas, Objective 2 took nearly 46 hours, which was the highest computation time. Objective 3 and 4 took approximately 5 and 13 hours respectively to compute.

\subsection{Conclusion}

Four optimal control objectives were developed for a bulk polymerization in a batch reactor based on a detailed non-isothermal process model. The objectives were: (i) maximization of monomer conversion in a specified operation time, (ii) minimization of operation time for specified, final monomer conversion, (iii) maximization of monomer conversion for a specified, final number average polymer molecular weight, and (vi) maximization of monomer conversion for a specified, final weight average polymer molecular weight. The temperature of heat-exchange fluid inside reactor jacket was employed as a control function of a specified independent variable. The process constraints of maximum reactor temperature, and the upper and lower limits to the heat-exchange fluid were imposed.

The above objectives were designed to help augment operational efficiency, and achieve a higher degree of product specificity in polymer production. Equations were provided to suitably transform the process model in the range of specified variable other than time, and to 
evaluate the elements of jacobian. Based on the process model, the objectives were realized for bulk batch polymerization of BMA using a genetic algorithms-based optimal control method. The results of optimal control showed significant performance improvements in the range, 34-395\%, over a batch operation without optimal control. 
Table 3.1: Summary of optimal control results

\begin{tabular}{|c|c|c|c|c|}
\hline Objective & Specification & $\begin{array}{l}J \text { in Base } \\
\text { Case }\end{array}$ & Optimal $J$ & $\begin{array}{l}\text { \% Improvement } \\
\text { in } J\end{array}$ \\
\hline 1 & $t_{\mathrm{f}}=70 \mathrm{~min}$ & $X_{\mathrm{f}}=25.5 \%$ & $\underset{\max }{X_{\mathrm{f}}}=36.5 \%$ & 43 \\
\hline 2 & $X_{\mathrm{f}}=40 \%$ & $t_{\mathrm{f}}=119.1 \mathrm{~min}$ & $\underset{\min }{t_{\mathrm{f}}}=79.1 \mathrm{~min}$ & 34 \\
\hline 3 & $\bar{M}_{\mathrm{n}, \mathrm{f}}=5 \times 10^{5}$ & $X_{\mathrm{f}}=7.8 \%$ & $\underset{\mathrm{f}}{X_{\mathrm{f}}}=38.6 \%$ & 395 \\
\hline 4 & $\bar{M}_{\mathrm{w}, \mathrm{f}}=9.4 \times 10^{5}$ & $X_{\mathrm{f}}=1.5 \%$ & $\underset{\max }{X_{\mathrm{f}}}=3 \%$ & 100 \\
\hline
\end{tabular}




\section{Mathematical Modeling for Solution, Batch MMA Polymerization With Monofunctional Initiator}

In this chapter, we discuss the development of mathematical model on the basis of free radical polymerization mechanism for the solution polymerization of methyl methacrylate with monofunctional initiator in a non-isothermal batch polymerization reactor, and the changes in the differential equation by applying normalized state variables, also the incorporation gel and glass effect model. Further, we discuss the formulation of four different optimal control objectives, and the development of analytical jacobian to integrate the developed model.

\subsection{Free Radical Polymerization Mechanism}

The following reaction mechanism has been used in this work.

Thermal Initiation:

$$
3 M \stackrel{K_{\mathrm{th}}}{\longrightarrow} 2 R_{1}
$$

Chemical Initiation:

$$
I \stackrel{K_{\mathrm{d}}}{\longrightarrow} 2 R_{\text {in }}
$$

Propagation:

$$
R_{l}+M \stackrel{K_{\mathrm{p}}}{\longrightarrow} R_{l+1}, \quad l \geq 1
$$

Termination:

$$
R_{l}+R_{k} \stackrel{K_{\mathrm{t}}}{\longrightarrow} P_{l+k}, \quad l, k \geq 1
$$


Transfer to Monomer:

$$
R_{l}+M \stackrel{K_{\mathrm{tf}, \mathrm{m}}}{\longrightarrow} P_{l}+R_{1}, \quad l \geq 1
$$

Transfer to Solvent:

$$
R_{l}+S \stackrel{K_{\mathrm{tf}, \mathrm{s}}}{\longrightarrow} P_{l}+R_{1}, \quad l \geq 1
$$

Transfer to Inhibitor (or Impurity):

$$
R_{l}+Z \stackrel{K_{\mathrm{tf}, \mathrm{z}}}{\longrightarrow} P_{l}+Z, \quad l \geq 1
$$

The above polymerization mechanism is based on the approach of Villalobos et al. [1993], and Gao and Penlidis [1996].

\subsection{Mathematical Model}

A mathematical model, following the approach of Villalobos et al. [1993], and Gao and Penlidis [1996], is provided below for the batch polymerization of MMA through mono functional initiator in a nonisothermal batch reactor. The model comprises the equations of change of volume $(V)$ and temperature $(T)$ of reactants, and the concentrations of monomer $(m)$, initiator $(i)$, solvent $(s)$, inhibitor $(z)$, and of the first three moments of radicals and dead polymer molecules. The equations are based on the above given free radical polymerization reaction mechanism. The symbols in following expressions are defined in Notation. 


$$
\begin{aligned}
\frac{\mathrm{d} V}{\mathrm{~d} t} & =-K_{\mathrm{p}} m \lambda_{0} V M_{\mathrm{m}}\left[\frac{1}{\rho_{\mathrm{p}}}-\frac{1}{\rho_{\mathrm{m}}}\right] \\
\frac{\mathrm{d} T}{\mathrm{~d} t} & =\frac{-\Delta H K_{\mathrm{p}} m \lambda_{0}}{\rho_{\mathrm{m}} C_{\mathrm{p}}}-\frac{U A\left(T-T_{\mathrm{j}}\right)}{V \rho_{\mathrm{m}} C_{\mathrm{p}}} \\
\frac{\mathrm{d} m}{\mathrm{~d} t} & =-K_{\mathrm{p}} m \lambda_{0}-\frac{m}{V} \frac{\mathrm{d} V}{\mathrm{~d} t} \\
\frac{\mathrm{d} i}{\mathrm{~d} t} & =K_{\mathrm{d}} i-\frac{i}{V} \frac{\mathrm{d} V}{\mathrm{~d} t} \\
\frac{\mathrm{d} s}{\mathrm{~d} t} & =-K_{\mathrm{tf}, \mathrm{s}} s \lambda_{0}-\frac{s}{V} \frac{\mathrm{d} V}{\mathrm{~d} t} \\
\frac{\mathrm{d} z}{\mathrm{~d} t} & =-K_{\mathrm{tf}, z} z \lambda_{0}-\frac{z}{V} \frac{\mathrm{d} V}{\mathrm{~d} t}
\end{aligned}
$$

For the moments of radicals:

$$
\begin{aligned}
\frac{\mathrm{d} \lambda_{0}}{\mathrm{~d} t}= & 2 K_{\mathrm{th}} m^{3}+2 f K_{\mathrm{d}} i-K_{\mathrm{t}} \lambda_{0}^{2}-K_{\mathrm{tf}, \mathrm{z}} z \lambda_{0}-\frac{\lambda_{0}}{V} \frac{\mathrm{d} V}{\mathrm{~d} t} \\
\frac{\mathrm{d} \lambda_{1}}{\mathrm{~d} t}= & 2 K_{\mathrm{th}} m^{3}+2 f K_{\mathrm{d}} i+K_{\mathrm{p}} m \lambda_{0}-K_{\mathrm{t}} \lambda_{0} \lambda_{1}+ \\
& \left(K_{\mathrm{tf}, \mathrm{m}} m+K_{\mathrm{tf}, \mathrm{s}} s\right)\left(\lambda_{0}-\lambda_{1}\right)-K_{\mathrm{tf}, \mathrm{z}} z \lambda_{1}-\frac{\lambda_{1}}{V} \frac{\mathrm{d} V}{\mathrm{~d} t} \\
\frac{\mathrm{d} \lambda_{2}}{\mathrm{~d} t}= & 2 K_{\mathrm{th}} m^{3}+2 f K_{\mathrm{d}} i+K_{\mathrm{p}} m\left(\lambda_{0}+2 \lambda_{1}\right)-K_{\mathrm{t}} \lambda_{0} \lambda_{2}+ \\
& \left(K_{\mathrm{tf}, \mathrm{m}} m+K_{\mathrm{tf}, \mathrm{s}} s\right)\left(\lambda_{0}-\lambda_{2}\right)-K_{\mathrm{tf}, \mathrm{z}} z \lambda_{2}-\frac{\lambda_{2}}{V} \frac{\mathrm{d} V}{\mathrm{~d} t}
\end{aligned}
$$


For the moments of dead polymer molecules:

$$
\begin{aligned}
& \frac{\mathrm{d} \mu_{0}}{\mathrm{~d} t}=\frac{K_{\mathrm{t}} \lambda_{0}^{2}}{2}+\left(K_{\mathrm{tf}, \mathrm{m}} m+K_{\mathrm{tf}, \mathrm{s}} s+K_{\mathrm{tf}, \mathrm{z}} z\right) \lambda_{0}-\frac{\mu_{0}}{V} \frac{\mathrm{d} V}{\mathrm{~d} t} \\
& \frac{\mathrm{d} \mu_{1}}{\mathrm{~d} t}=K_{\mathrm{t}} \lambda_{0} \lambda_{1}+\left(K_{\mathrm{tf}, \mathrm{m}} m+K_{\mathrm{tf}, \mathrm{s}} s+K_{\mathrm{tf}, \mathrm{z}} z\right) \lambda_{1}-\frac{\mu_{1}}{V} \frac{\mathrm{d} V}{\mathrm{~d} t} \\
& \frac{\mathrm{d} \mu_{2}}{\mathrm{~d} t}=K_{\mathrm{t}}\left(\lambda_{0} \lambda_{2}+\lambda_{1}^{2}\right)+\left(K_{\mathrm{tf}, \mathrm{m}} m+K_{\mathrm{tf}, \mathrm{s}} s+K_{\mathrm{tf}, \mathrm{z}} z\right) \lambda_{2}-\frac{\mu_{2}}{V} \frac{\mathrm{d} V}{\mathrm{~d} t}
\end{aligned}
$$

The equations of change for radicals and polymer are necessary to realize the optimal control objectives (Objectives 2-4 ahead), which specify parameters other than time as independent variables.

Let us define normalized state variables as

$$
\begin{aligned}
& \underline{\sim}=1-\frac{V}{V^{\mathrm{o}}}, \quad \underset{\sim}{T}=1-\frac{T}{T^{\mathrm{o}}}, \quad \underline{\sim}=1-\frac{m}{m^{0}}, \quad \underset{i}{=}=1-\frac{i}{i^{\mathrm{o}}} \\
& \underline{s}=1-\frac{s}{s^{0}}, \quad z=1-\frac{z}{z^{0}}, \quad \lambda_{j}=1-\frac{\lambda_{j}}{\mu^{0}}, \quad \mu_{j}=1-\frac{\mu_{j}}{\mu^{0}} \\
& j=0,1,2
\end{aligned}
$$

where $V^{\mathrm{o}}, T^{\mathrm{o}}, m^{\mathrm{o}}, i^{\mathrm{o}}, s^{\mathrm{o}}$ and $z^{\mathrm{o}}$ are the initial values of state variables $V, T, m, i, s$ and $z$, respectively, and $\mu^{\circ}$ is a parameter used to normalize radical and polymer moments. Then the equations of change for the normalized state variables are given by

$$
\frac{\mathrm{d} y_{k}}{\mathrm{~d} t}=\left\{\begin{array}{l}
-\frac{1}{y_{k}^{\circ}} \frac{\mathrm{d} y_{k}}{\mathrm{~d} t}, \text { if } y_{k}^{o} \neq 0 \\
0, \text { if } y_{k}^{o}=0
\end{array}\right\} ; k=0,1,2, \ldots, 11
$$

where $y_{k}$ is the normalized form of a state variable, $y_{k}$, with the normalization factor, $y_{k}^{o}$. 


\subsection{Rate Coefficient for Propagation}

Rate coefficient for propagation is given by

$$
K_{\mathrm{p}}=K_{\mathrm{p}, 1} \times K_{\mathrm{p}, 2} \quad[\mathrm{~L} / \mathrm{mol} \cdot \mathrm{min}]
$$

where, from Louie et al. [1985]:

$$
K_{\mathrm{p}, 1}=2.95 \times 10^{7} \exp \left(\frac{-2.1892 \times 10^{3}}{T+273.15}\right) \cdot[\mathrm{L} / \mathrm{mol} \cdot \mathrm{min}]
$$

from Schmidt and Ray [1981]:

$$
\begin{aligned}
& K_{\mathrm{p}, 2}=\left\{\begin{array}{l}
7.1 \times 10^{-5} \exp \left(171.53 V_{\mathrm{f}}\right), \text { if } V_{\mathrm{f}}<V_{\mathrm{fpc}} \\
1, \text { if } V_{\mathrm{f}} \geq V_{\mathrm{fpc}}
\end{array}\right. \\
& V_{\mathrm{fpc}}=0.05
\end{aligned}
$$

and from Sung-Mo et al. [1998]:

$$
\begin{aligned}
V_{\mathrm{f}} & =0.025+V_{\mathrm{f}, \mathrm{m}}+V_{\mathrm{f}, \mathrm{p}}+V_{\mathrm{f}, \mathrm{s}} \\
V_{\mathrm{f}, \mathrm{m}} & =\frac{\left(T-T_{\mathrm{g}, \mathrm{m}}\right) m M_{\mathrm{m}} \times 10^{-3}}{\rho_{\mathrm{m}}} \\
V_{\mathrm{f}, \mathrm{p}} & =\frac{\left(T-T_{\mathrm{g}, \mathrm{p}}\right)\left(m^{\circ}-m\right) M_{\mathrm{m}} \times 4.8 \times 10^{-4}}{\rho_{\mathrm{p}}} \\
V_{\mathrm{f}, \mathrm{s}} & =\frac{\left(T-T_{\mathrm{g}, \mathrm{s}}\right) s M_{\mathrm{s}} \times 10^{-3}}{\rho_{\mathrm{s}}}
\end{aligned}
$$




\subsection{Rate Coefficient for Termination}

Rate coefficient for termination is given by

$$
K_{\mathrm{t}}=K_{\mathrm{t}, 1} \times K_{\mathrm{t}, 2} \quad[\mathrm{~L} / \mathrm{mol} \cdot \mathrm{min}]
$$

where, from Sung-Mo et al. [1998]:

$$
K_{\mathrm{t}, 1}=3.12 \times 10^{10} \exp \left(\frac{-7.0156 \times 10^{2}}{T+273.15}\right) \quad[\mathrm{L} / \mathrm{mol} \cdot \mathrm{min}]
$$

and from Schmidt and Ray [1981]:

$$
\begin{aligned}
& K_{\mathrm{t}, 2}=\left\{\begin{array}{l}
2.3 \times 10^{-6} \exp \left(75 V_{\mathrm{f}}\right), \text { if } V_{\mathrm{f}}<V_{\mathrm{ftc}} \\
0.10575 \exp \left(17.15 V_{\mathrm{f}}-0.01715 T\right), \text { if } V_{\mathrm{f}} \geq V_{\mathrm{ftc}}
\end{array}\right. \\
& V_{\mathrm{ftc}}=0.1856-2.965 \times 10^{-4} T
\end{aligned}
$$

\subsection{Optimal Control Objectives}

Based on the above mathematical model, four different optimal control objectives for batch MMA polymerization are formulated in this section. The temperature of heat-exchange fluid in reactor jacket (or "jacket temperature") is considered as a control function of a specified parameter. An inequality constraint in the form of an upper limit to the temperature of reactants is imposed as

$$
T \leq T_{\max }
$$

There are two additional inequality constraints in the form of lower and upper limits to jacket temperature, i.e.,

$$
T_{\mathrm{j}, \min } \leq T_{\mathrm{j}} \leq T_{\mathrm{j}, \max }
$$




\subsubsection{Objective 1}

The optimal control objective is to determine the control policy for jacket temperature that would maximize monomer conversion in a specified batch operation time $\left(t_{\mathrm{f}}\right)$, i.e., the performance index,

$$
\underset{\max }{J}=X\left(t_{\mathrm{f}}\right)=X_{\mathrm{f}}
$$

In Equation (4.29), $X$ is monomer conversion given by

$$
X=1-\frac{m V}{m^{0} V^{0}}=1-(1-m)(1-V)
$$

This objective requires the satisfaction of Equations (4.1)-(4.7), or their normalized form given by Equation (4.14).

\subsubsection{Objective 2}

The optimal control objective is to determine the control policy for jacket temperature that would minimize operation time for a specified, final monomer conversion expressed in terms of fractional reduction in monomer concentration $\left(m_{\mathfrak{f}}\right)$, i. e., the performance index,

$$
\underset{\min }{J}=t\left(m_{\mathrm{f}}\right)=t_{\mathrm{f}}
$$

This objective requires the transformation of Equations (4.1)-(4.12) so that the independent variable is fractional reduction in monomer concentration $(m)$. The transformed equations are given by

$$
\begin{aligned}
& \frac{\mathrm{d} t}{\mathrm{~d} m}=\left[\frac{\mathrm{d} m}{\mathrm{~d} t}\right]^{-1} \quad \text { for } i=2 \\
& \frac{\mathrm{d} \underline{y}_{i}}{\mathrm{~d} m}=\left[\frac{\mathrm{d} m}{\mathrm{~d} t}\right]^{-1} \frac{\mathrm{d} y_{i}}{\mathrm{~d} t} ; \quad i=0,1,3,4, \ldots, 11
\end{aligned}
$$

with time as a new state variable. 


\subsubsection{Objective 3}

The optimal control objective is to determine the control policy for jacket temperature that would maximize monomer conversion for a specified, final weight average polymer molecular weight $\left(\bar{M}_{n, f}\right)$, i.e., the performance index,

$$
\underset{\max }{J}=X\left(\bar{M}_{\mathrm{n}, \mathrm{f}}\right)=X_{\mathrm{f}}
$$

This objective requires the satisfaction of Equations (4.1)-(4.12) after their transformation so that the independent variable is number average polymer molecular weight $\left(\bar{M}_{n}\right)$. The transformed equations are given by

$$
\frac{\mathrm{d} y_{i}}{\mathrm{~d} \bar{M}_{\mathrm{n}}}=\left[\frac{\mathrm{d} \bar{M}_{\mathrm{n}}}{\mathrm{d} t}\right]^{-1} \frac{\mathrm{d} y_{i}}{\mathrm{~d} t} ; \quad i=0,1, \ldots, 11
$$

where

$$
\begin{aligned}
\bar{M}_{\mathrm{n}} & =M_{\mathrm{m}}\left(\frac{\mu_{1}+\lambda_{1}}{\mu_{0}+\lambda_{0}}\right) \\
\frac{\mathrm{d} \bar{M}_{\mathrm{n}}}{\mathrm{d} t} & =\frac{M_{\mathrm{m}} \mu^{\mathrm{o}}}{\mu_{0}+\lambda_{0}}\left[\bar{M}_{\mathrm{n}}\left(\frac{\mathrm{d} \mu_{0}}{\mathrm{~d} t}+\frac{\mathrm{d} \lambda_{0}}{\mathrm{~d} t}\right)-\left(\frac{\mathrm{d} \tilde{\sim}_{1}}{\mathrm{~d} t}+\frac{\mathrm{d} \lambda_{1}}{\mathrm{~d} t}\right)\right]
\end{aligned}
$$

The additional equation of change for time as a state variable is given by

$$
\frac{\mathrm{d} t}{\mathrm{~d} \bar{M}_{\mathrm{n}}}=\left[\frac{\mathrm{d} \bar{M}_{\mathrm{n}}}{\mathrm{d} t}\right]^{-1} \quad \text { for } i=12
$$

\subsubsection{Objective 4}

The optimal control objective is to determine the control policy for jacket temperature that would maximize monomer conversion for a specified, final weight average polymer molecular weight $\left(\bar{M}_{\mathrm{w}, \mathrm{f}}\right)$, i. e., the performance index,

$$
\underset{\max }{J}=X\left(\bar{M}_{\mathrm{w}, \mathrm{f}}\right)=X_{\mathrm{f}}
$$


This objective requires the satisfaction of Equations (4.1)-(4.12) after their transformation so that the independent variable is weight average polymer molecular weight $\left(\bar{M}_{\mathrm{w}}\right)$. The transformed equations are given by

$$
\frac{\mathrm{d} y_{i}}{\mathrm{~d} \bar{M}_{\mathrm{w}}}=\left[\frac{\mathrm{d} \bar{M}_{\mathrm{w}}}{\mathrm{d} t}\right]^{-1} \frac{\mathrm{d} y_{i}}{\mathrm{~d} t} ; \quad i=0,1, \ldots, 11
$$

where

$$
\begin{aligned}
\bar{M}_{\mathrm{w}} & =M_{\mathrm{m}}\left(\frac{\mu_{2}+\lambda_{2}}{\mu_{1}+\lambda_{1}}\right) \\
\frac{\mathrm{d} \bar{M}_{\mathrm{w}}}{\mathrm{d} t} & =\frac{M_{\mathrm{m}} \mu^{\mathrm{o}}}{\mu_{1}+\lambda_{1}}\left[\bar{M}_{\mathrm{w}}\left(\frac{\mathrm{d} \mu_{1}}{\mathrm{~d} t}+\frac{\mathrm{d} \lambda_{1}}{\mathrm{~d} t}\right)-\left(\frac{\mathrm{d} \mu_{2}}{\mathrm{~d} t}+\frac{\mathrm{d} \lambda_{2}}{\mathrm{~d} t}\right)\right]
\end{aligned}
$$

The additional equation of change for time as a state variable is given by

$$
\frac{\mathrm{d} t}{\mathrm{~d} \bar{M}_{\mathrm{w}}}=\left[\frac{\mathrm{d} \bar{M}_{\mathrm{w}}}{\mathrm{d} t}\right]^{-1} \text { for } i=12
$$

For Objectives 2-4, the above transformations of the process model, Equations (4.1)-(4.12), enable its integration in the range of a specified independent variable (which is not time) up to its specified, final value.

\subsection{Integration of Batch Process Model}

The four optimal control objectives described above require the integration of batch process model with different independent variables $\left(t, \underset{\sim}{,}, \bar{M}_{\mathrm{n}}\right.$ and $\left.\bar{M}_{\mathrm{w}}\right)$ for performance index evaluations. These equations are highly non-linear, and stiff to integrate. In this work, they were numerically integrated using semi-implicit Bader-Deufhard algorithm, and adaptive step-size control [Press et al., 2002]. Analytical jacobians were employed for integration. The equations to evaluate the elements of jacobian corresponding to each optimal control objective are provided in the next section. 


\subsubsection{Equations to Evaluate Jacobians}

Equations for the analytical evaluation of jacobian are for normalized state variables, and time (for Objectives 2-4) with respect to the independent variable depending on an optimal control objective. Using the start-up values, $y_{i}^{\circ}$, and the basic jacobian elements, $\frac{\mathrm{d}}{\mathrm{d} y_{j}}\left(\frac{\mathrm{d} y_{i}}{\mathrm{~d} t}\right)$, the jacobian elements are sequentially calculable as described below.

\section{Jacobian for Objective 1}

For all state variables, the elements of the jacobian are given by

$$
\frac{\mathrm{d}}{\mathrm{d} y_{j}}\left(\frac{\mathrm{d} y_{i}}{\mathrm{~d} t}\right)=\left\{\begin{array}{l}
\frac{y_{j}^{\mathrm{o}}}{y_{i}^{\mathrm{o}}} \frac{\mathrm{d}}{\mathrm{d} y_{j}}\left(\frac{\mathrm{d} y_{i}}{\mathrm{~d} t}\right), \text { if } y_{i}^{\mathrm{o}}>0 \\
0, \text { if } y_{i}^{\mathrm{o}}=0
\end{array}\right\} ; i, j=0,1, \ldots, 11
$$

The above jacobian is same for other optimal control objectives until the independent variable of Equations (4.1)-(4.12), which initially is time, is changed to $\underset{\sim}{m}, \bar{M}_{\mathrm{n}}$ and $\bar{M}_{\mathrm{w}}$ for Objectives 2, 3 and 4, respectively. Time then becomes a new state variable. For this transformation, the new independent variable must be non-zero. The jacobians for Objectives 2-4 are then sequentially calculable as follows:

\section{Jacobian for Objective 2}

After the transformation of the independent variable to $\underset{\sim}{m}$, time becomes a new state variable (refer Equation (4.32)). The jacobian elements for time, corresponding to $i=2$, are given by

$$
\begin{aligned}
& \frac{\mathrm{d}}{\mathrm{d} t}\left(\frac{\mathrm{d} t}{\mathrm{~d} m}\right)=0 \quad \text { for } j=2 \\
& \frac{\mathrm{d}}{\mathrm{d} y_{j}}\left(\frac{\mathrm{d} t}{\mathrm{~d} m}\right)=-m^{\circ} y_{j}^{\circ}\left[\frac{\mathrm{d} m}{\mathrm{~d} t}\right]^{-2} \frac{\mathrm{d}}{\mathrm{d} y_{j}}\left(\frac{\mathrm{d} m}{\mathrm{~d} t}\right) ; j=0,1,3,4 \ldots, 11
\end{aligned}
$$


The jacobian elements for remaining state variables, corresponding to $i=0,1,3,4, \ldots, 11$, are given by

$$
\frac{\mathrm{d}}{\mathrm{d} y_{j}}\left(\frac{\mathrm{d} y_{i}}{\mathrm{~d} \underset{\sim}{m}}\right)=-\frac{1}{y_{i}^{0}} \frac{\mathrm{d} y_{i}}{\mathrm{~d} t} \frac{\mathrm{d}}{\mathrm{d} \underline{\sim}_{j}}\left(\frac{\mathrm{d} t}{\mathrm{~d} m}\right)+\alpha ; \quad j=0,1, \ldots, 11
$$

In Equation (4.47),

$$
\alpha=\left\{\begin{array}{l}
-m^{\circ}\left[\frac{\mathrm{d} m}{\mathrm{~d} t}\right]^{-1} \frac{y_{j}^{\mathrm{o}}}{y_{i}^{\circ}} \frac{\mathrm{d}}{\mathrm{d} y_{j}}\left(\frac{\mathrm{d} y_{i}}{\mathrm{~d} t}\right), \text { if } y_{i}^{\circ}>0 \\
0, \text { if } y_{i}^{\circ}=0
\end{array}\right.
$$

\section{Jacobian for Objective 3}

Let $\bar{M}_{\mathrm{n}}$ correspond to $i=12$ before the transformation of the independent variable. Then the basic jacobian elements for $\bar{M}_{\mathrm{n}}$ are given by

$$
\frac{\mathrm{d}}{\mathrm{d} \bar{M}_{\mathrm{n}}}\left(\frac{\mathrm{d} \bar{M}_{\mathrm{n}}}{\mathrm{d} t}\right)=0 \quad \text { for } j=12
$$




$$
\begin{aligned}
\frac{\mathrm{d}}{\mathrm{d} y_{j}}\left(\frac{\mathrm{d} \bar{M}_{\mathrm{n}}}{\mathrm{d} t}\right)= & \frac{M_{\mathrm{m}}}{\mu_{0}+\lambda_{0}}\left[\frac{\mathrm{d}}{\mathrm{d} y_{j}}\left(\frac{\mathrm{d} \mu_{1}}{\mathrm{~d} t}\right)+\frac{\mathrm{d}}{\mathrm{d} y_{j}}\left(\frac{\mathrm{d} \lambda_{1}}{\mathrm{~d} t}\right)\right]- \\
& \frac{M_{\mathrm{m}} \bar{M}_{\mathrm{n}}}{\mu_{0}+\lambda_{0}}\left[\frac{\mathrm{d}}{\mathrm{d} y_{j}}\left(\frac{\mathrm{d} \mu_{0}}{\mathrm{~d} t}\right)+\frac{\mathrm{d}}{\mathrm{d} y_{j}}\left(\frac{\mathrm{d} \lambda_{0}}{\mathrm{~d} t}\right)\right]+\beta_{0} ; \\
& j=0,1, \ldots, 11
\end{aligned}
$$

In Equation (4.50),

$$
\beta_{0}=\left\{\begin{array}{l}
\frac{-M_{\mathrm{m}}}{\left(\mu_{0}+\lambda_{0}\right)^{2}}\left[\left(\frac{\mathrm{d} \mu_{1}}{\mathrm{~d} t}+\frac{\mathrm{d} \lambda_{1}}{\mathrm{~d} t}\right)-2 \bar{M}_{\mathrm{n}}\left(\frac{\mathrm{d} \mu_{0}}{\mathrm{~d} t}+\frac{\mathrm{d} \lambda_{0}}{\mathrm{~d} t}\right)\right], \text { for } y_{j}=\mu_{0}, \lambda_{0} \\
\frac{-M_{\mathrm{m}}}{\left(\mu_{0}+\lambda_{0}\right)^{2}}\left(\frac{\mathrm{d} \mu_{0}}{\mathrm{~d} t}+\frac{\mathrm{d} \lambda_{0}}{\mathrm{~d} t}\right), \text { for } y_{j}=\mu_{1}, \lambda_{1} \\
0, \text { for remaining } y_{j} \mathrm{~s}
\end{array}\right.
$$

After the transformation of the independent variable to $\bar{M}_{\mathrm{n}}$, time becomes a new state variable (refer Equation (4.38)). The jacobian elements for time, corresponding to $i=12$, are given by

$$
\begin{aligned}
& \frac{\mathrm{d}}{\mathrm{d} y_{j}}\left(\frac{\mathrm{d} t}{\mathrm{~d} \bar{M}_{\mathrm{n}}}\right)=y_{j}^{\mathrm{o}}\left[\frac{\mathrm{d} \bar{M}_{\mathrm{n}}}{\mathrm{d} t}\right]^{-2} \frac{\mathrm{d}}{\mathrm{d} y_{j}}\left(\frac{\mathrm{d} \bar{M}_{\mathrm{n}}}{\mathrm{d} t}\right) ; j=0,1, \ldots, 11 \\
& \frac{\mathrm{d}}{\mathrm{d} t}\left(\frac{\mathrm{d} t}{\mathrm{~d} \bar{M}_{\mathrm{n}}}\right)=0 \quad \text { for } j=12
\end{aligned}
$$

The jacobian elements for remaining state variables, corresponding to $i=0,1, \ldots, 11$, are given by

$$
\begin{aligned}
& \frac{\mathrm{d}}{\mathrm{d} y_{j}}\left(\frac{\mathrm{d} \underline{y}_{i}}{\mathrm{~d} \bar{M}_{\mathrm{n}}}\right)=-\frac{1}{y_{i}^{\circ}} \frac{\mathrm{d} y_{i}}{\mathrm{~d} t} \frac{\mathrm{d}}{\mathrm{d} y_{j}}\left(\frac{\mathrm{d} t}{\mathrm{~d} \bar{M}_{\mathrm{n}}}\right)+\gamma_{0} ; j=0,1,2, \ldots, 11 \\
& \frac{\mathrm{d}}{\mathrm{d} t}\left(\frac{\mathrm{d} y_{i}}{\mathrm{~d} \bar{M}_{\mathrm{n}}}\right)=0 \text { for } j=12
\end{aligned}
$$


In Equation (4.54),

$$
\gamma_{0}=\left\{\begin{array}{l}
{\left[\frac{\mathrm{d} \bar{M}_{\mathrm{n}}}{\mathrm{d} t}\right]^{-1} \frac{y_{j}^{\mathrm{o}}}{y_{i}^{0}} \frac{\mathrm{d}}{\mathrm{d} y_{j}}\left(\frac{\mathrm{d} y_{i}}{\mathrm{~d} t}\right), \text { if } y_{i}^{\circ}>0} \\
0, \text { if } y_{i}^{\circ}=0
\end{array}\right.
$$

\section{Jacobian for Objective 4}

Let $\bar{M}_{\mathrm{w}}$ correspond to $i=12$ before the transformation of the independent variable. Then the basic jacobian elements for $\bar{M}_{\mathrm{w}}$ are given by

$$
\begin{aligned}
\frac{\mathrm{d}}{\mathrm{d} \bar{M}_{\mathrm{w}}}\left(\frac{\mathrm{d} \bar{M}_{\mathrm{w}}}{\mathrm{d} t}\right)= & 0 \text { for } j=12 \\
\frac{\mathrm{d}}{\mathrm{d} y_{j}}\left(\frac{\mathrm{d} \bar{M}_{\mathrm{w}}}{\mathrm{d} t}\right)= & \frac{M_{\mathrm{m}}}{\mu_{1}+\lambda_{1}}\left[\frac{\mathrm{d}}{\mathrm{d} y_{j}}\left(\frac{\mathrm{d} \mu_{2}}{\mathrm{~d} t}\right)+\frac{\mathrm{d}}{\mathrm{d} y_{j}}\left(\frac{\mathrm{d} \lambda_{2}}{\mathrm{~d} t}\right)\right]- \\
& \frac{M_{\mathrm{m}} \bar{M}_{\mathrm{w}}}{\mu_{1}+\lambda_{1}}\left[\frac{\mathrm{d}}{\mathrm{d} y_{j}}\left(\frac{\mathrm{d} \mu_{1}}{\mathrm{~d} t}\right)+\frac{\mathrm{d}}{\mathrm{d} y_{j}}\left(\frac{\mathrm{d} \lambda_{1}}{\mathrm{~d} t}\right)\right]+\beta_{1} \\
& j=0,1,2, \ldots, 11
\end{aligned}
$$

In Equation (4.58),

$$
\beta_{1}=\left\{\begin{array}{l}
\frac{-M_{\mathrm{m}}}{\left(\mu_{1}+\lambda_{1}\right)^{2}}\left[\left(\frac{\mathrm{d} \mu_{2}}{\mathrm{~d} t}+\frac{\mathrm{d} \lambda_{2}}{\mathrm{~d} t}\right)-2 \bar{M}_{\mathrm{w}}\left(\frac{\mathrm{d} \mu_{1}}{\mathrm{~d} t}+\frac{\mathrm{d} \lambda_{1}}{\mathrm{~d} t}\right)\right], \text { for } y_{j}=\mu_{1}, \lambda_{1} \\
\frac{-M_{\mathrm{m}}}{\left(\mu_{1}+\lambda_{1}\right)^{2}}\left(\frac{\mathrm{d} \mu_{1}}{\mathrm{~d} t}+\frac{\mathrm{d} \lambda_{1}}{\mathrm{~d} t}\right), \text { for } y_{j}=\mu_{2}, \lambda_{2} \\
0, \text { for remaining } y_{j} \mathrm{~s}
\end{array}\right.
$$

After the transformation of the independent variable to $\bar{M}_{\mathrm{w}}$, time becomes a new state variable (refer Equation (4.43)). The jacobian elements for time, corresponding to $i=12$, 
are given by

$$
\begin{aligned}
& \frac{\mathrm{d}}{\mathrm{d} y_{j}}\left(\frac{\mathrm{d} t}{\mathrm{~d} \bar{M}_{\mathrm{w}}}\right)=y_{j}^{\mathrm{o}}\left[\frac{\mathrm{d} \bar{M}_{\mathrm{w}}}{\mathrm{d} t}\right]^{-2} \frac{\mathrm{d}}{\mathrm{d} y_{j}}\left(\frac{\mathrm{d} \bar{M}_{\mathrm{w}}}{\mathrm{d} t}\right) ; j=0,1, \ldots, 11 \\
& \frac{\mathrm{d}}{\mathrm{d} t}\left(\frac{\mathrm{d} t}{\mathrm{~d} \bar{M}_{\mathrm{w}}}\right)=0 \quad \text { for } j=12
\end{aligned}
$$

The jacobian elements for remaining state variables, corresponding to $i=0,1, \ldots, 11$, are given by

$$
\begin{aligned}
& \frac{\mathrm{d}}{\mathrm{d} y_{j}}\left(\frac{\mathrm{d} y_{i}}{\mathrm{~d} \bar{M}_{\mathrm{w}}}\right)=-\frac{1}{y_{i}^{\mathrm{o}}} \frac{\mathrm{d} y_{i}}{\mathrm{~d} t} \frac{\mathrm{d}}{\mathrm{d} y_{j}}\left(\frac{\mathrm{d} t}{\mathrm{~d} \bar{M}_{\mathrm{w}}}\right)+\gamma_{1} ; \quad j=0,1, \ldots, 11 \\
& \frac{\mathrm{d}}{\mathrm{d} t}\left(\frac{\mathrm{d} y_{i}}{\mathrm{~d} \bar{M}_{\mathrm{w}}}\right)=0 \quad \text { for } j=12
\end{aligned}
$$

In Equation (4.62),

$$
\gamma_{1}=\left\{\begin{array}{l}
{\left[\frac{\mathrm{d} \bar{M}_{\mathrm{w}}}{\mathrm{d} t}\right]^{-1} \frac{y_{j}^{\mathrm{o}}}{y_{i}^{\mathrm{o}}} \frac{\mathrm{d}}{\mathrm{d} y_{j}}\left(\frac{\mathrm{d} y_{i}}{\mathrm{~d} t}\right), \text { if } y_{i}^{\mathrm{o}}>0} \\
0, \text { if } y_{i}^{\mathrm{o}}=0
\end{array}\right.
$$

For the integration of equations of change for Objectives 3 and $4, \mu^{\circ}$ was adjusted so that the difference between value of independent variable (e.g. $\bar{M}_{\mathrm{n}}$ or $\bar{M}_{\mathrm{w}}$ ), and that calculated using other state variables (e.g. from Equation (4.36) or (4.41)) is negligible. For Objectives 24 , the transformation of process model was done as soon as the new indepenclent variable achieved a finite value lying within the first stage of optimal control.

Various parameters used in calculations are provided in Table 4.1. The gel effect models for propagation and termination rate coefficients are provided in sections 4.3 and 4.4 , respectively. The reactants for polymerization are the MMA (monomer), benzoyl peroxicle (monofunctional initiator), benzene (solvent), and trace amount of some impurity (inhibitor). The product is the polymer, poly(MMA). The reference for the comparison of optimal control re. sults is the "base case" of isothermal, MMA polymerization at $70^{\circ} \mathrm{C}$, which was verified from 
the experimental data of Schulz and Harborth [1947] reproduced by Marten and Hamielec [1979].

\subsection{Optimal Control of PMMA with Monofunctional Initiator}

The mathematical model for the batch polymerization of MMA is highly non-linear. Furthermore, due to the inequality constraints of Equation (4.27) and (4.28), the relation between the performance index and jacket temperature for Objectives 1-4 would not necessarily be unimodal and continuous for the four optimal control objectives. To realize these difficult objectives, a robust optimal control method based on genetic algorithms [Upreti, 2004] was applied.

In this work, the temperature of heat-exchange fluid inside reactor jacket (or jacket temperature) was employed as a control function of specified independent variable. Jacket temperature was considered to be a series of five discrete step values equispaced in the range of independent variable. The number of step values (or control stages), the mathematical model of MMA polymerization in a batch reactor with its parameters, and the process constraints of Equations (4.27). and (4.28) were input to the optimal control method. These inputs are needed to evaluate the performance index (fitness) for a given control function. The application of the method yielded the optimal control function by stochastically applying genetic operations on a randomly generated set (population) of control functions constrained by Equation (4.28). Since the method generates optimal control functions within the control domain, the constraints of Equation (4.28) are satisfied automatically. The method eliminates any control function for which any other process constraint (Equation (4.27) in this application) is violated during the evaluation of corresponding performance index. 
Table 4.1: Model parameters used in calculations

\begin{tabular}{|c|c|c|}
\hline Parameter & Value or Expression & Source \\
\hline$f$ & 0.6 & \multirow{15}{*}{ This study } \\
\hline$i^{\circ}, \mathrm{mol} / \mathrm{L}$ & $4.13 \times 10^{-2}$ & \\
\hline$m^{\circ}, \mathrm{mol} / \mathrm{L}$ & 1.7648 & \\
\hline$s^{\circ}, \mathrm{mol} / \mathrm{L}$ & 8.4692 & \\
\hline$T^{\circ},{ }^{\circ} \mathrm{C}$ & 70 (Objectives $1 \& 2), 0$ (Objectives $3 \& 4$ ) & \\
\hline$T_{\max },{ }^{\circ} \mathrm{C}$ & 80 & \\
\hline$T_{\mathrm{j}, \max },{ }^{\circ} \mathrm{C}$ & 120 & \\
\hline$T_{\mathrm{j}, \min },{ }^{\circ} \mathrm{C}$ & 4 (Objectives $1 \&$ 2), -20 (Objectives $3 \& 4$ ) & \\
\hline$z^{\circ}, \mathrm{mol} / \mathrm{L}$ & $10^{-5}$ & \\
\hline$v^{\circ}, \mathrm{L}$ & 1 & \\
\hline$K_{\mathrm{th}}, \mathrm{L} / \mathrm{mol} \cdot \min$ & 0 & \\
\hline$K_{\mathrm{tf}, \mathrm{s}}, \mathrm{L} / \mathrm{mol} \cdot \min$ & $1.58 \times 10^{-5} K_{p}$ & \\
\hline$K_{\mathrm{tf}, \mathrm{z}}, \mathrm{L} / \mathrm{mol} \cdot \min$ & $10^{6} K_{\mathrm{p}}$ & \\
\hline$M_{\mathrm{m}}, \mathrm{g} / \mathrm{mol}$ & 100.12 (for MMA) & \\
\hline$M_{\mathrm{s}}, \mathrm{g} / \mathrm{mol}$ & 78.11 (for benzene) & \\
\hline$K_{\mathrm{d}}, 1 / \min$ & $1.014 \times 10^{16} \exp \left[-1.5098 \times 10^{4} /(T+273.15)\right]$ & $\begin{array}{l}\text { Louie et al. } \\
{[1985]}\end{array}$ \\
\hline$U A, \mathrm{~J} / \mathrm{min} \cdot \mathrm{K}$ & $6.5475 \times 10^{2}$ & \begin{tabular}{|l} 
Villalobos \\
et al. [1993]
\end{tabular} \\
\hline
\end{tabular}


Table 4.1: continued...

\begin{tabular}{|c|c|c|}
\hline Parameter & Value or Expression & Source \\
\hline$-\Delta H, \mathrm{~J} / \mathrm{mol}$ & $5.546 \times 10^{4}$ & $\begin{array}{l}\text { Brandrup } \\
\text { et al. [1999] }\end{array}$ \\
\hline$K_{\mathrm{tf}, \mathrm{m}}, \mathrm{L} / \mathrm{mol} \cdot \min$ & $5.358 \times 10^{-2} \exp \left[-1.1273 \times 10^{3} /(T+273.15)\right]$ & $\begin{array}{l}\text { Kalfas } \\
\text { et al. [1993] }\end{array}$ \\
\hline$\rho_{\mathrm{m}}, \mathrm{g} / \mathrm{L}$ & $309.85 \times 0.25357^{-[1-(T+273.15) / 564]^{0.28571}}$ & \multirow{3}{*}{$\begin{array}{l}\text { Yaws } \\
{[1999]}\end{array}$} \\
\hline$\rho_{\mathrm{s}}, \mathrm{g} / \mathrm{L}$ & $300.9 \times 0.2677^{-[1-(T+273.15) / 562.16]^{0.2818}}$ & \\
\hline$C_{\mathrm{p}}, \mathrm{J} / \mathrm{g} \cdot \mathrm{K}$ & $\begin{array}{l}4.2416 \times 10^{3}+1.08 \times 10^{2}(T+273.15)-3.1588 \times \\
10^{-1}(T+273.15)^{2}+3.7804 \times 10^{-4}(T+273.15)^{3} \\
\end{array}$ & \\
\hline$\rho_{\mathrm{p}}, \mathrm{g} / \mathrm{L}$ & $1.18 \times 10^{3}-(T+273.15)$ & $\begin{array}{l}\text { Sung-Mo } \\
\text { et al. [1998] }\end{array}$ \\
\hline
\end{tabular}




\section{Results for Solution, Batch MMA Polymer- ization with Monofunctional Initiator}

\section{$5.1 \quad$ Results}

The optimal control results for the four objectives are summarized and compared with the base case in Table 5.1. Note that the specified values of average polymer molecular weights in Objectives 3 and 4 are not attainable in base case.

\subsubsection{Results For Objective 1}

The optimal jacket temperature policy was determined, which maximizes monomer (MMA) conversion during the specified batch polymerization time of $100 \mathrm{~min}$. Figure 5.1 shows the optimal policy, which maximizes final monomer conversion to $65.2 \%$. This value is $57.8 \%$ higher than the monomer conversion in base case. The figure also shows how the temperature policy gets improved with the iterations of the optimal control method. It is observed that the optimal policy reaches close to the maximum allowable reactor temperature of $80^{\circ} \mathrm{C}$.

Figure 5.2 shows the change in optimal reactor temperature, and monomer conversion with time, which correspond to the application of optimal jacket temperature policy. Corresponding variables for base case are also shown in the figure. It is observed that optimal reactor temperature after the first control stage is close to its upper limit of $80^{\circ} \mathrm{C}$. This fact indicates that high reaction temperatures are needed in all control stages in order to increase overall polymerization, and achieve high monomer conversion. Optimal reactor temperature after the first control stage is found to be in phase with optimal jacket temperature (Figure 5.]). This behavior shows the strong influence of jacket temperature on reaction temperature, and explains why optimal jacket temperature does not surpass the upper limit of reactor temperature. At all times, optimal reactor temperature is well within that limit, which is specified through Equation (4.27). For time greater than zero, the optimal value of reactor 
Figure 5.1: Optimal reactor jacket temperature versus time for Objective 1

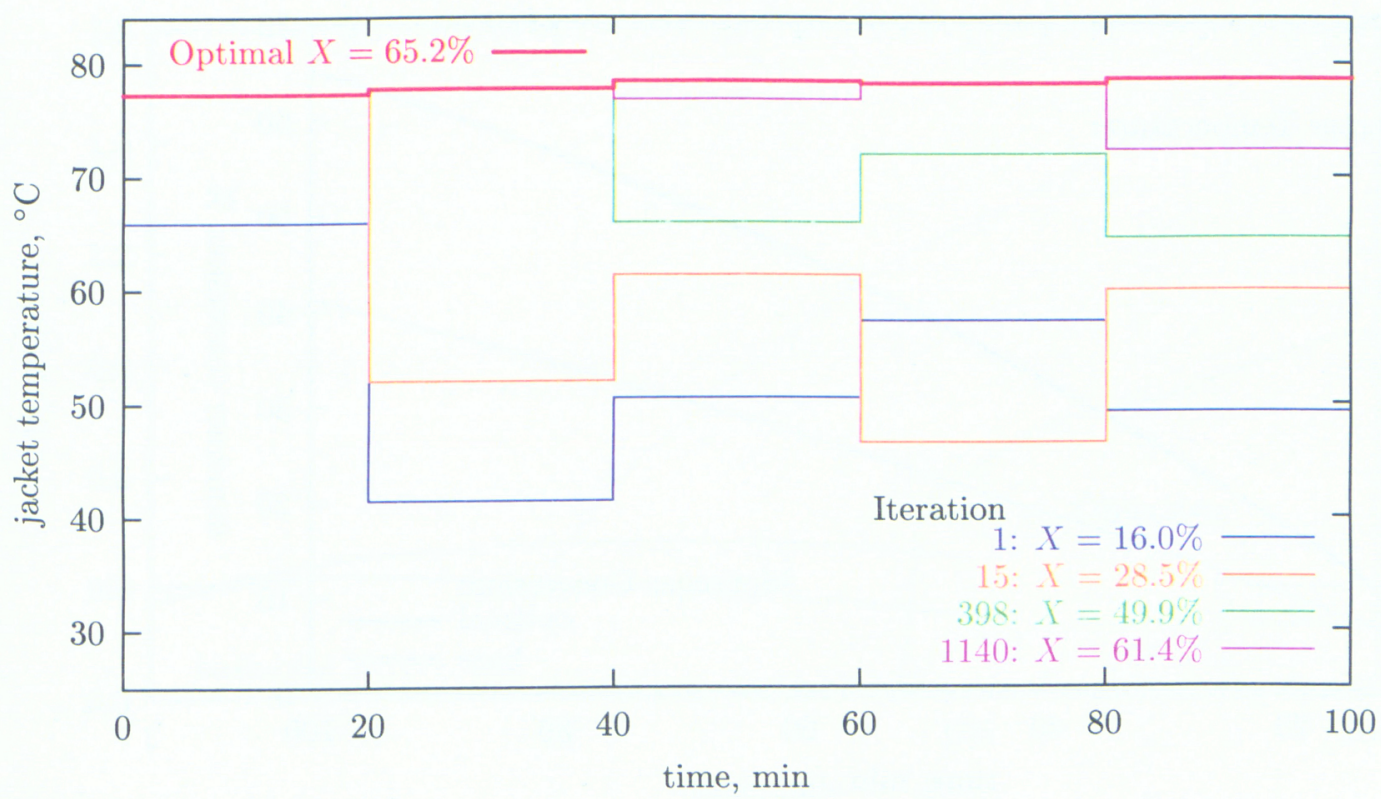

temperature exceeds that for base case. Correspondingly, optimal monomer conversion, for time greater than zero, is always higher than the monomer conversion for base case.

The optimal number and weight average polymer molecular weights $\left(\bar{M}_{\mathrm{n}}\right.$ and $\left.\bar{M}_{\mathrm{w}}\right)$ versus time are respectively shown in Figure 5.3 and 5.4 along with those for base case. It is observed that optimal $\bar{M}_{\mathrm{n}}$ as well as $\bar{M}_{\mathrm{w}}$ values are always lower than respectively those in base case. In comparison to base case, the final values of optimal $\bar{M}_{\mathrm{n}}$ and $\bar{M}_{\mathrm{w}}$ are reduced by about $45 \%$ and $41 \%$, respectively. This reduction suggests that optimal reactor temperature, which is higher than the reactor temperature in base case, has favored the generation of polymer molecules with smaller chain lengths.

\subsubsection{Results For Objective 2}

The optimal jacket temperature policy was determined, which minimizes batch polymerization time for the specified, final monomer conversion of 70\%. Shown in Figure 5.5, the 
Figure 5.2: Reactor temperature and monomer conversion versus time for Objective 1

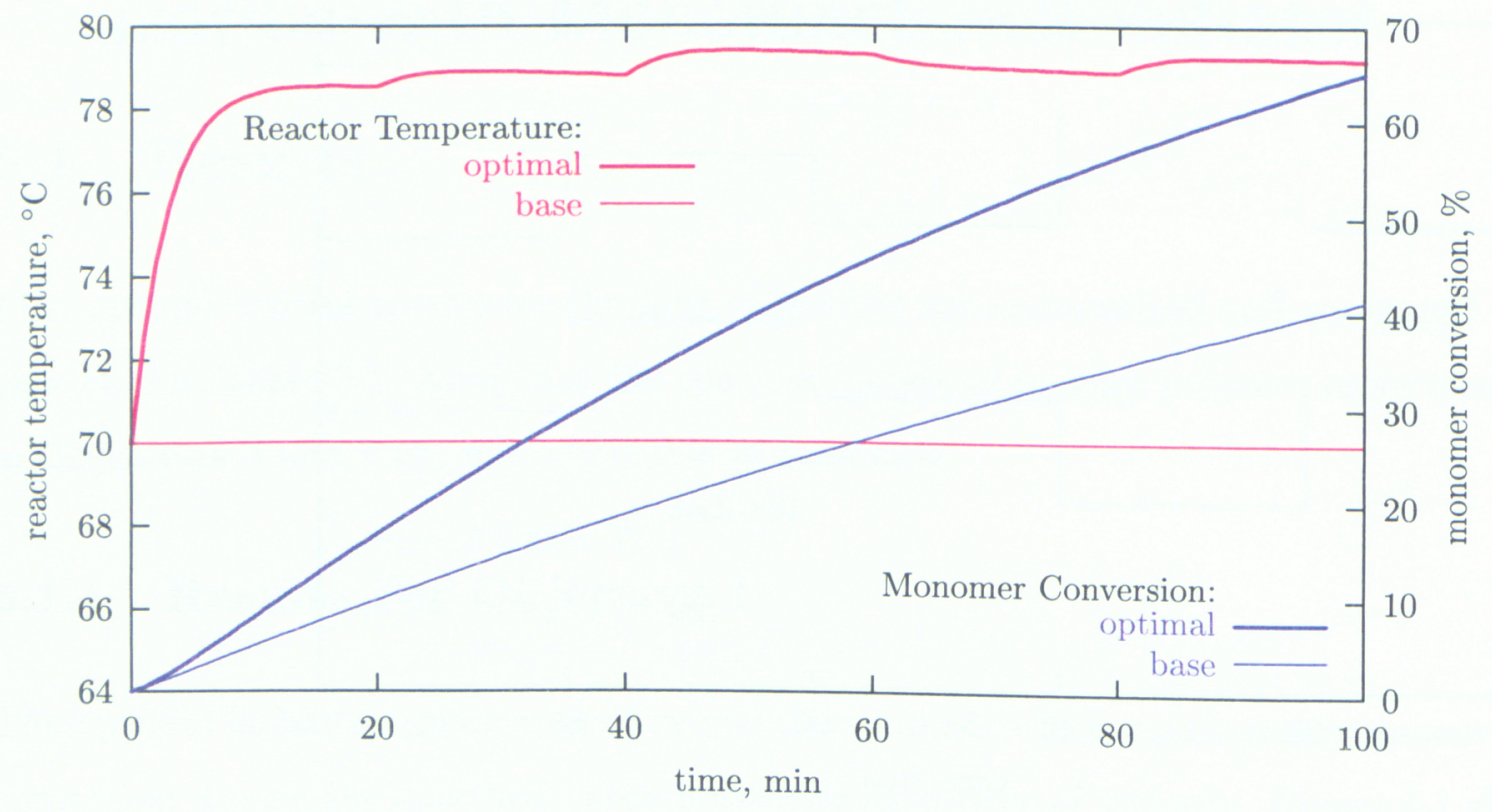

optimal policy is again close to the maximum allowable reactor temperature of $80^{\circ} \mathrm{C}$; similar to what was observed for Objective 1. Moreover, the time-averaged value of optimal jacket temperature is approximately same as that in case of Objective 1. This similarity of optimal jacket temperature is reasonable because the realization of each of Objectives 1 and 2 requires the maximization of the overall rate of monomer conversion.

Optimal reactor temperature, shown in Figure 5.7, closely follows optimal jacket temperature after the first control stage. This behavior was observed earlier in case of Objective 1. Corresponding to optimal jacket temperature, the optimal value of the operation time is 114.6 min, which is a reduction by $47 \%$ relative to that of base case.

Optimal monomer conversion is shown in Figure 5.6. It is observed to always higher than that for base case. The optimal number and weight average polymer molecular weights $\left(\bar{M}_{\mathrm{n}}\right.$ and $\bar{M}_{\mathrm{w}}$ ) are respectively shown in Figure 5.3 and 5.4. The changes in monomer conversion, and average molecular weights with time almost coincide with respectively those in case of 
Figure 5.3: Optimal number average molecular weight versus time for Objectives 1-4

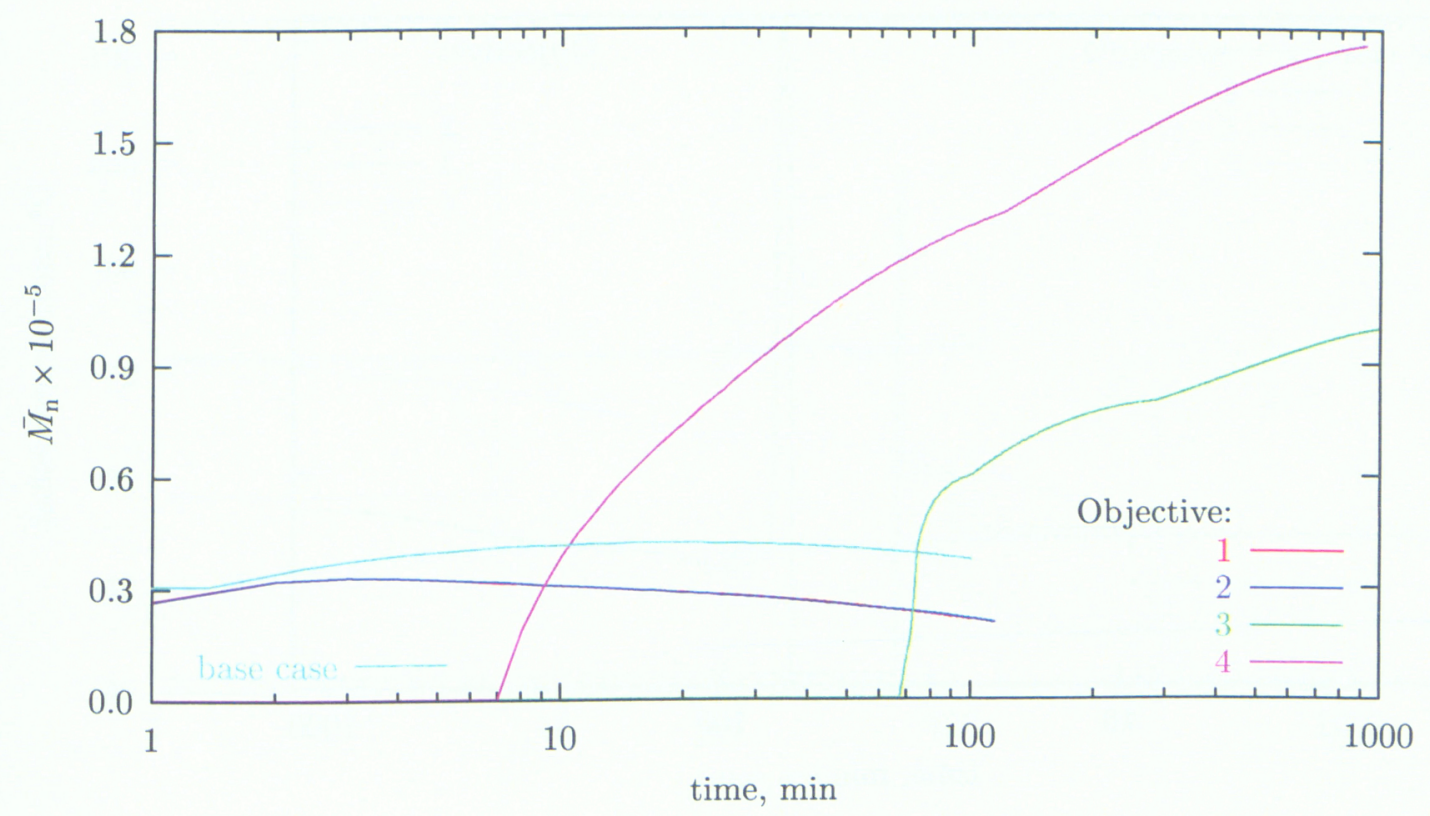

Objective 1. The reason is that corresponding optimal reactor and jacket temperatures for Objective 1 and 2 are not much different, and are close to their upper limit.

\subsubsection{Results For Objective 3}

The optimal jacket temperature policy was determined, which maximizes monomer (MMA) conversion for the specified, final number average molecular weight, $\bar{M}_{\mathrm{n}, \mathrm{f}}=10^{5}$. It may be noted that, as seen in Figure 5.3, this high value of $\bar{M}_{\mathrm{n}}$ is not achievable in base case. In general, the time needed to obtain polymer of a specified $\bar{M}_{\mathrm{n}, \mathrm{f}}$ increases with a decrease in reaction temperature. To provide extended application time for optimal control through jacket temperature, and to facilitate higher monomer conversion during that time, the initial temperature of reactor was set at a low value of $0^{\circ} \mathrm{C}$. Furthermore, wider range (for lower values) was made available to jacket temperature by reducing its lower limit to $-20^{\circ} \mathrm{C}$.

Figure 5.5 shows the resulting optimal control policy for jacket temperature, which spans 


\subsection{Results - Optimal control of PMMA with monofunctional initiator}

Figure 5.4: Optimal weight average molecular weight versus time for Objectives 1-4

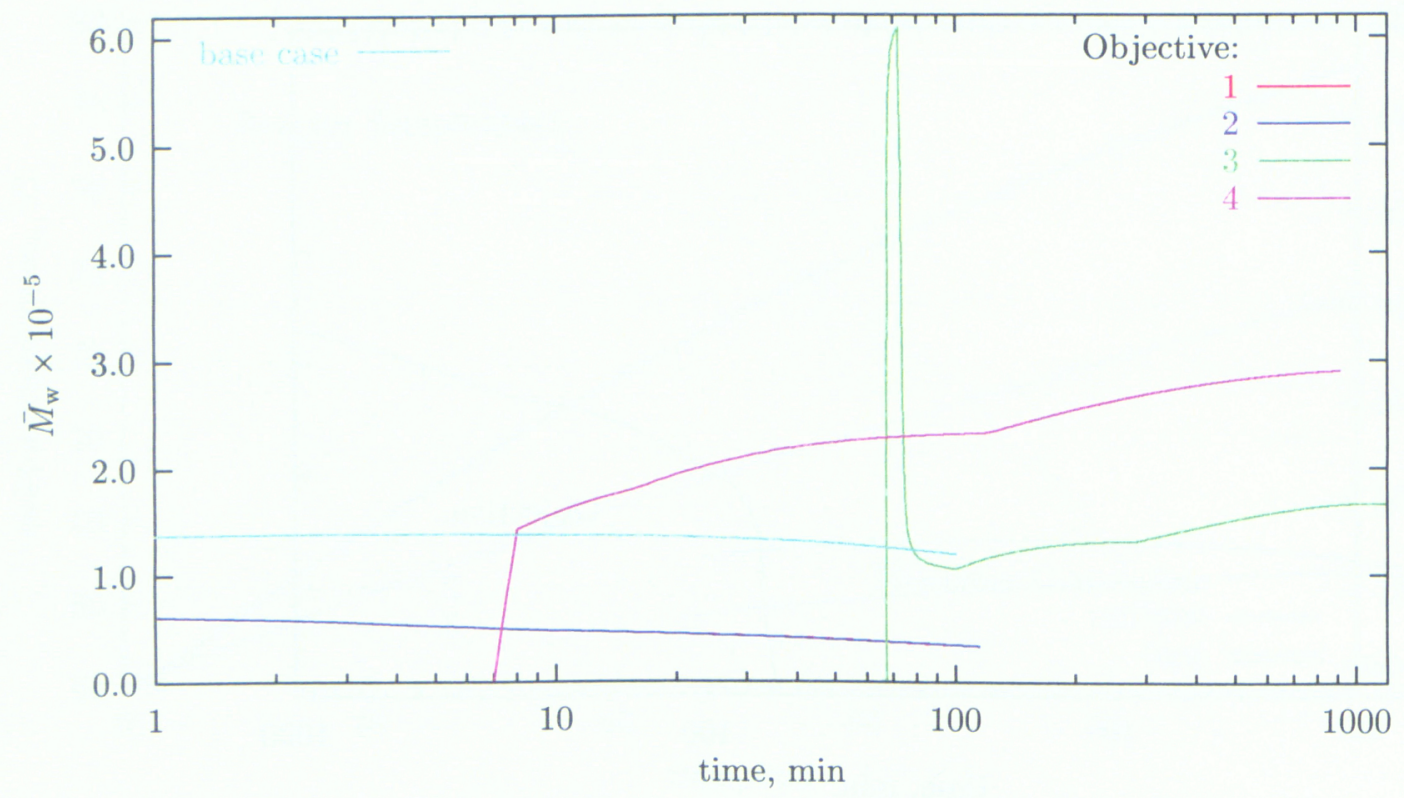

$1182.2 \mathrm{~min}$ of operation time, and yields the final monomer conversion of $63.0 \%$. Although the lower limit for jacket temperature is $-20^{\circ} \mathrm{C}$, its lowest optimal value is above $30^{\circ} \mathrm{C}$. Optimal jacket temperature almost reaches its upper limit of $120^{\circ} \mathrm{C}$ in the second control stage after which the temperature decreases in the following control stages. It is noticed that the second control stage is of short duration. The reason is that control stages are equispaced over the specified independent variable, $\bar{M}_{\mathrm{n}}$, which undergoes a rapid increase with time at the onset of the second control stage (see Figure 5.3). The trend of optimal jacket temperature after the first control stage is closely followed by corresponding optimal reactor temperature as seen in Figure 5.7. While lower, initial reactor temperature obviates the early attainment of $\bar{M}_{\mathrm{n}, \mathrm{f}}$ with low monomer conversion, higher reactor temperatures later on boost the final monomer conversion.

Due to low, initial reactor temperature, the optimal values of $\bar{M}_{\mathrm{n}}$ (Figure 5.3) and $\bar{M}_{\mathrm{w}}$ (Figure 5.4) are small, and increase slowly with time. For time less than 67.2 min, the 
Figure 5.5: Optimal jacket temperature versus time for Objectives 2-4

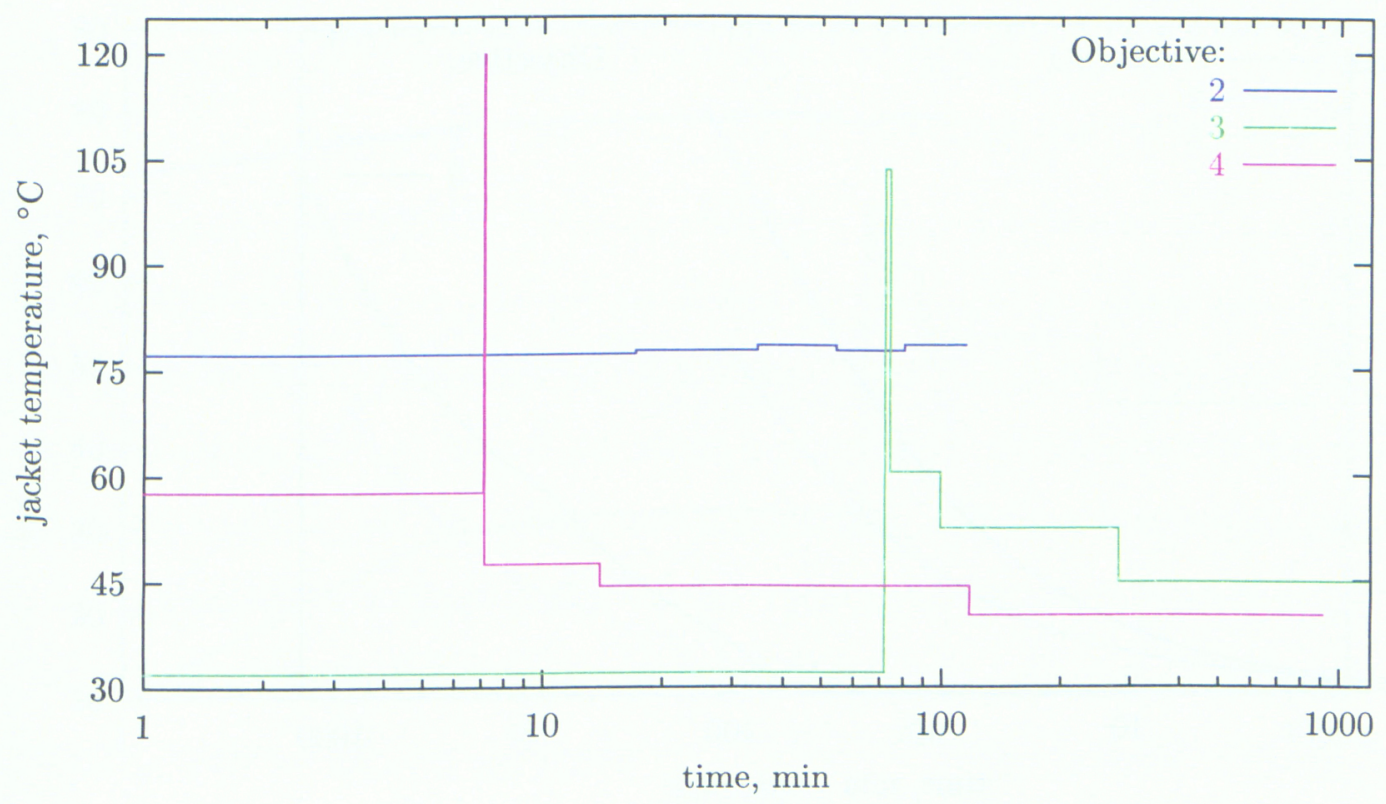

optimal values of $\bar{M}_{\mathrm{n}}$ and $\bar{M}_{\mathrm{w}}$ are of the order $10^{2}$ and $10^{4}$ respectively, and optimal monomer conversion (Figure 5.6) is of the order $10^{-5}$. Temperature rise in the second control stage at 73.9 min triggers polymerization so that optimal $\bar{M}_{\mathrm{n}}, \bar{M}_{\mathrm{w}}$ and monomer conversion begin to rise. Relative to optimal $\bar{M}_{\mathrm{n}}$, optimal $\bar{M}_{\mathrm{w}}$ is observed to be much more sensitive to the temperature rise. While the average change of optimal monomer conversion with time does not vary much later on with the stagewise drop of reaction temperature, the changes in optimal $\bar{M}_{\mathrm{n}}$ and $\bar{M}_{\mathrm{w}}$ with time are smaller compared to those in the second control stage.

\subsubsection{Results For Objective 4}

The optimal jacket temperature policy was determined, which maximizes monomer (MMA) conversion for the specified, final weight average molecular weight, $\bar{M}_{\mathrm{w}, \mathrm{f}}=2.9 \times 10^{5}$. It may be noted again that, as seen in Figure 5.4, this high value of $\bar{M}_{\mathrm{w}}$ is not achievable in base case. Optimal control results for this objective were obtained for the same initial reactor 
Figure 5.6: Optimal monomer conversion versus time for Objectives 2-4

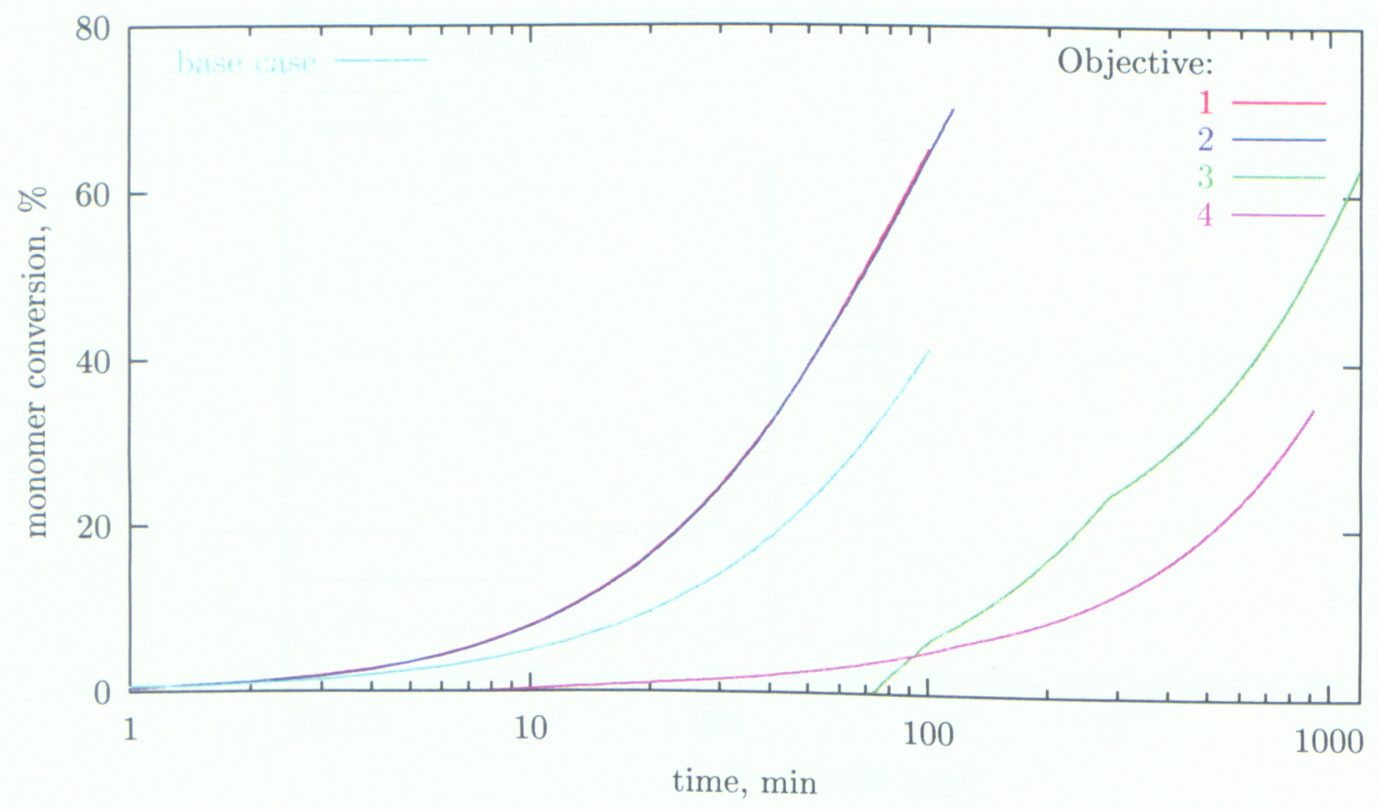

temperature, and the lower limit of jacket temperature that were used for Objective 3 . The realization of the present optimal control objective with high monomer conversions is more difficult than the previous one because the change in $\bar{M}_{\mathrm{w}}$ with time is significantly higher than that of $\bar{M}_{\mathrm{n}}$. This results in polymerization that meets the specification of $\bar{M}_{\mathrm{w}, \mathrm{f}}$ very quickly, thereby reducing the time available for optimal control through jacket temperature.

Figure 5.5 shows the resulting optimal jacket temperature versus time which spans 912.5 min of operation time, and yields a final monomer conversion of $34.7 \%$. This value is lower than that for the last objective. The variation in optimal jacket temperature with time is similar to that in case of Objective 3. After an initial increase in the second control stage, the temperature decreases in the following stages, and is closely followed by corresponding optimal reactor temperature as seen in Figure 5.7. Optimal $\bar{M}_{\mathrm{n}}$ (Figure 5.3), $\bar{M}_{\mathrm{w}}$ (Figure 5.4), and monomer conversion (Figure 5.6) show perceptible growth after 7 min due to the higher temperature of the second control stage. 
Figure 5.7: Optimal reactor temperature versus time for Objectives 2-4

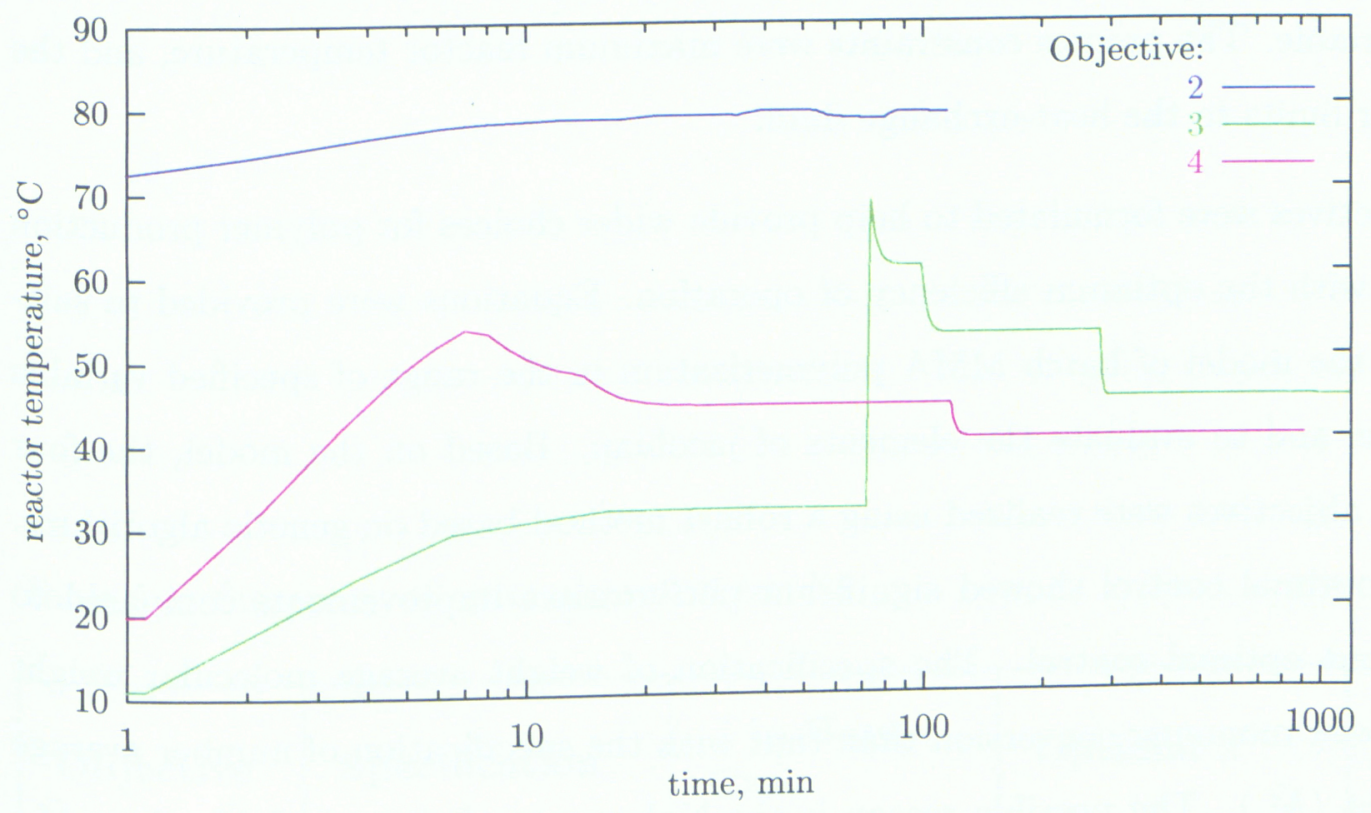

\subsection{Computational Time}

Objective 1 took nearly 31 hours to compute, which was the least computation time in the four objectives. Whereas, Objective 2 took nearly 140 hours, which was the highest computation time. Objective 3 and 4 took approximately 96 and 34 hours respectively to compute.

\subsection{Conclusion}

The optimal control of MMA polymerization in a nonisothermal batch reactor was implemented. The following four optimal control objectives were realized: (i) maximization of monomer conversion in a specified operation time, (ii) minimization of operation time for specified, final monomer conversion, (iii) maximization of monomer conversion for a specified, final number average polymer molecular weight, and (vi) maximization of monomer 
conversion for a specified, final weight average polymer molecular weight. The temperature of heat-exchange fluid in jacket of reactor was utilized as a control function of a specified independent variable. The process constraints were maximum reactor temperature, and the upper and lower limits to the heat-exchange fluid.

The above objectives were formulated to help provide wider choices for polymer production simultaneously with the optimum efficiency of operation. Equations were provided to suitably transform the model of batch MMA polymerization in the range of specified variable other than time, and to evaluate the elements of jacobian. Based on the model, the four optimal control objectives were realized using a robust method based on genetic algorithms. The results of optimal control showed significant performance improvements compared to base case without optimal control. The specification of weight average molecular weight $\left(\bar{M}_{\mathrm{w}}\right)$ yielded lower monomer conversion than that with the specification of number average molecular weight $\left(\bar{M}_{\mathrm{n}}\right)$. The possible reason is the higher rate of change of $\bar{M}_{\mathrm{w}}$ than $\bar{M}_{\mathrm{n}}$, which cuts down the time available for optimal control. Initially, the changes in both $\bar{M}_{\mathrm{n}}$ and $\bar{M}_{\mathrm{w}}$ with time were very high leading to shortening of the second control stage. 
Table 5.1: Summary of optimal control results

\begin{tabular}{|c|c|c|c|}
\hline Objective & Specification & $\begin{array}{l}J \text { in Base } \\
\text { Case }\end{array}$ & Optimal $J$ \\
\hline 1 & $t_{\mathrm{f}}=100 \mathrm{~min}$ & $X_{\mathrm{f}}=41.3 \%$ & $\underset{\max }{X_{\mathrm{f}}}=65.2 \%$ \\
\hline 2 & $X_{\mathrm{f}}=70 \%$ & $t_{\mathrm{f}}=217.6 \mathrm{~min}$ & $\underset{\min }{t_{\mathrm{f}}}=114.6 \mathrm{~min}$ \\
\hline 3 & $\bar{M}_{\mathrm{n}, \mathrm{f}}=10^{5}$ & not attainable & $\underset{\max }{X_{\mathrm{f}}}=63.0 \%$ \\
\hline 4 & $\bar{M}_{\mathrm{w}, \mathrm{f}}=2.9 \times 10^{5}$ & $"$ & $\underset{\max }{X_{\mathrm{f}}}=34.7 \%$ \\
\hline
\end{tabular}




\section{Mathematical Modeling for Solution, Batch MMA Polymerization with Bifunctional Ini- tiator}

In this chapter, we discuss the development of mathematical model on the basis of free radical polymerization mechanism for the solution polymerization of methyl methacrylate with bifunctional initiator in a non-isothermal batch polymerization reactor, and the changes in the differential equation by applying normalized state variables, also the incorporation gel and glass effect model. Further, we discuss the formulation of four different optimal control objectives, and the development of analytical jacobian to integrate the developed model.

\subsection{Free Radical Polymerization Mechanism}

Based on the approach of Villalobos et al. [1993], and Dhib et al. [2000], the following free radical polymerization mechanism is used in this study:

Thermal Initiation:

$$
3 M \stackrel{K_{\mathrm{th}}}{\longrightarrow} 2 R_{1}
$$

Chemical Initiation:

$$
\begin{gathered}
I \stackrel{2 K_{\mathrm{d} 1}}{\longrightarrow} R_{\mathrm{in}}+\tilde{R}_{\mathrm{in}}^{.} \\
\tilde{R}_{\mathrm{in}}+M \stackrel{2 K_{\mathrm{d} 1}}{\longrightarrow} \tilde{R}_{1}^{.} \\
\tilde{P}_{l} \stackrel{K_{\mathrm{d} 2}}{\longrightarrow} R_{\mathrm{in}}+R_{l}^{\cdot}, \quad l \geq 1 \\
\tilde{\tilde{P}}_{l} \stackrel{2 K_{d 2}}{\longrightarrow} R_{\mathrm{in}}+\tilde{R}_{l}, \quad l \geq 1
\end{gathered}
$$


Propagation:

$$
\begin{array}{ll}
R_{l}+M \stackrel{K_{\mathrm{p}}}{\longrightarrow} R_{l+1}, & l \geq 1 \\
\tilde{R}_{l}+M \stackrel{K_{\mathrm{p}}}{\longrightarrow} \tilde{R}_{l+1}, & l \geq 1
\end{array}
$$

Termination:

$$
\begin{array}{ll}
R_{l}+R_{k} \stackrel{K_{\mathrm{t}}}{\longrightarrow} P_{l+k}, & l, k \geq 1 \\
R_{l}+\tilde{R}_{k} \stackrel{K_{\mathrm{t}}}{\longrightarrow} \tilde{P}_{l+k}, & l, k \geq 1 \\
\tilde{R}_{l}+\tilde{R}_{k} \stackrel{K_{\mathrm{t}}}{\longrightarrow} \tilde{\tilde{P}}_{l+k}, & l, k \geq 1
\end{array}
$$

Transfer to Monomer:

$$
\begin{array}{cc}
R_{l}+M \stackrel{K_{\mathrm{tf}, \mathrm{m}}}{\longrightarrow} P_{l}+R_{1}, & l \geq 1 \\
\tilde{R}_{l}+M \stackrel{K_{\mathrm{tf}, \mathrm{m}}}{\longrightarrow} \tilde{P}_{l}+R_{1}, & l \geq 1
\end{array}
$$

Transfer to Solvent:

$$
\begin{array}{ll}
R_{l}+S \stackrel{K_{\mathrm{tf}, \mathrm{s}}}{\longrightarrow} P_{l}+R_{1}, & l \geq 1 \\
\tilde{R}_{l}+S \stackrel{K_{\mathrm{tf}, \mathrm{s}}}{\longrightarrow} \tilde{P}_{l}+R_{1}, & l \geq 1
\end{array}
$$

Transfer to Inhibitor (or Impurity):

$$
\begin{array}{ll}
R_{l}+Z \stackrel{K_{\mathrm{tf}, \mathrm{z}}}{\longrightarrow} P_{l}+Z ; & l \geq 1 \\
R_{l}+Z \stackrel{K_{\mathrm{tf}, \mathrm{z}}}{\longrightarrow} \tilde{P}_{l}+Z ; & l \geq 1
\end{array}
$$




\subsection{Mathematical Model}

A mathematical model, following the approach of Villalobos et al. [1993], and Gao and Penlidis [1996], is provided below for the batch polymerization of MMA in a nonisothermal batch reactor using a bifunctional initiator.

The model comprises the equations of change of volume $(V)$ and temperature $(T)$ of reactants, the concentrations of monomer $(m)$, initiator $(i)$, solvent $(s)$, inhibitor $(z)$, and of the first three moments of regular radicals $\left(\lambda_{0}, \lambda_{1}, \lambda_{2}\right)$, radicals with one undecomposed peroxide $\left(\tilde{\lambda}_{0}, \tilde{\lambda}_{1}, \tilde{\lambda}_{2}\right)$, regular dead polymer molecules $\left(\mu_{0}, \mu_{1}, \mu_{2}\right)$, and dead polymer molecules with one and two undecomposed peroxides $\left(\tilde{\mu}_{0}, \tilde{\mu}_{1}, \tilde{\mu}_{2}\right.$; and $\left.\tilde{\tilde{\mu}}_{0}, \tilde{\tilde{\mu}}_{1}, \tilde{\tilde{\mu}}_{2}\right)$. The equations are based on the above given free radical polymerization reaction mechanism. The symbols in following expressions are defined in Notation.

$$
\begin{aligned}
\frac{\mathrm{d} V}{\mathrm{~d} t} & =-K_{\mathrm{p}} m\left(\lambda_{0}+\tilde{\lambda}_{0}\right) V M_{\mathrm{m}}\left[\frac{1}{\rho_{\mathrm{p}}}-\frac{1}{\rho_{\mathrm{m}}}\right] \\
\frac{\mathrm{d} T}{\mathrm{~d} t} & =\frac{-\Delta H K_{\mathrm{p}} m\left(\lambda_{0}+\tilde{\lambda}_{0}\right)}{\rho C_{\mathrm{p}}}-\frac{U A\left(T-T_{\mathrm{c}}\right)}{V \rho C_{\mathrm{p}}} \\
\frac{\mathrm{d} m}{\mathrm{~d} t} & =-K_{\mathrm{p}} m\left(\lambda_{0}+\tilde{\lambda}_{0}\right)-\frac{m}{V} \frac{\mathrm{d} V}{\mathrm{~d} t} \\
\frac{\mathrm{d} i}{\mathrm{~d} t} & =2 K_{\mathrm{d} \mathrm{1}} i-\frac{i}{V} \frac{\mathrm{d} V}{\mathrm{~d} t} \\
\frac{\mathrm{d} s}{\mathrm{~d} t} & =-K_{\mathrm{tfs}} s\left(\lambda_{0}+\tilde{\lambda}_{0}\right)-\frac{s}{V} \frac{\mathrm{d} V}{\mathrm{~d} t} \\
\frac{\mathrm{d} z}{\mathrm{~d} t} & =-K_{\mathrm{tf} z} z\left(\lambda_{0}+\tilde{\lambda}_{0}\right)-\frac{z}{V} \frac{\mathrm{d} V}{\mathrm{~d} t}
\end{aligned}
$$


For the moments of regular radicals:

$$
\begin{aligned}
\frac{\mathrm{d} \lambda_{0}}{\mathrm{~d} t}= & 2 K_{\mathrm{th}} m^{3}+2 f_{1} K_{\mathrm{d} 1} i+2 f_{2} K_{\mathrm{d} 2}\left(\tilde{\mu}_{0}+\tilde{\tilde{\mu}}_{0}\right)-K_{\mathrm{tc}} \lambda_{0}\left(\lambda_{0}+\tilde{\lambda}_{0}\right)+\left(K_{\mathrm{tfm}} m\right. \\
& \left.+K_{\mathrm{tfs}} s\right) \tilde{\lambda}_{0}-K_{\mathrm{tfz}} z \lambda_{0}-\frac{\lambda_{0}}{V} \frac{\mathrm{d} V}{\mathrm{~d} t} \\
\frac{\mathrm{d} \lambda_{1}}{\mathrm{~d} t}= & 2 K_{\mathrm{th}} m^{3}+2 f_{1} K_{\mathrm{d} 1} i+f_{2} K_{\mathrm{d} 2}\left(\tilde{\mu}_{0}+\tilde{\mu}_{1}+2 \tilde{\tilde{\mu}}_{0}\right)+K_{\mathrm{p}} m \lambda_{0}-K_{\mathrm{tc}} \lambda_{1}\left(\lambda_{0}+\tilde{\lambda}_{0}\right) \\
& +\left(K_{\mathrm{tfm}} m+K_{\mathrm{tfs}} s\right)\left(\lambda_{0}-\lambda_{1}+\tilde{\lambda}_{0}\right)-K_{\mathrm{tfz}} z \lambda_{1}-\frac{\lambda_{1}}{V} \frac{\mathrm{d} V}{\mathrm{~d} t} \\
\frac{\mathrm{d} \lambda_{2}}{\mathrm{~d} t}= & 2 K_{\mathrm{th}} m^{3}+2 f_{1} K_{\mathrm{d} 1} i+f_{2} K_{\mathrm{d} 2}\left(\tilde{\mu}_{0}+\tilde{\mu}_{2}+2 \tilde{\tilde{\mu}}_{0}\right)+K_{\mathrm{p}} m\left(\lambda_{0}+2 \lambda_{1}\right) \\
& \quad-K_{\mathrm{tc}} \lambda_{2}\left(\lambda_{0}+\tilde{\lambda}_{0}\right)+\left(K_{\mathrm{tfm}} m+K_{\mathrm{tfs}} s\right)\left(\lambda_{0}-\lambda_{2}+\tilde{\lambda}_{0}\right)-K_{\mathrm{tfz}} z \lambda_{2}-\frac{\lambda_{2}}{V} \frac{\mathrm{d} V}{\mathrm{~d} t}
\end{aligned}
$$

For the moments of radicals with one undecomposed peroxide:

$$
\begin{aligned}
\frac{\mathrm{d} \tilde{\lambda}_{0}}{\mathrm{~d} t}= & 2 f_{1} K_{\mathrm{d} 1} i+2 f_{2} K_{\mathrm{d} 2} \tilde{\tilde{\mu}}_{0}-K_{\mathrm{tc}} \tilde{\lambda}_{0}\left(\lambda_{0}+\tilde{\lambda}_{0}\right)-\left(K_{\mathrm{tfm}} m+K_{\mathrm{tfs}} s+K_{\mathrm{tfz}} z\right) \tilde{\lambda}_{0} \\
& -\frac{\tilde{\lambda}_{0}}{V} \frac{\mathrm{d} V}{\mathrm{~d} t} \\
\frac{\mathrm{d} \tilde{\lambda}_{1}}{\mathrm{~d} t}= & 2 f_{1} K_{\mathrm{d} 1} i+2 f_{2} K_{\mathrm{d} 2} \tilde{\tilde{\mu}}_{1}+K_{\mathrm{p}} m \tilde{\lambda}_{0}-K_{\mathrm{tc}} \tilde{\lambda}_{1}\left(\lambda_{0}+\tilde{\lambda}_{0}\right)-\left(K_{\mathrm{tfm}} m+K_{\mathrm{tfs}} s\right. \\
& \left.+K_{\mathrm{tfz}} z\right) \tilde{\lambda}_{1}-\frac{\tilde{\lambda}_{1}}{V} \frac{\mathrm{d} V}{\mathrm{~d} t} \\
\frac{\mathrm{d} \tilde{\lambda}_{2}}{\mathrm{~d} t}= & 2 f_{1} K_{\mathrm{d} 1} i+2 f_{2} K_{\mathrm{d} 2} \tilde{\tilde{\mu}}_{2}+K_{\mathrm{p}} m\left(\tilde{\lambda}_{0}+2 \tilde{\lambda}_{1}\right)-K_{\mathrm{tc}} \tilde{\lambda}_{2}\left(\lambda_{0}+\tilde{\lambda}_{0}\right)-\left(K_{\mathrm{tfm}} m \tilde{\lambda}_{2}\right. \\
& \left.+K_{\mathrm{tfs}} s+K_{\mathrm{tfz}} z\right) \tilde{\lambda}_{2}-\frac{\tilde{\lambda}_{2}}{V} \frac{\mathrm{d} V}{\mathrm{~d} t}
\end{aligned}
$$

For the moments of dead polymer molecules:

$$
\begin{aligned}
& \frac{\mathrm{d} \mu_{0}}{\mathrm{~d} t}=\frac{K_{\mathrm{tc}} \lambda_{0}^{2}}{2}+\left(K_{\mathrm{tfm}} m+K_{\mathrm{tfs}} s+K_{\mathrm{tfz}} z\right) \lambda_{0}-\frac{\mu_{0}}{V} \frac{\mathrm{d} V}{\mathrm{~d} t} \\
& \frac{\mathrm{d} \mu_{1}}{\mathrm{~d} t}=K_{\mathrm{tc}} \lambda_{0} \lambda_{1}+\left(K_{\mathrm{tfm}} m+K_{\mathrm{tfs}} s+K_{\mathrm{tfz} z} z \lambda_{1}-\frac{\mu_{1}}{V} \frac{\mathrm{d} V}{\mathrm{~d} t}\right. \\
& \frac{\mathrm{d} \mu_{2}}{\mathrm{~d} t}=K_{\mathrm{tc}}\left(\lambda_{0} \lambda_{2}+\lambda_{1}^{2}\right)+\left(K_{\mathrm{tfm}} m+K_{\mathrm{tfs}} s+K_{\mathrm{tfz}} z\right) \lambda_{2}-\frac{\mu_{2}}{V} \frac{\mathrm{d} V}{\mathrm{~d} t}
\end{aligned}
$$


balances for the moments of dead polymer molecules with one undecomposed peroxide:

$$
\begin{aligned}
& \frac{\mathrm{d} \tilde{\mu}_{0}}{\mathrm{~d} t}=-K_{\mathrm{d} 2} \tilde{\mu}_{0}+K_{\mathrm{tc}} \lambda_{0} \tilde{\lambda}_{0}+\left(K_{\mathrm{tfm}} m+K_{\mathrm{tfs}} s+K_{\mathrm{tfz}} z\right) \tilde{\lambda}_{0}-\frac{\tilde{\mu}_{0}}{V} \frac{\mathrm{d} V}{\mathrm{~d} t} \\
& \frac{\mathrm{d} \tilde{\mu}_{1}}{\mathrm{~d} t}=-K_{\mathrm{d} 2} \tilde{\mu}_{1}+K_{\mathrm{tc}}\left(\lambda_{0} \tilde{\lambda}_{1}+\lambda_{1} \tilde{\lambda}_{0}\right)+\left(K_{\mathrm{tfm}} m+K_{\mathrm{tfs}} s+K_{\mathrm{tfz}} z\right) \tilde{\lambda}_{1} \\
& -\frac{\tilde{\mu}_{1}}{V} \frac{\mathrm{d} V}{\mathrm{~d} t} \\
& \frac{\mathrm{d} \tilde{\mu}_{2}}{\mathrm{~d} t}=-K_{\mathrm{d} 2} \tilde{\mu}_{2}+K_{\mathrm{tc}}\left(\lambda_{2} \tilde{\lambda}_{0}+2 \lambda_{1} \tilde{\lambda}_{1}+\lambda_{0} \tilde{\lambda}_{2}\right)+\left(K_{\mathrm{tfm}} m+K_{\mathrm{tfs}} s+K_{\mathrm{tfz}} z\right) \tilde{\lambda}_{2} \\
& -\frac{\tilde{\mu}_{2}}{V} \frac{\mathrm{d} V}{\mathrm{~d} t}
\end{aligned}
$$

balances for the moments of dead polymer molecules with two undecomposed peroxide:

$$
\begin{aligned}
& \frac{\mathrm{d} \tilde{\tilde{\mu}}_{0}}{\mathrm{~d} t}=-2 K_{\mathrm{d} 2} \tilde{\tilde{\mu}}_{0}+\frac{K_{\mathrm{tc}} \tilde{\lambda}_{0}^{2}}{2}-\frac{\tilde{\tilde{\mu}}_{0}}{V} \frac{\mathrm{d} V}{\mathrm{~d} t} \\
& \frac{\mathrm{d} \tilde{\tilde{\mu}}_{1}}{\mathrm{~d} t}=-2 K_{\mathrm{d} 2} \tilde{\tilde{\mu}}_{1}+K_{\mathrm{tc}} \tilde{\lambda}_{0} \tilde{\lambda}_{1}-\frac{\tilde{\tilde{\mu}}_{1}}{V} \frac{\mathrm{d} V}{\mathrm{~d} t} \\
& \frac{\mathrm{d} \tilde{\tilde{\mu}}_{2}}{\mathrm{~d} t}=-2 K_{\mathrm{d} 2} \tilde{\tilde{\mu}}_{2}+K_{\mathrm{tc}}\left(\tilde{\lambda}_{0} \tilde{\lambda}_{2}+\tilde{\lambda}_{1}^{2}\right)-\frac{\tilde{\tilde{\mu}}_{2}}{V} \frac{\mathrm{d} V}{\mathrm{~d} t}
\end{aligned}
$$

Let us define normalized state variables as

$$
\begin{aligned}
& \underset{\sim}{V}=1-\frac{V}{V^{\mathrm{o}}}, \quad \underset{\sim}{T}=1-\frac{T}{T^{\mathrm{o}}}, \quad \underset{\sim}{m}=1-\frac{m}{m^{\mathrm{o}}}, \quad \underset{\sim}{i}=1-\frac{i}{i^{\mathrm{0}}}, \quad \underline{\sim}=1-\frac{s}{s^{\mathrm{o}}}, \\
& \underset{z}{z}=1-\frac{z}{z^{0}}, \quad \lambda_{j}=1-\frac{\lambda_{j}}{\mu^{0}}, \quad \tilde{\lambda}_{j}=1-\frac{\tilde{\lambda}_{j}}{\mu^{0}}, \quad \stackrel{\sim}{\mu}_{j}=1-\frac{\mu_{j}}{\mu^{0}}, \quad \tilde{\sim}_{j}=1-\frac{\tilde{\mu}_{j}}{\mu^{0}}, \\
& \tilde{\tilde{\tilde{\mu}}}_{j}=1-\frac{\tilde{\tilde{\mu}}_{j}}{\mu^{0}} ; \quad j=0,1,2
\end{aligned}
$$

where $V^{\circ}, T^{\circ}, m^{\circ}, i^{\circ}, s^{\circ}$ and $z^{\circ}$ are the initial values of $V, T, m, i, s$ and $z$, respectively, and $\mu^{\circ}$ is a parameter used to normalize radical and polymer moments. Then the equations 
of change. for the normalized state variables are given by

$$
\frac{\mathrm{d} y_{i}}{\mathrm{~d} t}=\left\{\begin{array}{l}
-\frac{1}{y_{i}^{\circ}} \frac{\mathrm{d} y_{i}}{\mathrm{~d} t}, \text { if } y_{i}^{\circ} \neq 0 \\
0, \text { if } y_{i}^{\circ}=0
\end{array}\right\} ; \quad i=0,1,2, \ldots, 20
$$

where $\underline{y}_{i}$ is the normalized form of a state variable, $y_{i}$, with the normalization factor, $y_{i}^{\mathbf{o}}$.

\subsection{Rate Coefficient for Propagation}

Rate coefficient for propagation is given by

$$
K_{\mathrm{p}}=K_{\mathrm{p}, 1} \times K_{\mathrm{p}, 2} \quad[\mathrm{~L} / \mathrm{mol} \cdot \mathrm{min}]
$$

where, from Louie et al. [1985]:

$$
K_{\mathrm{p}, 1}=2.95 \times 10^{7} \exp \left(\frac{-2.1892 \times 10^{3}}{T+273.15}\right) \quad[\mathrm{L} / \mathrm{mol} \cdot \mathrm{min}]
$$

from Schmidt and Ray [1981]:

$$
\begin{aligned}
& K_{\mathrm{p}, 2}=\left\{\begin{array}{l}
7.1 \times 10^{-5} \exp \left(171.53 V_{\mathrm{f}}\right), \text { if } V_{\mathrm{f}}<V_{\mathrm{fpc}} \\
1, \text { if } V_{\mathrm{f}} \geq V_{\mathrm{fpc}}
\end{array}\right. \\
& V_{\mathrm{fpc}}=0.05
\end{aligned}
$$


and from Sung-Mo et al. [1998]:

$$
\begin{aligned}
V_{\mathrm{f}} & =0.025+V_{\mathrm{f}, \mathrm{m}}+V_{\mathrm{f}, \mathrm{p}}+V_{\mathrm{f}, \mathrm{s}} \\
V_{\mathrm{f}, \mathrm{m}} & =\frac{\left(T-T_{\mathrm{g}, \mathrm{m}}\right) m M_{\mathrm{m}} \times 10^{-3}}{\rho_{\mathrm{m}}} \\
V_{\mathrm{f}, \mathrm{p}} & =\frac{\left(T-T_{\mathrm{g}, \mathrm{p}}\right)\left(m^{\mathrm{o}}-m\right) M_{\mathrm{m}} \times 4.8 \times 10^{-4}}{\rho_{\mathrm{p}}} \\
V_{\mathrm{f}, \mathrm{s}} & =\frac{\left(T-T_{\mathrm{g}, \mathrm{s}}\right) s M_{\mathrm{s}} \times 10^{-3}}{\rho_{\mathrm{s}}}
\end{aligned}
$$

\subsection{Rate Coefficient for Termination}

Rate coefficient for termination is given by

$$
K_{\mathrm{t}}=K_{\mathrm{t}, 1} \times K_{\mathrm{t}, 2} \quad[\mathrm{~L} / \mathrm{mol} \cdot \mathrm{min}]
$$

where, from Sung-Mo et al. [1998]:

$$
K_{\mathrm{t}, 1}=3.12 \times 10^{10} \exp \left(\frac{-7.0156 \times 10^{2}}{T+273.15}\right) \quad[\mathrm{L} / \mathrm{mol} \cdot \mathrm{min}]
$$

and from Schmidt and Ray [1981]:

$$
\begin{aligned}
& K_{\mathrm{t}, 2}=\left\{\begin{array}{l}
2.3 \times 10^{-6} \exp \left(75 V_{\mathrm{f}}\right), \text { if } V_{\mathrm{f}}<V_{\mathrm{ftc}} \\
0.10575 \exp \left(17.15 V_{\mathrm{f}}-0.01715 T\right), \text { if } V_{\mathrm{f}} \geq V_{\mathrm{ftc}}
\end{array}\right. \\
& V_{\mathrm{ftc}}=0.1856-2.965 \times 10^{-4} T
\end{aligned}
$$




\subsection{Optimal Control Objectives}

Based on the above mathematical model, four different optimal control objectives for batch MMA polymerization are formulated in this section. The temperature of heat-exchange fluid in reactor jacket (or "jacket temperature") is considered as a control function of a specified parameter. An inequality constraint in the form of an upper limit to the temperature of reactants is enforced as

$$
T \leq T_{\max }
$$

There are two additional inequality constraints in the form of lower and upper limits to jacket temperature, i.e.,

$$
T_{\mathrm{j}, \min } \leq T_{\mathrm{j}} \leq T_{\mathrm{j}, \max }
$$

\subsubsection{Objective 1}

The optimal control objective is to determine the control policy for jacket temperature that would maximize monomer conversion in a specified batch operation time $\left(t_{\mathrm{f}}\right)$, i.e., the performance index,

$$
\underset{\max }{J}=X\left(t_{\mathrm{f}}\right)=X_{\mathrm{f}}
$$

In Equation (6.38), $X$ is monomer conversion given by

$$
X=1-\frac{m V}{m^{0} V^{0}}=1-(1-m)(1-V)
$$

This objective requires the satisfaction of Equations (6.1)-(6.7), (6.10), (6.13), (6.16) and (6.19); or their normalized form given by Equation (6.23).

\subsubsection{Objective 2}

The optimal control objective is to determine the control policy for jacket temperature that would minimize operation time for a specified, final monomer conversion expressed in terms 
of fractional reduction in monomer concentration $\left({\underset{\sim}{\mathrm{f}}}_{\mathrm{f}}\right)$, i.e., the performance index,

$$
\underset{\min }{J}=t\left({\underset{\sim}{\mathrm{f}}}_{\mathrm{f}}\right)=t_{\mathrm{f}}
$$

This objective requires the transformation of Equations (6.1)-(6.21) so that the independent variable is the fractional reduction in monomer concentration $(\mathfrak{m})$. The transformed equations are given by

$$
\begin{aligned}
& \frac{\mathrm{d} t}{\mathrm{~d} \underline{\sim}}=\left[\frac{\mathrm{d} m}{\mathrm{~d} t}\right]^{-1} \quad \text { for } i=2 \\
& \frac{\mathrm{d} y_{i}}{\mathrm{~d} \underline{\sim}}=\left[\frac{\mathrm{d} \underset{\sim}{m}}{\mathrm{~d} t}\right]^{-1} \frac{\mathrm{d} y_{i}}{\mathrm{~d} t} ; \quad i=0,1,3,4, \ldots, 20
\end{aligned}
$$

with time as a new state variable.

\subsubsection{Objective 3}

The optimal control objective is to determine the control policy for jacket temperature that would maximize monomer conversion for a specified, final weight average polymer molecular weight $\left(\bar{M}_{\mathrm{n}, \mathrm{f}}\right)$, i.e., the performance index,

$$
\underset{\max }{J}=X\left(\bar{M}_{\mathrm{n}, \mathrm{f}}\right)=X_{\mathrm{f}}
$$

This objective requires the satisfaction of Equations (6.1)-(6.21) after their transformation so that the independent variable is number average polymer molecular weight $\left(\bar{M}_{\mathrm{n}}\right)$. The transformed equations are given by

$$
\frac{\mathrm{d} y_{i}}{\mathrm{~d} \bar{M}_{\mathrm{n}}}=\left[\frac{\mathrm{d} \bar{M}_{\mathrm{n}}}{\mathrm{d} t}\right]^{-1} \frac{\mathrm{d} y_{i}}{\mathrm{~d} t} ; \quad i=0,1, \ldots, 20
$$


where

$$
\begin{aligned}
& \bar{M}_{\mathrm{n}}=M_{\mathrm{m}}\left(\frac{\mu_{1}+\tilde{\mu}_{1}+\tilde{\tilde{\mu}}_{1}+\lambda_{1}+\tilde{\lambda}_{1}}{\mu_{0}+\tilde{\mu}_{0}+\tilde{\tilde{\mu}}_{0}+\lambda_{0}+\tilde{\lambda}_{0}}\right) \\
& \frac{\mathrm{d} \bar{M}_{\mathrm{n}}}{\mathrm{d} t}=\frac{M_{\mathrm{m}} \mu^{\mathrm{o}}}{\mu_{0}+\tilde{\mu}_{0}+\tilde{\tilde{\mu}}_{0}+\lambda_{0}+\tilde{\lambda}_{0}}\left[\bar{M}_{\mathrm{n}}\left(\frac{\mathrm{d} \mu_{0}}{\mathrm{~d} t}+\frac{\mathrm{d} \tilde{\mu}_{0}}{\mathrm{~d} t}+\frac{\mathrm{d} \tilde{\tilde{\mu}}_{0}}{\mathrm{~d} t}+\frac{\mathrm{d} \lambda_{0}}{\mathrm{~d} t}+\frac{\mathrm{d} \tilde{\lambda}_{0}}{\mathrm{~d} t}\right)\right. \\
& \left.-\left(\frac{\mathrm{d} \tilde{\mu}_{1}}{\mathrm{~d} t}+\frac{\mathrm{d} \tilde{\mu}_{1}}{\mathrm{~d} t}+\frac{\mathrm{d} \tilde{\tilde{\mu}}_{1}}{\mathrm{~d} t}+\frac{\mathrm{d}{\underset{\sim}{1}}_{1}}{\mathrm{~d} t}+\frac{\mathrm{d} \tilde{\lambda}_{1}}{\mathrm{~d} t}\right)\right]
\end{aligned}
$$

The additional equation of change for time as a state variable is given by

$$
\frac{\mathrm{d} t}{\mathrm{~d} \bar{M}_{\mathrm{n}}}=\left[\frac{\mathrm{d} \bar{M}_{\mathrm{n}}}{\mathrm{d} t}\right]^{-1} \quad \text { for } i=21
$$

\subsubsection{Objective 4}

The optimal control objective is to determine the control policy for jacket temperature that would maximize monomer conversion for a specified, final weight average polymer molecular weight $\left(\bar{M}_{\mathrm{w}, \mathrm{f}}\right)$, i.e., the performance index,

$$
\underset{\max }{J}=X\left(\bar{M}_{\mathrm{w}, \mathrm{f}}\right)=X_{\mathrm{f}}
$$

This objective requires the satisfaction of Equations (6.1)-(6.21) after their transformation so that the independent variable is weight average polymer molecular weight $\left(\bar{M}_{\mathrm{w}}\right)$. The transformed equations are given by

$$
\frac{\mathrm{d} y_{i}}{\mathrm{~d} \bar{M}_{\mathrm{w}}}=\left[\frac{\mathrm{d} \bar{M}_{\mathrm{w}}}{\mathrm{d} t}\right]^{-1} \frac{\mathrm{d} y_{i}}{\mathrm{~d} t} ; \quad i=0,1, \ldots, 20
$$


where

$$
\begin{aligned}
\bar{M}_{\mathrm{w}}= & M_{\mathrm{m}}\left(\frac{\mu_{2}+\tilde{\mu}_{2}+\tilde{\tilde{\mu}}_{2}+\lambda_{2}+\tilde{\lambda}_{2}}{\mu_{1}+\tilde{\mu}_{1}+\tilde{\tilde{\mu}}_{1}+\lambda_{1}+\tilde{\lambda}_{1}}\right) \\
\frac{\mathrm{d} \bar{M}_{\mathrm{w}}}{\mathrm{d} t}=\frac{M_{\mathrm{m}} \mu^{\mathrm{o}}}{\mu_{1}+\tilde{\mu}_{1}+\tilde{\tilde{\mu}}_{1}+\lambda_{1}+\tilde{\lambda}_{1}} & {\left[\bar{M}_{\mathrm{w}}\left(\frac{\mathrm{d} \tilde{\mu}_{1}}{\mathrm{~d} t}+\frac{\mathrm{d} \tilde{\mu}_{1}}{\mathrm{~d} t}+\frac{\mathrm{d} \tilde{\tilde{\mu}}_{1}}{\mathrm{~d} t}+\frac{\mathrm{d} \tilde{\lambda}_{1}}{\mathrm{~d} t}+\frac{\mathrm{d} \tilde{\pi}_{1}}{\mathrm{~d} t}\right)\right.} \\
& \left.-\left(\frac{\mathrm{d} \mu_{2}}{\mathrm{~d} t}+\frac{\mathrm{d} \tilde{\mu}_{2}}{\mathrm{~d} t}+\frac{\mathrm{d} \tilde{\tilde{\mu}}_{2}}{\mathrm{~d} t}+\frac{\mathrm{d} \lambda_{2}}{\mathrm{~d} t}+\frac{\mathrm{d} \tilde{\lambda}_{2}}{\mathrm{~d} t}\right)\right]
\end{aligned}
$$

The additional equation of change for time as a state variable is given by

$$
\frac{\mathrm{d} t}{\mathrm{~d} \bar{M}_{\mathrm{w}}}=\left[\frac{\mathrm{d} \bar{M}_{\mathrm{w}}}{\mathrm{d} t}\right]^{-1} \text { for } i=21
$$

For Objectives 2-4, the above transformations of the process model, Equations (6.1)-(6.21), enable its integration in the range of a specified independent variable (which is not time) up to its specified, final value.

\subsection{Integration of Batch Process Model}

The four optimal control objectives described above require the integration of corresponding equations of change with different independent variables $\left(t, \underset{\sim}{m}, \bar{M}_{\mathrm{n}}\right.$ and $\left.\bar{M}_{\mathrm{w}}\right)$ for performance index evaluations. These equations are very stiff and non-linear. In this work, they were numerically integrated using semi-implicit Bader-Deufhard algorithm, and adaptive step-size control [Press et al., 2002]. Analytical jacobians were employed for integration. The equations to evaluate the elements of jacobian corresponding to each optimal control objective are provided in the next section.

\subsubsection{Equations to Evaluate Jacobians}

Equations for the analytical evaluation of jacobian are for normalized state variables, and time (for Objectives 2-4) with respect to the independent variable depending on an optimal 
control objective. Using the start-up values, $y_{i}^{\circ}$, and the basic jacobian elements, $\frac{\mathrm{d}}{\mathrm{d} y_{j}}\left(\frac{\mathrm{d} y_{i}}{\mathrm{~d} t}\right)$, the jacobian elements are sequentially calculable as described below.

\section{Jacobian for Objective 1}

For all state variables, the elements of the jacobian are given by

$$
\frac{\mathrm{d}}{\mathrm{d} y_{j}}\left(\frac{\mathrm{d} y_{i}}{\mathrm{~d} t}\right)=\left\{\begin{array}{l}
\frac{y_{j}^{\mathrm{o}}}{y_{i}^{\mathrm{o}}} \frac{\mathrm{d}}{\mathrm{d} y_{j}}\left(\frac{\mathrm{d} y_{i}}{\mathrm{~d} t}\right), \text { if } y_{i}^{\circ}>0 \\
0, \text { if } y_{i}^{\circ}=0
\end{array}\right\} ; \quad i, j=0,1,2, \ldots, 20
$$

Equation (6.53) is same for other optimal control objectives until the independent variable of Equations (6.1)-(6.21), which initially is time, is changed to $\underset{\sim}{m}, \bar{M}_{\mathrm{n}}$ and $\bar{M}_{\mathrm{w}}$ for Objectives 2, 3 and 4, respectively. Time then becomes a new state variable. For this transformation, the new independent variable must be non-zero. The jacobians for Objectives 2-4 are then sequentially calculable as follows:

\section{Jacobian for Objective 2}

The jacobian elements for time, corresponding to $i=0$, are given by

$$
\begin{aligned}
& \frac{\mathrm{d}}{\mathrm{d} t}\left(\frac{\mathrm{d} t}{\mathrm{~d} \not}\right)=0 \quad \text { for } j=2 \\
& \frac{\mathrm{d}}{\mathrm{d} y_{j}}\left(\frac{\mathrm{d} t}{\mathrm{~d} m}\right)=-m^{\circ} y_{j}^{\circ} \cdot\left[\frac{\mathrm{d} m}{\mathrm{~d} t}\right]^{-2} \frac{\mathrm{d}}{\mathrm{d} y_{j}}\left(\frac{\mathrm{d} m}{\mathrm{~d} t}\right) ; j=0,1,3,4 \ldots, 20
\end{aligned}
$$

The jacobian elements for remaining state variables, corresponding to $i=0,1,3,4, \ldots, 20$, are given by

$$
\frac{\mathrm{d}}{\mathrm{d} \underline{y}_{j}}\left(\frac{\mathrm{d} \underline{i}_{i}}{\mathrm{~d} m}\right)=-\frac{1}{y_{i}^{0}} \frac{\mathrm{d} y_{i}}{\mathrm{~d} t} \frac{\mathrm{d}}{\mathrm{d} \underline{\sim}_{j}}\left(\frac{\mathrm{d} t}{\mathrm{~d} m}\right)+\alpha ; \quad j=0,1, \ldots, 20
$$


In Equation (6.56),

$$
\alpha=\left\{\begin{array}{l}
-m^{\circ}\left[\frac{\mathrm{d} m}{\mathrm{~d} t}\right]^{-1} \frac{y_{j}^{\mathrm{o}}}{y_{i}^{\circ}} \frac{\mathrm{d}}{\mathrm{d} y_{j}}\left(\frac{\mathrm{d} y_{i}}{\mathrm{~d} t}\right), \text { if } y_{i}^{\circ}>0 \\
0, \text { if } y_{i}^{\circ}=0
\end{array}\right.
$$

\section{Jacobian for Objective 3}

Let $\bar{M}_{\mathrm{n}}$ correspond to $i=21$ before the transformation of the independent variable. Then the basic jacobian elements for $\bar{M}_{\mathrm{n}}$ are given by

$$
\frac{\mathrm{d}}{\mathrm{d} \bar{M}_{\mathrm{n}}}\left(\frac{\mathrm{d} \bar{M}_{\mathrm{n}}}{\mathrm{d} t}\right)=0 \text { for } j=21
$$




$$
\begin{aligned}
\frac{\mathrm{d}}{\mathrm{d} y_{j}}\left(\frac{\mathrm{d} \bar{M}_{\mathrm{n}}}{\mathrm{d} t .}\right)= & \frac{M_{\mathrm{m}}}{\mu_{0}+\tilde{\mu}_{0}+\tilde{\tilde{\mu}}_{0}+\lambda_{0}+\tilde{\lambda}_{0}}\left[\frac{\mathrm{d}}{\mathrm{d} y_{j}}\left(\frac{\mathrm{d} \mu_{1}}{\mathrm{~d} t}\right)+\frac{\mathrm{d}}{\mathrm{d} y_{j}}\left(\frac{\mathrm{d} \tilde{\mu}_{1}}{\mathrm{~d} t}\right)+\frac{\mathrm{d}}{\mathrm{d} y_{j}}\left(\frac{\mathrm{d} \tilde{\tilde{\mu}}_{1}}{\mathrm{~d} t}\right)\right. \\
& \left.+\frac{\mathrm{d}}{\mathrm{d} y_{j}}\left(\frac{\mathrm{d} \lambda_{1}}{\mathrm{~d} t}\right)+\frac{\mathrm{d}}{\mathrm{d} y_{j}}\left(\frac{\mathrm{d} \tilde{\lambda}_{1}}{\mathrm{~d} t}\right)\right]- \\
& \frac{M_{\mathrm{m}} \bar{M}_{\mathrm{n}}}{\mu_{0}+\tilde{\mu}_{0}+\tilde{\tilde{\mu}}_{0}+\lambda_{0}+\tilde{\lambda}_{0}}\left[\frac{\mathrm{d}}{\mathrm{d} y_{j}}\left(\frac{\mathrm{d} \mu_{0}}{\mathrm{~d} t}\right)+\frac{\mathrm{d}}{\mathrm{d} y_{j}}\left(\frac{\mathrm{d} \tilde{\mu}_{0}}{\mathrm{~d} t}\right)+\frac{\mathrm{d}}{\mathrm{d} y_{j}}\left(\frac{\mathrm{d} \tilde{\tilde{\mu}}_{0}}{\mathrm{~d} t}\right)\right. \\
& \left.+\frac{\mathrm{d}}{\mathrm{d} y_{j}}\left(\frac{\mathrm{d} \lambda_{0}}{\mathrm{~d} t}\right)+\frac{\mathrm{d}}{\mathrm{d} y_{j}}\left(\frac{\mathrm{d} \tilde{\lambda}_{0}}{\mathrm{~d} t}\right)\right] \\
& +\beta_{0} ; \quad j=0,1, \ldots, 20
\end{aligned}
$$

In Equation (6.59),

$$
\beta_{0}=\left\{\begin{aligned}
& \frac{-M_{\mathrm{m}}}{\left(\mu_{0}+\tilde{\mu}_{0}+\tilde{\tilde{\mu}}_{0}+\lambda_{0}+\tilde{\lambda}_{0}\right)^{2}}[\left(\frac{\mathrm{d} \mu_{1}}{\mathrm{~d} t}+\frac{\mathrm{d} \tilde{\mu}_{1}}{\mathrm{~d} t}+\frac{\mathrm{d} \tilde{\tilde{\mu}}_{1}}{\mathrm{~d} t}+\frac{\mathrm{d} \lambda_{1}}{\mathrm{~d} t}+\frac{\mathrm{d} \tilde{\lambda}_{1}}{\mathrm{~d} t}\right) \\
&\left.-2 \bar{M}_{\mathrm{n}}\left(\frac{\mathrm{d} \mu_{0}}{\mathrm{~d} t}+\frac{\mathrm{d} \tilde{\mu}_{0}}{\mathrm{~d} t}+\frac{\mathrm{d} \tilde{\tilde{\mu}}_{0}}{\mathrm{~d} t}+\frac{\mathrm{d} \lambda_{0}}{\mathrm{~d} t}+\frac{\mathrm{d} \tilde{\lambda}_{0}}{\mathrm{~d} t}\right)\right] \\
& \text { for } y_{j}=\mu_{0}, \tilde{\mu}_{0}, \tilde{\tilde{\mu}}_{0}, \lambda_{0}, \tilde{\lambda}_{0} \\
& \frac{-M_{\mathrm{m}}}{\left(\mu_{0}+\tilde{\mu}_{0}+\tilde{\tilde{\mu}}_{0}+\lambda_{0}+\tilde{\lambda}_{0}\right)^{2}}\left(\frac{\mathrm{d} \mu_{0}}{\mathrm{~d} t}+\frac{\mathrm{d} \tilde{\mu}_{0}}{\mathrm{~d} t}+\frac{\mathrm{d} \tilde{\mu}_{0}}{\mathrm{~d} t}+\frac{\mathrm{d} \lambda_{0}}{\mathrm{~d} t}+\frac{\mathrm{d} \tilde{\lambda}_{0}}{\mathrm{~d} t}\right) \\
& \text { for } y_{j}=\mu_{1}, \tilde{\mu}_{1}, \tilde{\tilde{\mu}}_{1}, \lambda_{1}, \tilde{\lambda}_{1} \\
& 0, \text { for remaining } y_{j} \mathrm{~s}
\end{aligned}\right.
$$

After the transformation of the independent variable to $\bar{M}_{\mathrm{n}}$, time becomes a new state variable (refer Equation (6.47)). The jacobian elements for time, corresponding to $i=21$, 
are given by

$$
\begin{aligned}
& \frac{\mathrm{d}}{\mathrm{d} y_{j}}\left(\frac{\mathrm{d} t}{\mathrm{~d} \bar{M}_{\mathrm{n}}}\right)=y_{j}^{\circ}\left[\frac{\mathrm{d} \bar{M}_{\mathrm{n}}}{\mathrm{d} t}\right]^{-2} \frac{\mathrm{d}}{\mathrm{d} y_{j}}\left(\frac{\mathrm{d} \bar{M}_{\mathrm{n}}}{\mathrm{d} t}\right) ; j=0,1, \ldots, 20 \\
& \frac{\mathrm{d}}{\mathrm{d} t}\left(\frac{\mathrm{d} t}{\mathrm{~d} \bar{M}_{\mathrm{n}}}\right)=0 \quad \text { for } j=21
\end{aligned}
$$

The jacobian elements for remaining state variables, corresponding to $i=0,1, \ldots, 20$, are given by

$$
\begin{aligned}
& \frac{\mathrm{d}}{\mathrm{d} y_{j}}\left(\frac{\mathrm{d} y_{i}}{\mathrm{~d} \bar{M}_{\mathrm{n}}}\right)=-\frac{1}{y_{i}^{0}} \frac{\mathrm{d} y_{i}}{\mathrm{~d} t} \frac{\mathrm{d}}{\mathrm{d} y_{j}}\left(\frac{\mathrm{d} t}{\mathrm{~d} \bar{M}_{\mathrm{n}}}\right)+\gamma_{0} ; j=0,1,2, \ldots, 20 \\
& \frac{\mathrm{d}}{\mathrm{d} t}\left(\frac{\mathrm{d} y_{i}}{\mathrm{~d} \bar{M}_{\mathrm{n}}}\right)=0 \quad \text { for } j=21
\end{aligned}
$$

In Equation (6.63),

$$
\gamma_{0}=\left\{\begin{array}{l}
{\left[\frac{\mathrm{d} \bar{M}_{\mathrm{n}}}{\mathrm{d} t}\right]^{-1} \frac{y_{j}^{\mathrm{o}}}{y_{i}^{\mathrm{o}}} \frac{\mathrm{d}}{\mathrm{d} y_{j}}\left(\frac{\mathrm{d} y_{i}}{\mathrm{~d} t}\right), \text { if } y_{i}^{\mathrm{o}}>0} \\
0, \text { if } y_{i}^{\mathrm{o}}=0
\end{array}\right.
$$




\section{Jacobian for Objective 4}

Let $\bar{M}_{\mathrm{w}}$ correspond to $i=21$ before the transformation of the independent variable. Then the basic jacobian elements for $\bar{M}_{\mathrm{w}}$ are given by

$$
\begin{aligned}
& \frac{\mathrm{d}}{\mathrm{d} \bar{M}_{\mathrm{w}}}\left(\frac{\mathrm{d} \bar{M}_{\mathrm{w}}}{\mathrm{d} t}\right)=0 \quad \text { for } j=21 \\
& \frac{\mathrm{d}}{\mathrm{d} y_{j}}\left(\frac{\mathrm{d} \bar{M}_{\mathrm{w}}}{\mathrm{d} t}\right)=\frac{M_{\mathrm{m}}}{\mu_{1}+\tilde{\mu}_{1}+\tilde{\tilde{\mu}}_{1}+\lambda_{1}+\tilde{\lambda}_{1}}\left[\frac{\mathrm{d}}{\mathrm{d} y_{j}}\left(\frac{\mathrm{d} \mu_{2}}{\mathrm{~d} t}\right)+\frac{\mathrm{d}}{\mathrm{d} y_{j}}\left(\frac{\mathrm{d} \tilde{\mu}_{2}}{\mathrm{~d} t}\right)+\frac{\mathrm{d}}{\mathrm{d} y_{j}}\left(\frac{\mathrm{d} \tilde{\tilde{\mu}}_{2}}{\mathrm{~d} t}\right)\right. \\
& \left.+\frac{\mathrm{d}}{\mathrm{d} y_{j}}\left(\frac{\mathrm{d} \lambda_{2}}{\mathrm{~d} t}\right)+\frac{\mathrm{d}}{\mathrm{d} y_{j}}\left(\frac{\mathrm{d} \tilde{\lambda}_{2}}{\mathrm{~d} t}\right)\right]- \\
& \frac{M_{\mathrm{m}} \bar{M}_{\mathrm{w}}}{\mu_{1}+\tilde{\mu}_{1}+\tilde{\tilde{\mu}}_{1}+\lambda_{1}+\tilde{\lambda}_{1}}\left[\frac{\mathrm{d}}{\mathrm{d} y_{j}}\left(\frac{\mathrm{d} \mu_{1}}{\mathrm{~d} t}\right)+\frac{\mathrm{d}}{\mathrm{d} y_{j}}\left(\frac{\mathrm{d} \tilde{\mu}_{1}}{\mathrm{~d} t}\right)+\frac{\mathrm{d}}{\mathrm{d} y_{j}}\left(\frac{\mathrm{d} \tilde{\tilde{\mu}}_{1}}{\mathrm{~d} t}\right)\right. \\
& \left.+\frac{\mathrm{d}}{\mathrm{d} y_{j}}\left(\frac{\mathrm{d} \lambda_{1}}{\mathrm{~d} t}\right)+\frac{\mathrm{d}}{\mathrm{d} y_{j}}\left(\frac{\mathrm{d} \tilde{\lambda}_{1}}{\mathrm{~d} t}\right)\right] \\
& +\beta_{1} ; j=0,1,2, \ldots, 20
\end{aligned}
$$


In Equation (6.67),

$$
\beta_{1}=\left\{\begin{aligned}
& \frac{-M_{\mathrm{m}}}{\left(\mu_{1}+\tilde{\mu}_{1}+\tilde{\tilde{\mu}}_{1}+\lambda_{1}+\tilde{\lambda}_{1}\right)^{2}}[\left(\frac{\mathrm{d} \mu_{2}}{\mathrm{~d} t}+\frac{\mathrm{d} \tilde{\mu}_{2}}{\mathrm{~d} t}+\frac{\mathrm{d} \tilde{\tilde{\mu}}_{2}}{\mathrm{~d} t}+\frac{\mathrm{d} \lambda_{2}}{\mathrm{~d} t}+\frac{\mathrm{d} \tilde{\lambda}_{2}}{\mathrm{~d} t}\right) \\
&\left.-2 \bar{M}_{\mathrm{w}}\left(\frac{\mathrm{d} \mu_{1}}{\mathrm{~d} t}+\frac{\mathrm{d} \tilde{\mu}_{1}}{\mathrm{~d} t}+\frac{\mathrm{d} \tilde{\tilde{\mu}}_{1}}{\mathrm{~d} t}+\frac{\mathrm{d} \lambda_{1}}{\mathrm{~d} t}+\frac{\mathrm{d} \tilde{\lambda}_{1}}{\mathrm{~d} t}\right)\right] \\
& \text { for } y_{j}=\mu_{1}, \tilde{\mu}_{1}, \tilde{\tilde{\mu}}_{1}, \lambda_{1}, \tilde{\lambda}_{1} \\
& \frac{-M_{\mathrm{m}}}{\left(\mu_{1}+\tilde{\mu}_{1}+\tilde{\tilde{\mu}}_{1}+\lambda_{1}+\tilde{\lambda}_{1}\right)^{2}}\left(\frac{\mathrm{d} \mu_{1}}{\mathrm{~d} t}+\frac{\mathrm{d} \tilde{\mu}_{1}}{\mathrm{~d} t}+\frac{\mathrm{d} \tilde{\tilde{\mu}}_{1}}{\mathrm{~d} t}+\frac{\mathrm{d} \lambda_{1}}{\mathrm{~d} t}+\frac{\mathrm{d} \tilde{\lambda}_{1}}{\mathrm{~d} t}\right) \\
& \text { for } y_{j}=\mu_{2}, \tilde{\mu}_{2}, \tilde{\tilde{\mu}}_{2}, \lambda_{2}, \tilde{\lambda}_{2} \\
& 0, \text { for remaining } y_{j} \mathrm{~s}
\end{aligned}\right.
$$

After the transformation of the independent variable to $\bar{M}_{\mathrm{w}}$, time becomes a new state variable (refer Equation (6.52)). The jacobian elements for time, corresponding to $i=21$, are given by

$$
\begin{aligned}
& \frac{\mathrm{d}}{\mathrm{d} y_{j}}\left(\frac{\mathrm{d} t}{\mathrm{~d} \bar{M}_{\mathrm{w}}}\right)=y_{j}^{\mathrm{o}}\left[\frac{\mathrm{d} \bar{M}_{\mathrm{w}}}{\mathrm{d} t}\right]^{-2} \frac{\mathrm{d}}{\mathrm{d} y_{j}}\left(\frac{\mathrm{d} \bar{M}_{\mathrm{w}}}{\mathrm{d} t}\right) ; j=0,1, \ldots, 20 \\
& \frac{\mathrm{d}}{\mathrm{d} t}\left(\frac{\mathrm{d} t}{\mathrm{~d} \bar{M}_{\mathrm{w}}}\right)=0 \quad \text { for } j=21
\end{aligned}
$$

The jacobian elements for remaining state variables, corresponding to $i=0,1, \ldots, 20$, are given by

$$
\begin{aligned}
& \frac{\mathrm{d}}{\mathrm{d} y_{j}}\left(\frac{\mathrm{d} y_{i}}{\mathrm{~d} \bar{M}_{\mathrm{w}}}\right)=-\frac{1}{y_{i}^{0}} \frac{\mathrm{d} y_{i}}{\mathrm{~d} t} \frac{\mathrm{d}}{\mathrm{d} \underline{y}_{j}}\left(\frac{\mathrm{d} t}{\mathrm{~d} \bar{M}_{\mathrm{w}}}\right)+\gamma_{1} ; \quad j=0,1, \ldots, 20 \\
& \frac{\mathrm{d}}{\mathrm{d} t}\left(\frac{\mathrm{d} y_{i}}{\mathrm{~d} \widetilde{M}_{\mathrm{w}}}\right)=0 \quad \text { for } j=21
\end{aligned}
$$


In Equation (6.71),

$$
\gamma_{1}=\left\{\begin{array}{l}
{\left[\frac{\mathrm{d} \bar{M}_{\mathrm{w}}}{\mathrm{d} t}\right]^{-1} \frac{y_{j}^{\mathrm{o}}}{y_{i}^{\mathrm{o}}} \frac{\mathrm{d}}{\mathrm{d} y_{j}}\left(\frac{\mathrm{d} y_{i}}{\mathrm{~d} t}\right), \text { if } y_{i}^{\mathrm{o}}>0} \\
0, \text { if } y_{i}^{\mathrm{o}}=0
\end{array}\right.
$$

For the integration of equations of change for Objectives 3 and $4, \mu^{\circ}$ was adjusted so that the difference between value of independent variable (e.g. $\bar{M}_{\mathrm{n}}$ or $\bar{M}_{\mathrm{w}}$ ), and that calculated using other state variables (e.g. from Equation (6.45) or (6.50)) is negligible. For Objectives 24 , the transformation of process model was done as soon as the new independent variable achieved a finite value lying within the first stage of optimal control.

Various parameters used in calculations are provided in Table 6.1. The gel effect models for propagation and termination rate coefficients are provided in sections 6.3 and 6.4 , respectively. The reactants for polymerization are the MMA (monomer), N,N'-bis[(4-t-butylazo4-cyanovaleryl)oxyethyl]-azo-bis-formamide (bifunctional initiator), benzene (solvent), and trace amount of some impurity (inhibitor). The product is the polymer, poly(MMA). No experimental data are available for the free radical polymerization of MMA using bifunctional initiator. As such, we will compare the results of optimal control with the base case simulation of batch MMA polymerization with bifunctional initiator at a constant reaction temperature of $70^{\circ} \mathrm{C}$.

\subsection{Optimal Control of PMMA with Bifunctional Ini- tiator}

The mathematical model for the batch polymerization of MMA is highly non-linear. Furthermore, due to the inequality constraints of Equation (6.36) and (6.37), the relation between the performance index and jacket temperature for Objectives 1-4 would not necessarily be unimodal and continuous for the four optimal control objectives. To realize these difficult 
objectives, a robust optimal control method based on genetic algorithms [Upreti, 2004] was applied.

In this work, the temperature of heat-exchange fluid inside reactor jacket (or jacket temperature) was employed as a control function of specified independent variable. Jacket temperature was considered to be a series of five discrete step values equispaced in the range of independent variable. The number of step values (or control stages), the mathematical model of MMA polymerization in a batch reactor with its parameters, and the process constraints of Equations (6.36) and (6.37) were input to the optimal control method. These inputs are needed to evaluate the performance index (fitness) for a given control function. The application of the method yielded the optimal control function by stochastically applying genetic operations on a randomly generated set (population) of control functions constrained by Equation (6.37). Since the method generates optimal control functions within the control domain, the constraints of Equation (6.37) are satisfied automatically. The method eliminates any control function for which any other process constraint (Equation (6.36) in this application) is violated during the evaluation of corresponding performance index. 
Table 6.1: Model parameters used in calculations

\begin{tabular}{|c|c|c|}
\hline Parameter & Value or Expression & Source \\
\hline$f$ & 0.6 & \multirow{15}{*}{ This study } \\
\hline$i^{\mathrm{o}}, \mathrm{mol} / \mathrm{L}$ & $4.13 \times 10^{-2}$ & \\
\hline$m^{\circ}, \mathrm{mol} / \mathrm{L}$ & 1.7648 & \\
\hline$s^{\mathrm{o}}, \mathrm{mol} / \mathrm{L}$ & 8.4692 & \\
\hline$T^{\circ},{ }^{\circ} \mathrm{C}$ & 70 (Objectives $1 \& 2$ ), 0 (Objectives $3 \& 4$ ) & \\
\hline$T_{\max },{ }^{\circ} \mathrm{C}$ & 80 & \\
\hline$T_{\mathrm{j}, \max },{ }^{\circ} \mathrm{C}$ & 120 & \\
\hline$T_{\mathrm{j}, \min },{ }^{\circ} \mathrm{C}$ & 4 (Objectives $1 \& 2$ ), -20 (Objectives $3 \& 4$ ) & \\
\hline$z^{\mathrm{o}}, \mathrm{mol} / \mathrm{L}$ & $10^{-5}$ & \\
\hline$v^{\mathrm{o}}, \mathrm{L}$ & 1 & \\
\hline$K_{\mathrm{th}}, \mathrm{L} / \mathrm{mol} \cdot \min$ & 0 & \\
\hline$K_{\mathrm{tf}, \mathrm{s}}, \mathrm{L} / \mathrm{mol} \cdot \min$ & $1.58 \times 10^{-5} K_{\mathrm{p}}$ & \\
\hline$K_{\mathrm{tf}, \mathrm{z}}, \mathrm{L} / \mathrm{mol} \cdot \min$ & $10^{6} K_{\mathrm{p}}$ & \\
\hline$M_{\mathrm{m}}, \mathrm{g} / \mathrm{mol}$ & 100.12 (for MMA) & \\
\hline$M_{\mathrm{s}}, \mathrm{g} / \mathrm{mol}$ & 78.11 (for benzene) & \\
\hline$K_{\mathrm{d} 1}, 1 / \mathrm{min}$ & $3 \times 10^{11} \exp \left[-1.1299 \times 10^{4} /(T+273.15)\right]$ & \multirow[t]{2}{*}{$\begin{array}{l}\text { Simionescu } \\
\text { et al. [1990] }\end{array}$} \\
\hline$K_{\mathrm{d} 2}, 1 / \min$ & $3 \times 10^{11} \exp \left[-1.1299 \times 10^{4} /(T+273.15)\right]$ & \\
\hline
\end{tabular}


Table 6.1: continued...

\begin{tabular}{|c|c|c|}
\hline Parameter & Value or Expression & Source \\
\hline$U A, \mathrm{~J} / \mathrm{min} \cdot \mathrm{K}$ & $6.5475 \times 10^{2}$ & $\begin{array}{l}\text { Villalobos } \\
\text { et al. [1993] }\end{array}$ \\
\hline$-\Delta H, \mathrm{~J} / \mathrm{mol}$ & $5.546 \times 10^{4}$ & $\begin{array}{l}\text { Brandrup } \\
\text { et al. [1999] }\end{array}$ \\
\hline$K_{\mathrm{tf}, \mathrm{m}}, \mathrm{L} / \mathrm{mol} \cdot \min$ & $5.358 \times 10^{-2} \exp \left[-1.1273 \times 10^{3} /(T+273.15)\right]$ & $\begin{array}{l}\text { Kalfas } \\
\text { et al. [1993] }\end{array}$ \\
\hline$\rho_{\mathrm{m}}, \mathrm{g} / \mathrm{L}$ & $309.85 \times 0.25357^{-[1-(T+273.15) / 564]^{0.28571}}$ & \multirow{3}{*}{$\begin{array}{l}\text { Yaws } \\
{[1999]}\end{array}$} \\
\hline$\rho_{\mathrm{s}}, \mathrm{g} / \mathrm{L}$ & $300.9 \times 0.2677^{-[1-(T+273.15) / 562.16]^{0.2818}}$ & \\
\hline$C_{\mathrm{p}}, \mathrm{J} / \mathrm{g} \cdot \mathrm{K}$ & \begin{tabular}{|l|}
$4.2416 \times 10^{3}+1.08 \times 10^{2}(T+273.15)-3.1588 \times$ \\
$10^{-1}(T+273.15)^{2}+3.7804 \times 10^{-4}(T+273.15)^{3}$ \\
\end{tabular} & \\
\hline$\rho_{\mathrm{p}}, \mathrm{g} / \mathrm{L}$ & $1.18 \times 10^{3}-(T+273.15)$ & $\begin{array}{l}\text { Sung-Mo } \\
\text { et al. [1998] }\end{array}$ \\
\hline
\end{tabular}




\section{Results for Solution, Batch MMA Polymer- ization with Bifunctional Initiator}

\section{$7.1 \quad$ Results}

The optimal control results for the four objectives are summarized and compared with the base case in Table 7.1. Note that the specified values of average polymer molecular weights in Objectives 3 and 4 are not attainable in base case.

\subsubsection{Results For Objective 1}

The optimal jacket temperature policy was determined, which maximizes final monomer (MMA) conversion during the specified batch polymerization time of $100 \mathrm{~min}$. Figure 7.1 shows the optimal policy, which maximizes final monomer conversion to $85.6 \%$. This value is $30 \%$ higher than the monomer conversion in base case. The figure also shows how the temperature pölicy gets improved with the iterations of the optimal control method. It is observed that the optimal policy reaches close to the maximum allowable reactor temperature of $80^{\circ} \mathrm{C}$.

Figure 7.2 shows the change in optimal reactor temperature, and monomer conversion with time, which correspond to the optimal jacket temperature policy. Corresponding variables for base case are also shown in the figure. It is observed that optimal reactor temperature increases very quickly, and gets close to its upper limit of $80^{\circ} \mathrm{C}$ in less than $10 \mathrm{~min}$. In the following time, the temperature is observed to be in phase with the optimal jacket temperature (Figure 7.1) in the lower vicinity of its upper limit. This fact indicates that high reaction temperatures are needed in all control stages in order to increase overall polymerization, and achieve high monomer conversion. This behavior shows the strong influence of jacket temperature on reaction temperature, and explains why optimal jacket temperature does not surpass the upper limit of reactor temperature. At all times, optimal reactor temperature 
Figure 7.1: Optimal reactor jacket temperature versus time for Objective 1

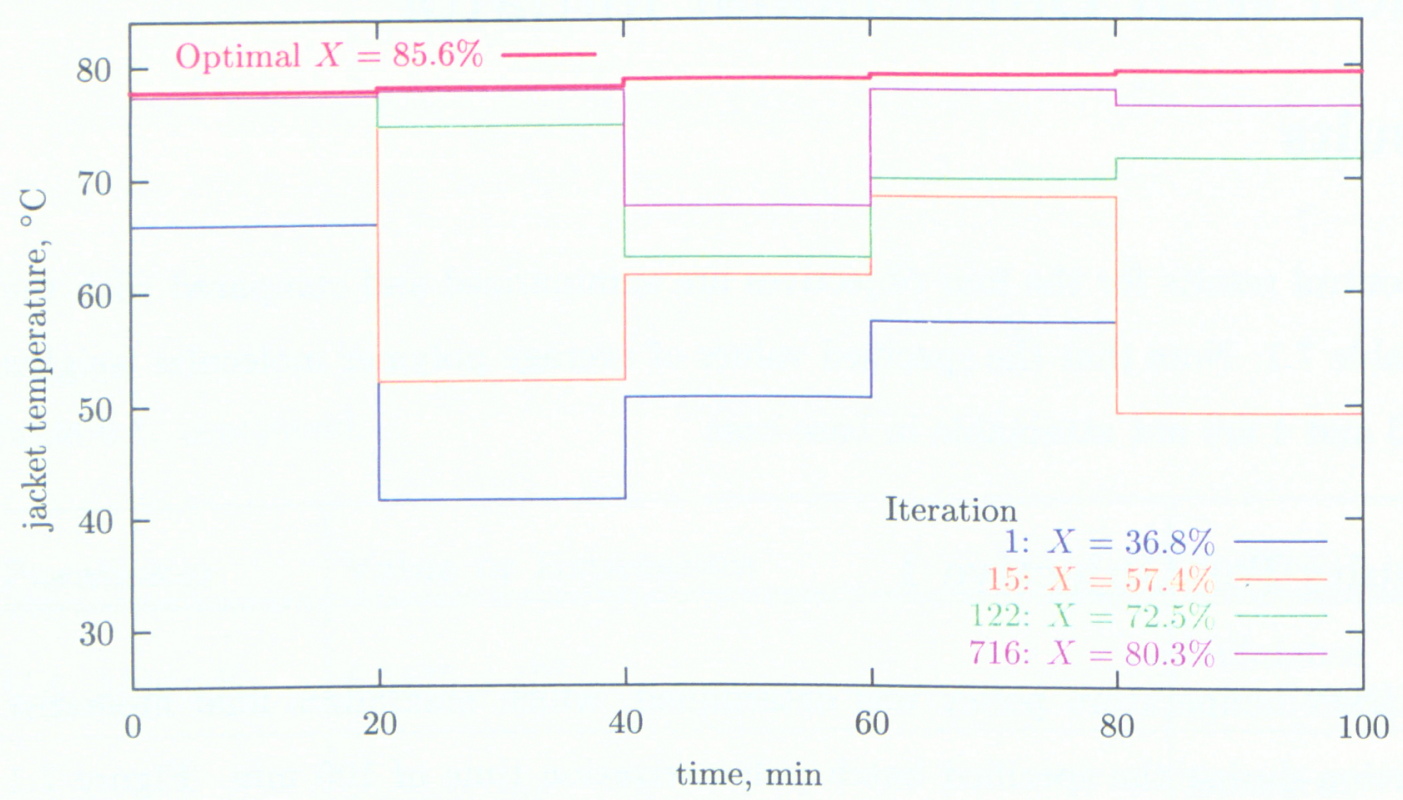

is well within that limit, which is specified through Equation (6.36). For time greater than zero, the optimal value of reactor temperature exceeds that for base case. Correspondingly, optimal monomer conversion, for time greater than zero, is always higher than the monomer conversion for base case.

The optimal number and weight average polymer molecular weights $\left(\bar{M}_{\mathrm{n}}\right.$ and $\left.\bar{M}_{\mathrm{w}}\right)$ versus time are respectively shown in Figure 7.3 and 7.4 along with those for base case. It is observed that optimal $\bar{M}_{\mathrm{n}}$ as well as $\bar{M}_{\mathrm{w}}$ values are always lower than respectively those in base case. In comparison to base case, the final values of optimal $\bar{M}_{\mathrm{n}}$ and $\bar{M}_{\mathrm{w}}$ are reduced by about $58 \%$ and $64 \%$, respectively. This reduction suggests that optimal reactor temperature, which is higher than the reactor temperature in base case, has favored the generation of polymer molecules with smaller chain lengths. 
Figure 7.2: Reactor temperature and monomer conversion versus time for Objective 1

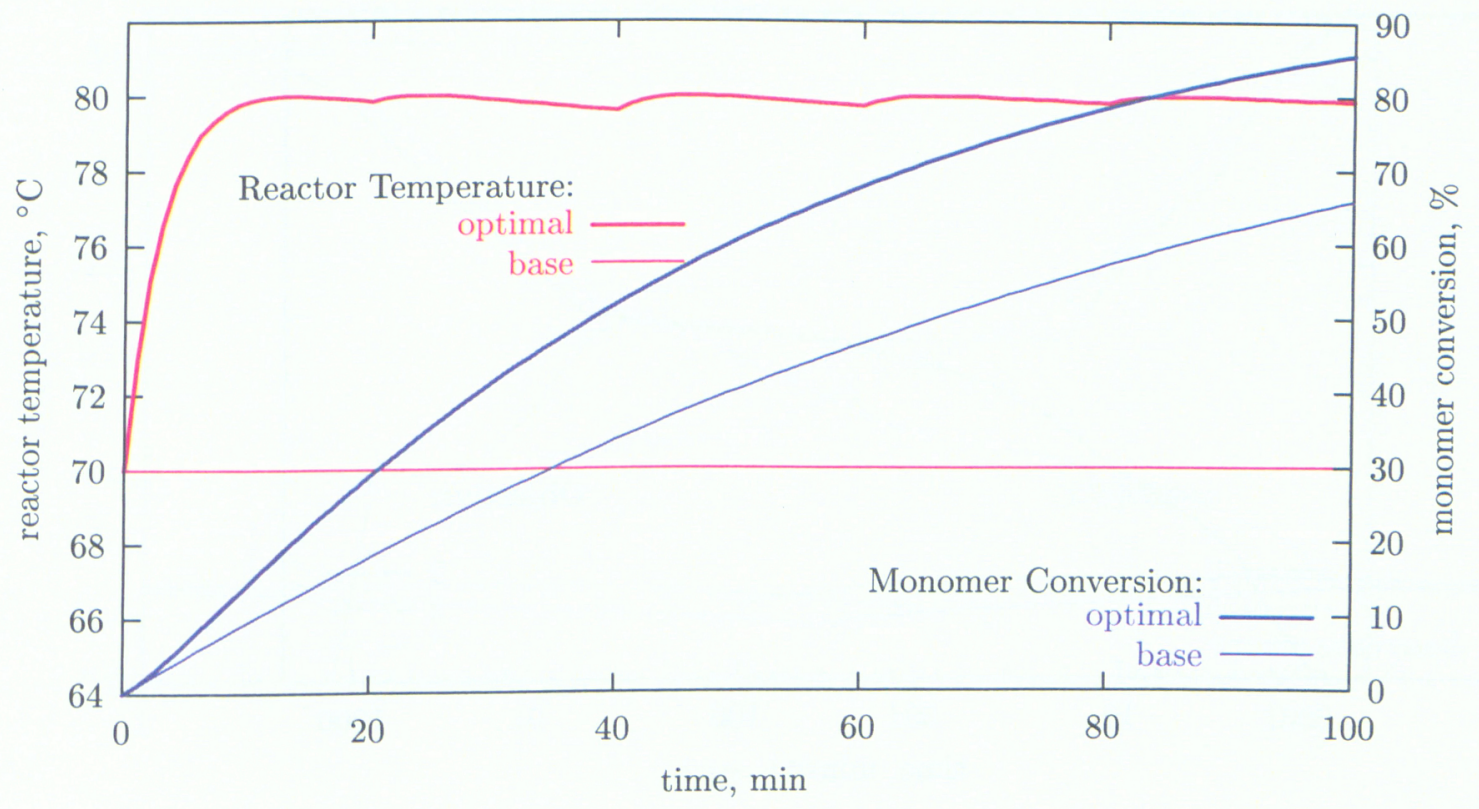

\subsubsection{Results For Objective 2}

The optimal jacket temperature policy was determined, which minimizes batch polymerization time for the specified, final monomer conversion of $70 \%$. Shown in Figure 7.5, the optimal policy is again close to the maximum allowable reactor temperature of $80^{\circ} \mathrm{C}$; similar to what was observed for Objective 1. Moreover, the time-averaged value of optimal jacket temperature is approximately same as that in case of Objective 1. This similarity of optimal jacket temperature is reasonable because the realization of each of Objectives 1 and 2 requires the maximization of overall rate of monomer conversion.

Optimal reactor temperature, shown in Figure 7.7, closely follows optimal jacket temperature after the first control stage. This behavior was observed earlier in case of Objective 1. Corresponding to optimal jacket temperature, the optimal value of the operation time is $63.8 \mathrm{~min}$, which is a reduction by $57 \%$ relative to base case. 
Figure 7.3: Optimal number average molecular weight versus time for Objectives 1-4

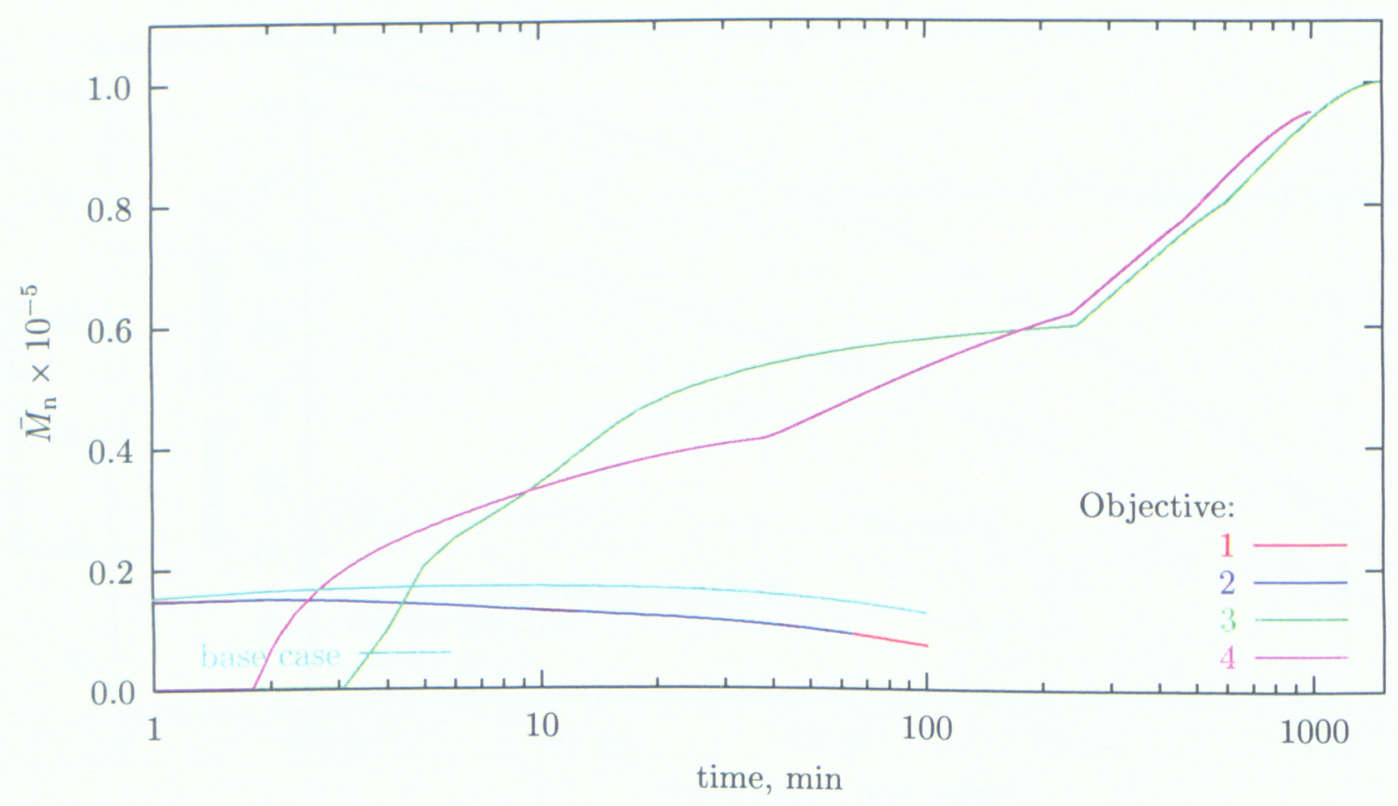

Optimal monomer conversion is shown in Figure 7.6. It is observed to be always higher than that for base case. The optimal number and weight average polymer molecular weights $\left(\bar{M}_{\mathrm{n}}\right.$ and $\bar{M}_{\mathrm{w}}$ ) are respectively shown in Figure 7.3 and 7.4. The changes in monomer conversion, and average molecular weights with time almost coincide with respectively those in case of Objective 1. The reason is that corresponding optimal reactor and jacket temperatures for Objective 1 and 2 are not much different, and are close to their upper limit.

\subsubsection{Results For Objective 3}

The optimal jacket temperature policy was determined, which maximizes the final monomer conversion with the specified final number average molecular weight $\left(\bar{M}_{\mathrm{n}, \mathrm{f}}\right)$ of $10^{5}$. It may be noted that, as seen in Figure 7.3, this high value of $\bar{M}_{\mathrm{n}}$ is not achievable in base case. In general, the time needed to obtain polymer of a specified $\bar{M}_{\mathrm{n}, \mathrm{f}}$ increases with a decrease in reaction temperature. To provide extended application time for optimal control through 
Figure 7.4: Optimal weight average molecular weight versus time for Objectives 1-4

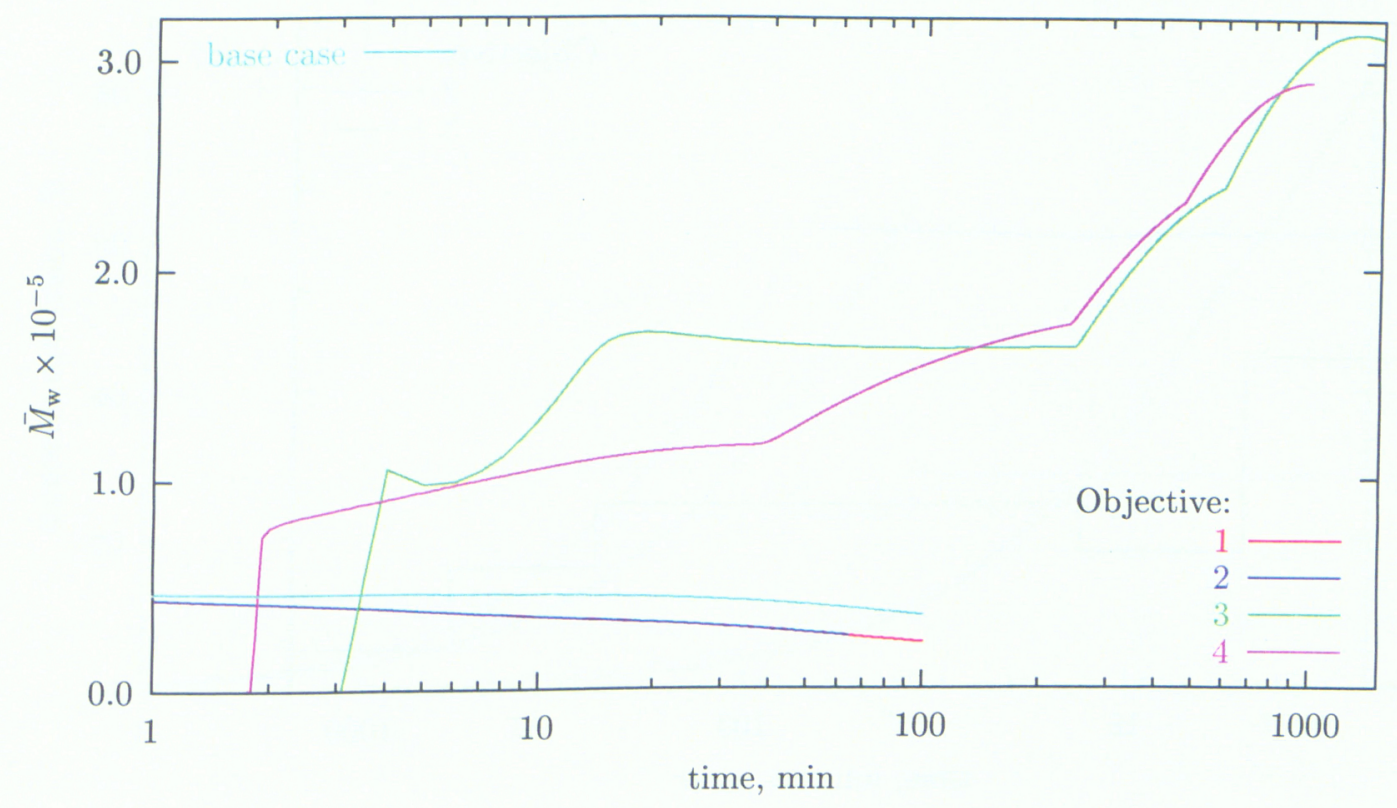

jacket temperature, and to facilitate higher monomer conversion during that time, the initial temperature of reactor was set at a low value of $0^{\circ} \mathrm{C}$. Furthermore, wider range (for lower values) was made available to jacket temperature by reducing its lower limit to $-20^{\circ} \mathrm{C}$.

Figure 7.5 shows the resulting optimal control policy for jacket temperature, which spans $1510.1 \mathrm{~min}$ of operation time, and yields the final monomer conversion of $82.9 \%$. Although the lower limit for jacket temperature is $-20^{\circ} \mathrm{C}$, its lowest optimal value is above $16^{\circ} \mathrm{C}$. At the beginning optimal jacket temperature is $59.5^{\circ} \mathrm{C}$ which is the highest for all control stages. The temperature generally declines later on except for the third control stage. It is noticed that the third control stage is quite longer duration than other stages. The reason is that control stages are equispaced over the specified independent variable, $\bar{M}_{\mathrm{n}}$, which undergoes the slowest change with time in the third control stage (see Figure 7.3). In fact, the rates of change of both $\bar{M}_{\mathrm{n}}$ and $\bar{M}_{\mathrm{w}}$ (Figure 7.4) with time are reduced in the third control. The rate of change of $M w$ is mostly negative in the third control stage. This behavior is due 
Figure 7.5: Optimal jacket temperature versus time for Objectives 2-4

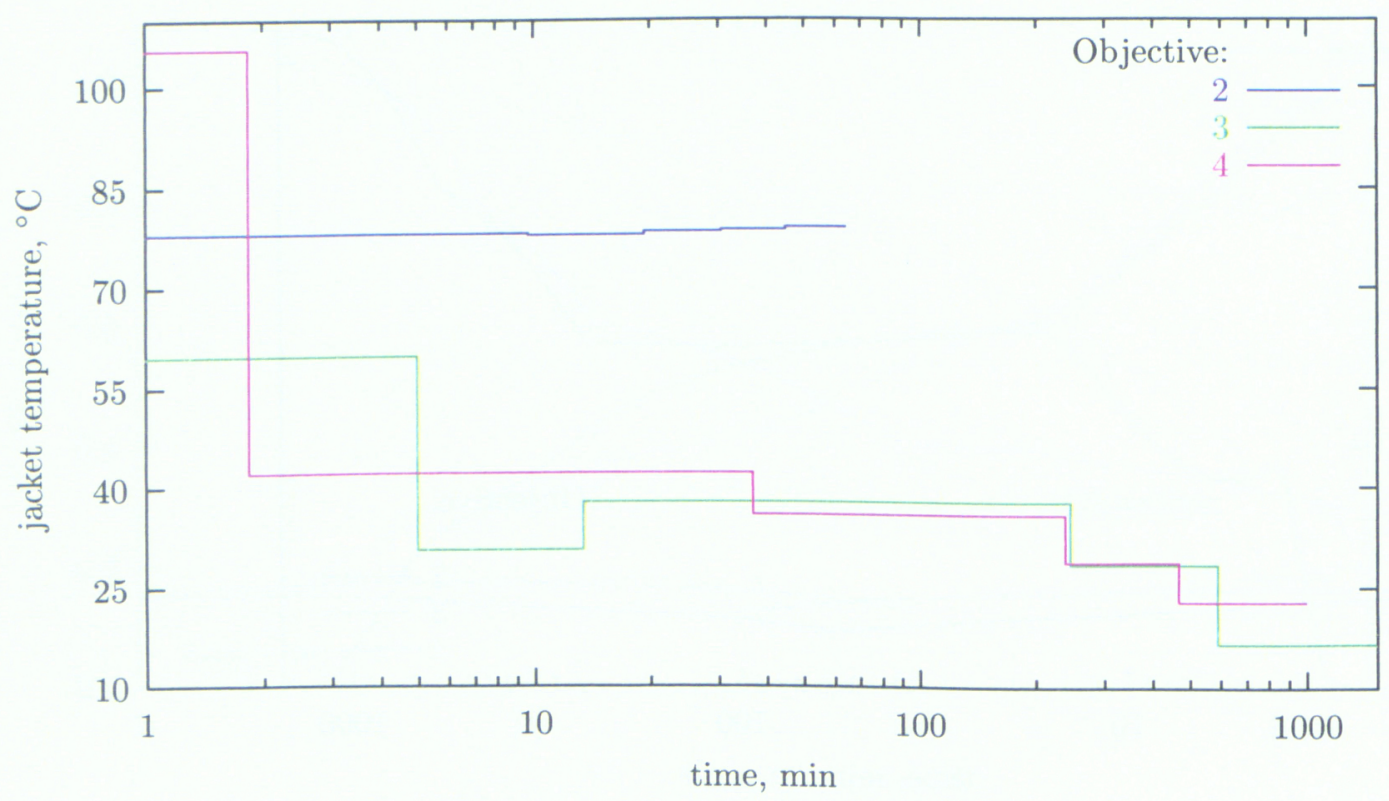

to the higher optimal jacket and reactor temperatures in the third stage, which favor the generation of polymer molecules with smaller chain lengths. The trend of optimal jacket temperature after the first control stage is closely followed by corresponding optimal reactor temperature as seen in Figure 7.7.

The change in optimal monomer conversion with time, as seen in Figure 7.6, is very small up to the first half of the third stage after which the conversion rises to the final value of $82.9 \%$.

\subsubsection{Results For Objective 4}

The optimal jacket temperature policy was determined, which maximizes the final monomer conversion with the specified final weight average molecular weight $\left(\bar{M}_{\mathrm{w}, \mathrm{f}}\right)$ of $2.9 \times 10^{5}$. It may be noted again that, as seen in Figure 7.4, this high value of $\bar{M}_{\mathrm{w}}$ is not achievable in base case. Optimal control results for this objective were obtained for the same initial reactor 
Figure 7.6: Optimal monomer conversion versus time for Objectives 2-4

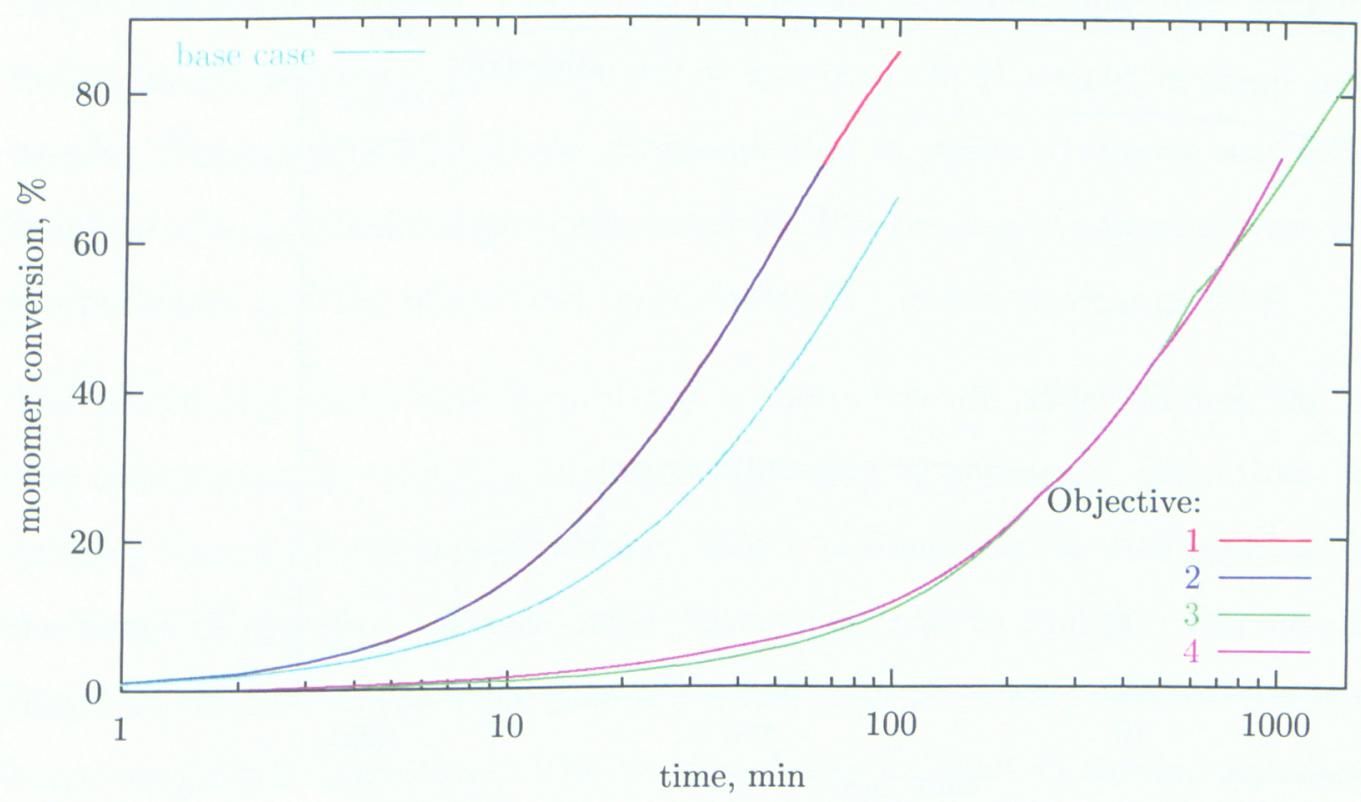

temperature, and the lower limit of jacket temperature that were used for Objective 3 . The realization of the present optimal control objective with high monomer conversions is lower than the previous Objective 3 . The reason is the initial increase of $\bar{M}_{\mathrm{w}}$ with time being higher than that of $\bar{M}_{\mathrm{n}}$. This limitation results in polymerization that meets the specification of $\bar{M}_{\text {w,f }}$ very quickly, thereby reducing the time available for optimal control through jacket temperature.

Figure 7.5 shows the resulting optimal jacket temperature versus time which spans 990.9 min of operation time, and yields a final monomer conversion of $71.4 \%$. This value (as well as operation time) is lower than that for Objective 3, thereby indicating the effect of the above mentioned limitation. After the first control stage, the temperature goes down progressively, and is closely followed by optimal reactor temperature as seen in Figure 7.7. Optimal $\bar{M}_{\mathrm{n}}$ (Figure 7.3), $\bar{M}_{\mathrm{w}}$ (Figure 7.4) for this objective are observed to increase monotonically with time. The change in optimal monomer conversion with time, as seen in Figure 7.6, is similar 
Figure 7.7: Optimal reactor temperature versus time for Objectives 2-4

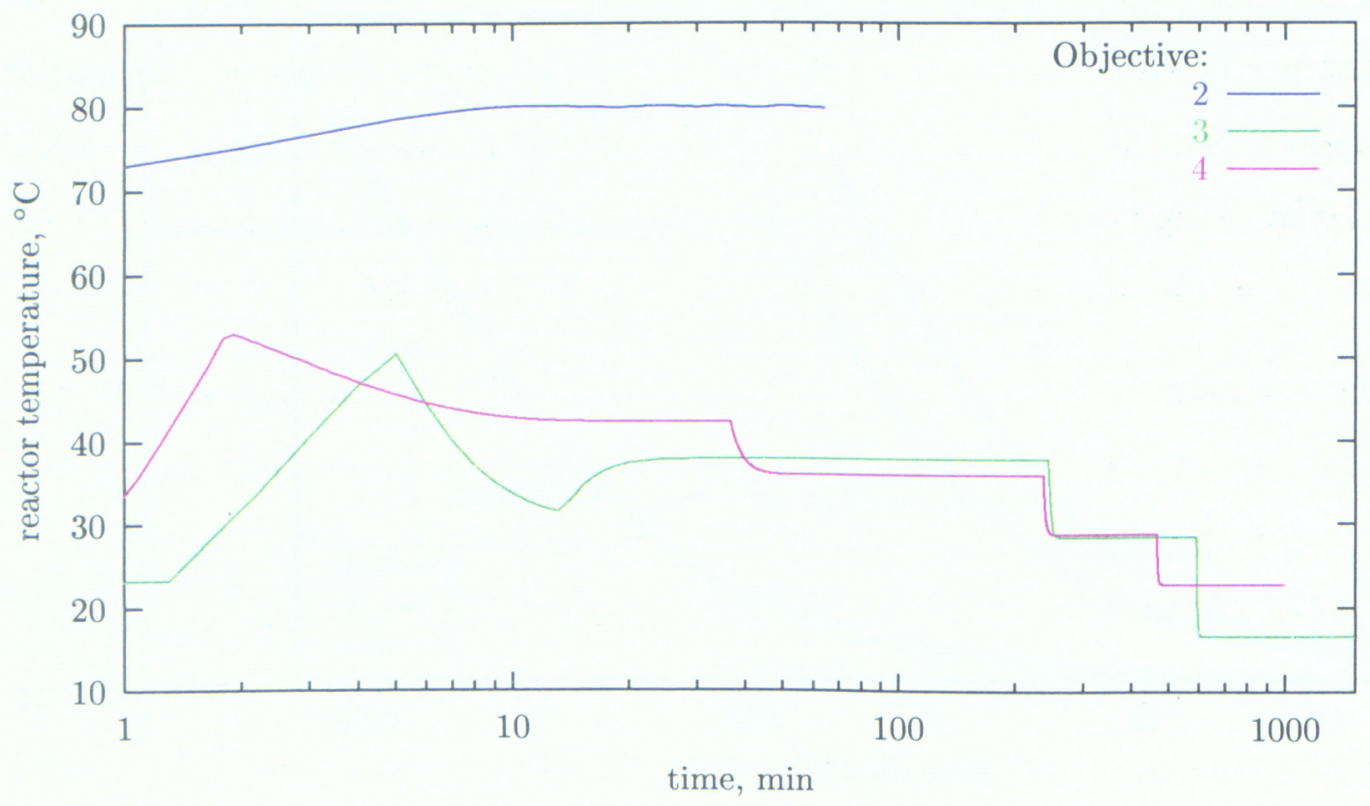

to that in case of Objective 3 .

\subsection{Computational Time}

Objective 4 took nearly 38 hours to compute, which was the least computation time in the four objectives. Whereas, Objective 2 took nearly 154 hours, which was the highest computation time. Objective 1 and 3 took approximately 46 and 126 hours respectively to compute.

\subsection{Conclusion}

The optimal control of MMA polymerization with a bifunctional initiator was determined in a nonisothermal batch reactor. The following four optimal control objectives were realized: (i) maximization of monomer conversion in a specified operation time, (ii) minimization 
of operation time for specified, final monomer conversion, (iii) maximization of monomer conversion for a specified, final number average polymer molecular weight, and (vi) maximization of monomer conversion for a specified, final weight average polymer molecular weight. The temperature of heat-exchange fluid in jacket of reactor was utilized as a control function of a specified independent variable. The process constraints were maximum reactor temperature, and the upper and lower limits to the heat-exchange fluid.

The above objectives were formulated to help provide wider choices for polymer production simultaneously with the optimum efficiency of operation. Equations were provided to suitably transform the model of batch MMA polymerization with a bifunctional initiator in the range of specified variable other than time, and to evaluate the elements of jacobian. Based on the model, the four optimal control objectives were realized using a robust method based on genetic algorithms. The results of optimal control showed significant performance improvements compared to base case without optimal control. 
Table 7.1: Summary of optimal control results

\begin{tabular}{|c|c|c|c|c|}
\hline Objective & Specification & $\begin{array}{l}J \text { in Base } \\
\text { Case }\end{array}$ & Optimal $J$ & $\begin{array}{l}\text { \% Improvement } \\
\text { in } J\end{array}$ \\
\hline 1 & $t_{\mathrm{f}}=100 \mathrm{~min}$ & $X_{\mathrm{f}}=65.9 \%$ & $\underset{\max }{X_{\mathrm{f}}}=85.6 \%$ & 30 \\
\hline 2 & $X_{\mathrm{f}}=70 \%$ & $t_{\mathrm{f}}=111.9 \mathrm{~min}$ & $\underset{\min }{t_{\mathrm{f}}}=63.8 \mathrm{~min}$ & 57 \\
\hline 3 & $\bar{M}_{\mathrm{n}, \mathrm{f}}=10^{5}$ & not attainable & $\underset{\max }{X_{\mathrm{f}}}=82.9 \%$ & - \\
\hline 4 & $\bar{M}_{\mathrm{w}, \mathrm{f}}=2.9 \times 10^{5}$ & $"$ & $\underset{\max }{X_{\mathrm{f}}}=71.4 \%$ & $\therefore \cdots$ \\
\hline
\end{tabular}




\section{Final Conclusion and Future Work}

Optimal control policies were determined for the free radical polymerization of three different polymerization processes, in a non-isothermal batch reactor as follows:

\section{Bulk polymerization of BMA}

2. Solution polymerization of MMA with monofunctional initiator

3. Solution polymerization of MMA with bifunctional initiator

Four optimal control objectives were developed for the above three different free radical polymerization processes in a non-isothermal batch reactor. The objectives were:

1. maximization of monomer conversion in a specified operation time,

2. minimization of operation time for a specified, final monomer conversion,

3. maximization of monomer conversion for a specified, final number average polymer molecular weight, and

4. maximization of monomer conversion for a specified, final weight average polymer molecular weight.

The above objectives were designed to achieve higher production rate with minimum processing time. The temperature of heat-exchange fluid inside reactor jacket was employed as a control function of a specified independent variable. Process model equations were provided for the above three polymerization processes. Equations were provided to suitably transform the process model in the range of specified variable other than time, and to evaluate the elements of jacobian. Based on the detailed non-isothermal process model developed for the above three polymerization processes, the objectives were realized using a genetic algorithms-based optimal control method. 


\subsection{Future Work}

The results of optimal control, for bulk batch polymerization of BMA, batch polymerization of MMA with monofunctional initiator, and batch polymerization of MMA with bifunctional initiator, showed significant performance improvements compared to base case without optimal control.

\subsection{Future Work}

1. In the last objective of optimal control of BMA polymerization, monomer conversion was not high as that in case of other objectives. Also, a couple of initial control stages were of very short duration. In the future optimal control studies, by dealing these challenges, one can deliver high monomer conversion with specified weight average polymer molecular weight.

2. One can work on the optimal control studies of BMA polymerization in the presence of benzene solvent, by implementing the restriction of a minimum duration for a control stage.

3. One can work in the last two optimal control objectives of optimal control of MMA polymerization with monofunctional initiator, with the additional restriction of minimum duration for a control stage.

4. Reaction mechanism for the MMA polymerization with bifunctional initiator, shown in this thesis, is applicable for the styrene polymerization. One can perform optimal control studies on the styrene polymerization by using more than one control function. In addition to the controlling of jacket temperature, one can also control the initiator addition in a semi-batch polymerization system. 


\section{Bibliography}

R. Aris. On Denbigh's optimum temperature sequence. Chem. Eng. Sci., 12:56-64, 1960.

L. T. Biegler, A. M. Cervantes, and A. Wchter. Advances in simultaneous strategies for dynamic process optimization. Chem. Eng. Sci., 57:575-593, 2002.

B. Bojkov and R. Luus. Optimal control of nonlinear systems with unspecified final times. Chem. Eng. Sci., 51:905-919, 1996.

J. Brandrup, E. H. Immergut, and E. A. Grulke, editors. Polymer HandBook. WileyInterscience, New York, fourth edition, 1999.

M. Buback, U. Geers, and H. Kurz. Propagation rate coefficients in free radical homopolymerizations of butyl methacrylate and dodecyl methacrylate. Macromol. Chem. Phys., 198:3451-3464, 1997.

G. M. Burnett, P. Evans, and H. W. Melville. Polymerization of esters of methacrylic acid. Trans. Faraday Soc., 49:1096-1105, 1953.

J. S. Chang and J. L. Lai. Computation of optimal temperature policy for molecular weight control in a batch polymerization reactor. Ind. Eng. Chem. Res., 31(3):861-868, 1992.

S. A. Chen and N. W. Huang. Minimum end time policies for batchwise radical chain polymerization-III. Chem. Eng. Sci., 36:1295-1305, 1981.

T. P. Davis and K. F. O'Driscoll. Copolymerization propagation kinetics of styrene with alkyl methacrylates. Macromolecules, 23:2113-2119, 1990.

K. G. Denbigh. Optimum temperature sequences in reactors. Chem. Eng. Sci., 8:125-132, 1958.

R. Dhib, J. Gao, and A. Penlidis. Simulation of free radical bulk/solution homopolymerization using mono- and bi-functional initiators. Poly. React. Eng., 8(4):299-464, 2000. 
J. Gao and A. Penlidis. A comprehensive simulator/database package for reviewing free radical homopolymerizations. J. Macromol. Sci. Rev. Macromol. Chem. Phy., C36:199404, 1996.

Y. P. Gupta. Semiexhaustive search for solving nonlinear optimal control problems. Chem. Eng. Sci., 34(11):3878-3884, 1995.

J. M. Hicks, A. Mohan, and W. H. Ray. The optimal control of polymerization reactors. Can. J. Chem. Eng., 47:590-598, 1969.

K. Y. Hsu and S. A. Chen. Minimum end-time policies for batchwise radical chain polymerization: The piecewise initiator addition policy. Chem. Eng. Sci., 43(6):1311-1321, 1988.

G. Kalfas, H. Yuan, and W. H. Ray. Modeling and experimental studies of aqueous suspension polymerization processes. 2. experiments in batch reactor. Ind. Eng. Chem. Res., 32: 1831-1838, 1993.

P. E. King and J. M. Skaates. Two-position control of a batch prepolymerization. Ind. Eng. Chem. Proc. Des. Dev., 8(1):114-119, 1969.

D. E. Kirk. Optimal Control Theory. Prentice-Hall, New Jersey, 1970.

M. H. Lee, C. Han, and K. S. Chang. Hierarchical time-optimal control of a continuous copolymerization reactor during start-up or grade change operation using genetic algorithms. Comp. Chem. Eng., 21:S1037-S1042, 1997.

M. H. Lee, C. Han, and K. S. Chang. Dynamic optimization of a continuous polymer reactor using a modified differential evolution algorithm. Ind. Eng. Chem. Rës., 38(12):4825-4831, 1999.

J. S. Logsdon and L. T. Biegler. A relaxed reduced space for SQP strategy for dynamic optimization problems. Comp. Chem. Eng., 17:367-372, 1993. 
B. M. Louie, G. M. Carratt, and D. S. Soong. Modeling the freee radical solution and bulk polymerization of methyl methacrylate. J. Appl. Poly. Sci., 30:3985-4012, 1985.

R. Luus. Application of dynamic programming to high-dimensional nonlinear optimal control problems. Intl. J. Cont., 52:239-250, 1990.

R. Luus. Optimal control of batch reactors by iterative dynamic programming. J. Proc. Cont., 4(4):218-226, 1994.

R. Luus and D. Hennessy. Optimization of fed-batch reactors by the Luus-Jakola optimization procedure. Ind. Eng. Chem. Res., 38(5):1948-1955, 1999.

R. Luus and O. N. Okongwu. Towards practical optimal control of batch reactors. Chem. Eng. J., 75:1-9, 1999.

F. L. Marten and A. E. Hamielec. High conversion diffusion-controlled polymerization. $A m$. Chem. Soc., 43(104):43-70, 1979.

A. S. Nair and M. S. Muthana. Studies on the polymerization of methacrylic esters. part i: Polymerization of n-butyl methacrylate and isobutyl methacrylate. Makiomol. Chem., 47:114-127, 1961.

K . F. O'Driscoll and S . R. Ponnuswamy. Optimization of batch polymerization reactor as the final stage of conversion.II molecular weight constraint. J. Appl. Polym. Sci., 39(6): 1299-1308, 1990.

K . F. O'Driscoll, S . R . Ponnuswamy, and A. Penlidis. Optimization of a batch polymerization reactor at the final stage conversion. Acs Symposium Series, 404:321-336, 1989.

S. R. Ponnuswamy, S. L. Shah, and C. A. Kipaissides. Computer optimal control of batch polymerization reactors. Ind. Eng. Chem. Res., 26(11):2229-2236, 1987.

L. S. Pontryagin, V. G. Boltyanskii, R. Gamkrelidge, and E. Mishchenko: The mathematical Theory of Optimal Processes. Interscience, New york, 1962. 
W. H. Press, S. A. Teukolsky, W. T. Vetterling, and B. P. Flannery. Numerical Recipes in C++. The Art of Scientific Computing, pages 719-727. Cambridge University Press, New York, 2nd edition, 2002.

A. D. Schmidt and W. H. Ray. The dynamic behavior of continuous polymerization reactorsI. Chem. Eng. Sci., 36:1401-1410, 1981.

G. V. Schulz and G. Harborth. Uber den mechanismus des explosiven polymerisationsverlaufes des methacrylsauremethylesters. Die Makromol. Chem., 1(1):106-139, 1947.

I. C. Simionescu, A. A. Popa, E. Comanita, and M. Pastravanu. Kinetics of methyl methacrylate polymerization initiated with n,n'-bis[(4-t-butylazo-4-cyanovaleryl)oxyethyl]-azo-bisformamide. Brit. Poly. J., 23:347-351, 1990.

I. C. Simionescu, A. A. Popa, E. Comanita, M. Pastravanu, and S. Dumitriu. Kinetics of methyl methacrylate polymerization initiated with phenylazoformamidoethyl 4-t-butylazo4-cyanovalerate. Euro. Polym. J., 24(6):515-519, 1988.

R. V. Subramanian and S. L. Kapur. Bifunctional peroxide initiated vinyl polymerisation. Makromol. Chem., 28:83-90, 1958.

B. S. Sundaram and S. R. Upreti. Optimal control of batch MMA polymerization with specified time, monomer conversion, and average polymer molecular weights. Chem. Eng. Sci., 2004. Submitted for publication.

Ahn Sung-Mo, Chang Soon-Cheol, and Rhee Hyun-Ku. Application of optimal temperature trajectory to batch PMMA polymerization reactor. J. Appl. Poly. Sci., 69:59-68, 1998.

I. M. Thomas and C. Kiparissides. Computation of the near-optimal temperature and initiator policies for a batch polymerizatio reactor. Can. J. Chem. Eng., 62(2):284-291, 1984. 
Y. Tian, J. Zhang, and J. Morris. Modeling and optimal control of a batch polymerization reactor using a hybrid stacked recurrent neural network model. Ind. Eng. Chem. Res., 40: 4525-4535, 2001.

S. R. Upreti. A new robust technique for optimal control of chemical engineering processes. Comp. Chem. Eng., 28(8):1325--1336, 2004.

S. R. Upreti and B. S. Sundaram. Optimal control of MMA polymerization in nonisothermal batch reactor using bifunctional initiator. Intl. J. Chem. Reactor Eng., 2004a. Submitted for publication.

S. R. Upreti and B. S. Sundaram. Optimal control of n-butyl methacrylate polymerization in a non-isothermal batch reactor. Intl. J. Chem. Reactor Eng., 2004b. Submitted for publication.

M. A. Villalobos, A. E. Hamielec, and P. E. Wood. Bulk and suspension polymerization of styrene in the presence of $n$-pentane. an evaluation of monofunctional and bifunctional initiation. J. Appl. Poly. Sci., 50(2):327-343, 1993.

F. Wang and J. Chiou. Optimal control and optimal time location problems of differentialalgebraic systems by differential evolution. Ind. Eng. Chem. Res., 36(12):5348-5357, 1997.

F. Z. Yao, A. Lohi, S. R. Upreti, and R. Dhib. Modeling, simulation and optimal control of ethylene polymerization in non-isothermal, high-pressure tubular reactors. Intl. J. Chem. Reuctor Eng., 2(A.16), 2004.

C. L. Yaws. Chemical Properties Handbook. McGraw-Hill, New York, 1999. 